\title{
Interventional TeChniques in The Management of Chronic Spinal Pain: Evidence-Based Practice Guidelines
}

\author{
Mark V. Boswell, MD, PhD, Rinoo V. Shah, MD, Clifford R. Everett, MD, Nalini Sehgal, MD, Anne Marie Mckenzie- \\ Brown, MD, Salahadin Abdi, MD, PhD, Richard C. Bowman, MD, PhD, Timothy R. Deer, MD, Sukdeb Datta, MD, \\ James D. Colson, MD, William F. Spillane, MD, Howard S. Smith, MD, Linda F. Lucas, MD, Allen W. Burton, MD, \\ Pradeep Chopra, MD, Peter S. Staats, MD, Ronald A. Wasserman, MD, and Laxmaiah Manchikanti, MD
}

Background: The lifetime prevalence of spinal pain has been reported as $54 \%$ to $80 \%$, with as many as $60 \%$ of patients continuing to have chronic pain five years or longer after the initial episode. Spinal pain is associated with significant economic, societal, and health impact. Available evidence documents a wide degree of variance in the definition and the practice of interventional pain management.

Objective: To develop evidence-based clinical practice guidelines for interventional techniques in the management of chronic spinal pain, with utilization of all types of evidence, applying an evidence-based approach, with broad representation of specialists from academic and clinical practices.

Design: A systematic review of diagnostic and therapeutic interventions applied in managing chronic spinal pain by a policy committee. Design consisted of formulation of essentials of guidelines and a series of potential evidence linkages representing conclusions, and statements about relationships between clinical interventions and outcomes.

Methods: The elements of the guideline preparation process included literature searches, literature synthesis, systematic review, consensus evaluation, open forum presentation, formal endorsement by the Board of Directors of the American Society of Inter-

From American Society Of Interventional Pain Physicians, Paducah, KY

Address Correspondence: Mark V. Boswell, MD,PhD Chief, Pain Medicine Service, 2533 Lakeside, University Hospitals of Cleveland, 11100 Euclid Avenue, Cleveland, Ohio 44106

Disclaimer: Nothing of monetary value was received in the preparation of this manuscript.

Conflict of Interest: None

Funding: Internal funding was provided by American Society of Interventional Pain Physicians limited to travel and lodging expenses to the authors ventional Pain Physicians (ASIPP), and blinded peer review.

Methodologic quality evaluation criteria utilized included AHRQ criteria, QUADAS criteria, and Cochrane review criteria. The designation of levels of evidence was from Level I (conclusive), Level II (strong), Level III (moderate), Level IV (limited), to Level V (indeterminate).

Results: The accuracy of facet joint nerve blocks was strong in the diagnosis of lumbar and cervical facet joint pain, whereas, it was moderate in the diagnosis of thoracic facet joint pain. The evidence was strong for lumbar discography, whereas, the evidence was limited for cervical and thoracic discography.

The evidence was moderate for transforaminal epidural injections or selective nerve root blocks in the preoperative evaluation of patients with negative or inconclusive imaging studies. The evidence was moderate for sacroiliac joint injections in the diagnosis of sacroiliac joint pain.

The evidence for therapeutic lumbar intraarticular facet injections of local anesthetics and steroids was moderate for shortterm improvement and limited for long-term improvement, whereas, it was negative for cervical facet joint injections. The evidence for lumbar and cervical medial branch blocks was moderate. The evidence for medial branch neurotomy was moderate to strong for relief of chronic low back and neck pain.

The evidence for caudal epidural steroid injections was strong for short-term relief and moderate for long-term relief in managing chronic low back and radicular pain, and limited in managing pain of postlumbar laminectomy syndrome. The evidence for interlaminar epidural steroid injections was strong for short-term relief and limited for long-term relief in managing lumbar radiculopathy, whereas, for cervical radiculopathy the evidence was moderate. The evidence for transforaminal epidural steroid injections was strong for short-term and moderate for long-term improvement in managing lumbar nerve root pain, whereas, it was moderate for cervical nerve root pain and limited for lumbar post laminectomy syndrome and spinal stenosis.

The evidence for percutaneous epidural adhesiolysis was strong. For spinal endoscopic adhesiolysis, the evidence was strong for short-term relief and moderate for longterm relief.

For sacroiliac intraarticular injections, the evidence was moderate for short-term relief and limited for long-term relief. The evidence for radiofrequency neurotomy for sacroiliac joint pain was indeterminate.

The evidence for intradiscal electrothermal therapy was strong for short-term relief and moderate for long-term relief in managing chronic discogenic low back pain, whereas, for nucleoplasty, the evidence was limited.

The evidence for spinal cord stimulation in failed back surgery syndrome and complex regional pain syndrome was strong for shortterm relief and moderate for long-term relief. The evidence for implantable intrathecal infusion systems was moderate to strong.

Conclusion: These guidelines included the evaluation of evidence for diagnostic and therapeutic procedures in managing chronic spinal pain and recommendations for managing spinal pain. However, these guidelines do not constitute inflexible treatment recommendations. These guidelines do not represent a "standard of care."

Keywords: Interventional techniques, chronic spinal pain, diagnostic blocks, therapeutic interventions, facet joint interventions, epidural injections, epidural adhesiolysis, discography, radiofrequency, spinal cord stimulation, intrathecal implantable systems 


CONTENTS
1.0 Introduction
1.1 Purpose
1.2 Rationale and Importance
1.3 Population and Preferences
1.4 Implementation and Review
1.5 Application
1.6 Focus
1.7 Technology
1.8 Methodology
2.0 Chronic Pain
2.1 Definition
2.2 Prevalence
2.3 Spinal Pain
2.4 Chronicity
2.5 Health and Economic Impact
3.0 Structural Basis
3.1 Facet Joint
3.2 Intervertebral Disc
3.3 Dorsal Root Ganglion
3.4 Sacroiliac Joint
3.5 Postlaminectomy Syndrome
3.6 Spinal Stenosis

4.0 Interventional Techniques

4.1 Mechanism of Action

5.0 Diagnostic Interventional Techniques 5.1 Facet or Zygapophysial Joint Blocks 5.2 Provocative Discography

5.3 Transforaminal Epidural Injections or Selective Nerve Root Blocks

5.4 Sacroiliac Joint Blocks

6.0 Therapeutic Interventional Techniques

6.1 Facet Joint Interventions

6.1.1 Intraarticular Blocks

6.1.2 Medial Branch Blocks

6.1.3 Medial Branch Neurotomy

6.2 Epidural Injections

6.2.1 Caudal Epidural Injections

6.2.2 Interlaminar Epidural Injections

6.2.3 Transforaminal Epidural Injections

6.3 Epidural Adhesiolysis

6.3.1 Percutaneous Adhesiolysis

6.3.2 Endoscopic Adhesiolysis

6.4 Sacroiliac Joint Interventions

6.4.1 Intraarticular Injections

6.4.2 Radiofrequency neurotomy
6.5 Intradiscal Therapies

6.5.1 Intradiscal Electrothermal Therapy

6.5.2 Nucleoplasty

6.6 Implantable Therapies

6.6.1 Spinal Cord Stimulation

6.6.2 Implantable Intrathecal Drug

Administration Systems

7.0 Evaluation And Management

7.1 Evaluation

7.2 Medical Necessity Management

8.0 Delivery of Interventional Technology

8.1 Facet Joint Injections and Medial

Branch Blocks

8.2 Medial Branch Neurotomy

8.3 Epidural Injections

8.4 Percutaneous Adhesiolysis

8.5 Spinal Endoscopic Adhesiolysis

8.6 Sacroiliac Joint Injections

8.7 Sacroiliac Joint Radiofrequency

Neurotomy

9. An Algorithmic Approach

10. Conclusion

\subsection{InTRODUCTION}

\subsection{Purpose}

Evidence-based clinical practice guidelines for interventional techniques in the management of chronic spinal pain are statements developed to improve quality of care, patient access, treatment outcomes, appropriateness of care, efficiency and effectiveness, and achieve cost containment by improving the cost-benefit ratio (1).

\subsection{Rationale and Importance}

Available evidence documents a wide degree of variance in the definition and the practice of interventional pain management (1). Application of interventional techniques by multiple specialties is highly variable for even the most commonly performed procedures and treated condition(s).

National Uniform Claims Commit-

1 The National Uniform Claims Committee. Specialty Designation for Interventional Pain Management- 09.

2 Medicare Payment Advisory Commission Report to the Congress. Paying for Interventional Pain Services in Ambulatory Settings. Decem ber 2001 . tee (NUCC) $)^{1}$ defines interventional pain management as the discipline of medicine devoted to the diagnosis and treatment of pain and related disorders by the application of interventional techniques in managing subacute, chronic, persistent, and intractable pain, independently or in conjunction with other modalities of treatments.

Medicare Payment Advisory Commission (MedPAC) ${ }^{2}$ described interventional techniques as minimally invasive procedures including percutaneous precision needle placement, with placement of drugs in targeted areas or ablation of targeted nerves; and some surgical techniques such as laser or endoscopic diskectomy, intrathecal infusion pumps and spinal cord stimulators, for the diagnosis and management of chronic, persistent or intractable pain.

Many of the conditions of spinal pain and other chronic pain conditions are considered as either acute recurrent problems that are characterized by periods of quiescence punctuated by flareups, or chronic diseases, like diabetes or hypertension, requiring long-term treatment with ongoing care. On the basis of advances in imaging, neural anatomic findings, new discoveries in chemical mediation, the development of precision di- agnostic and therapeutic injection techniques, and reported non-operative treatment successes, the importance of interventional techniques in managing chronic spinal pain has been defined.

Many guidelines, systematic reviews, Cochrane Reviews, and other publications pertaining to interventional pain management have been seriously questioned (110). Neither cancer pain nor spine surgery guidelines may be applied to manage chronic spinal pain. It has been highlighted that such reviews have some major shortcomings, with potentially harmful health care implications for patients in the United States (10).

These guidelines address the issues of systematic evaluation and ongoing care of chronic or persistent pain. Primarily, these guidelines provide information about the scientific basis of recommended procedures. The guidelines, properly applied, should increase compliance, dispel misconceptions, contribute to appropriate patient expectations, and facilitate the relationship between patients, physicians, and the payers.

\subsection{Population and Preferences}

The population covered by these guidelines includes all patients suffering with chronic spinal pain eligible to under- 
go commonly utilized and effective interventional technique(s). A treatment plan must be established taking into consideration the evidence, patient preferences, and risk-benefit ratio.

\subsection{Implementation and Review}

The dates for implementation and review were established:

- Effective date - February 1, 2005

- Expiration date - January 31, 2007

- Scheduled review - April 1,2006

\subsection{Application}

These guidelines are intended for use by interventional pain physicians. However, these guidelines do not constitute inflexible treatment recommendations. It is expected that a provider will establish a plan of care on a case-by-case basis, taking into account an individual patient's medical condition, personal needs, and preferences, and the physician's experience. Based on an individual patient's needs, treatment different from that outlined here could be warranted. These guidelines do not represent "standard of care."

\subsection{Focus}

These guidelines focus on a range of interventions that are the essential elements of effective management of chronic spinal pain. It is recognized that management of chronic spinal pain takes place in a wide context of healthcare, involving multiple specialists, and multiple techniques which also include non-interventional techniques. Consequently, the decision to implement a particular management approach should be based on a comprehensive assessment of the patient's overall health status, requirements, and preferences.

\subsection{Technology}

These guidelines describe multiple interventional techniques available in the management of chronic spinal pain, both diagnostic and therapeutic. The diagnostic interventional techniques include facet joint blocks, provocative discography, sacroiliac joint blocks, and transforaminal epidural injections. Therapeutic interventional techniques include facet joint interventions encompassing intraarticular injections, medial branch blocks, and medial branch neurotomy; sacroiliac joint interventions, including sacroiliac joint blocks, and radiofrequency neurotomy; epidural injections including caudal epi- dural injections, interlaminar epidural injections, and transforaminal epidural injections; epidural adhesiolysis including percutaneous adhesiolysis, and spinal endoscopic adhesiolysis; intradiscal therapies including intradiscal electrothermal therapy (IDET), nucleoplasty, and implantable therapies, which include spinal cord stimulation and intrathecal drug administration systems.

These guidelines also describe evaluation and management services, delivery of interventional technology, and an algorithmic approach to diagnosis and management of chronic spinal pain.

\subsection{Methodology}

In developing these guidelines, all types of evidence are utilized. If an evidence-based approach failed to provide adequate levels of evidence, consensus and expert opinions have been utilized. These approaches are described in separate publications (1, 11-19).

While an evidence-based approach may seem to enhance the scientific rigor of guideline development, recommendations may not always meet the highest scientific standards (11-17). Evidencebased medicine is defined as the conscientious, explicit, and judicious use of current best evidence in making decisions about the care of individual patients (15).

In preparation of these guidelines, it is recognized that at the core of an evidence-based approach to clinical or public health issues is, inevitably, the evidence itself which needs to be carefully gathered and collated from a systematic literature review of the particular issues. Consequently, the process by which the strength of scientific evidence is evaluated in the development of evidence-based medicine recommendations and guidelines is crucial. The practice of evidence-based medicine requires the integration of individual clinical expertise with the best available clinical evidence from systematic research.

A policy committee, with broad representation, consisting of academic and clinical practitioners recognized as experts in one or more interventional techniques of concern and representing a variety of practices and geographic areas, were included and convened. This committee formalized the essentials of guidelines. This was followed by formulation of a series of potential evidence linkages, representing conclusions and statements about relationships between clinical interventions and outcomes. The elements of the guideline preparation process included literature searches, literature syntheses, systematic review, consensus evaluation, open forum presentations, formal endorsement by the Board of Directors of the American Society of Interventional Pain Physicians (ASIPP), and blinded peer review.

Descriptions of evidence synthesis and guideline preparation are described in multiple documents (11-20). In addition, multiple systematic, narrative, and/ or best evidence synthesis reviews pertaining to interventional techniques have been considered and included (1-8, 21$40)$. In synthesizing the evidence, systematic reviews, randomized clinical trials, observational studies, and diagnostic accuracy studies were evaluated utilizing reporting criteria and quality evaluation criteria $(7,11,12,16,18-20,41-45)$. Details of evidence synthesis are described in multiple publications $(11,12,16,18,19)$. For a particular technique, if at least ten randomized trials were not available, nonrandomized or observational studies were also included.

Systems for grading the strength of a body of evidence are much less uniform and consistent than those for rating study quality. Consequently, the guideline committee designed levels of evidence from Level I through Level V, modified from various publications (Table 1) $(1,11,12,16,18,19)$.

\subsection{Chronic Pain}

\subsection{Definition}

Chronic pain has numerous definitions. Consequently, single or a combination of multiple definitions are utilized (1).

- Pain which persists a month beyond the usual course of an acute disease or a reasonable time for any injury to heal that is associated with chronic pathologic processes that cause continuous pain or pain at intervals for months or years.

- Persistent pain that is not amenable to routine pain control methods.

- Pain that exists beyond an expected time frame for healing.

- Pain, where healing may never occur.

Pain is a highly disagreeable sensation that results from an extraordinarily 
Table 1. Designation of levels of evidence

\begin{tabular}{|l|l|}
\hline Level I & $\begin{array}{l}\text { Conclusive: Research-based evidence with multiple relevant and high-quality } \\
\text { scientific studies or consistent reviews of meta-analyses }\end{array}$ \\
\hline Level II & $\begin{array}{l}\text { Strong: Research-based evidence from at least one properly designed random- } \\
\text { ized, controlled trial; or research-based evidence from multiple properly de- } \\
\text { signed studies of smaller size; or multiple low quality trials. }\end{array}$ \\
\hline Level III & $\begin{array}{l}\text { Moderate: a) Evidence obtained from well-designed pseudorandomized con- } \\
\text { trolled trials (alternate allocation or some other method); b) evidence obtained } \\
\text { from comparative studies with concurrent controls and allocation not random- } \\
\text { ized (cohort studies, case-controlled studies, or interrupted time series with a } \\
\text { control group); c) evidence obtained from comparative studies with historical } \\
\text { control, two or more single-arm studies, or interrupted time series without a } \\
\text { parallel control group. }\end{array}$ \\
\hline Level IV & $\begin{array}{l}\text { Limited: Evidence from well-designed nonexperimental studies from more than } \\
\text { one center or research group; or conflicting evidence with inconsistent findings } \\
\text { in multiple trials }\end{array}$ \\
\hline Level V & $\begin{array}{l}\text { Indeterminate: Opinions of respected authorities, based on clinical evidence, } \\
\text { descriptive studies, or reports of expert committees. }\end{array}$ \\
\hline
\end{tabular}

Adapted and modified from ref $(1,11,12,16,18,19)$

complex and interactive series of mechanisms integrated at all levels of the neuraxis, from the periphery to higher cortical structures.

\subsection{Prevalence}

A review of 15 epidemiological studies led to the conclusion that, in the adult population, chronic pain ranges from $2 \%$ to $40 \%$, with a median point prevalence of $15 \%$ (46). Various studies (47-51), defining chronic pain of $>3$ months duration, reported prevalence rates of chronic pain ranging from approximately $11 \%$ to $24 \%$. A World Health Organization Study in primary care evaluating persistent pain and well being reported an overall prevalence of pain in $20 \%$ of primary care patients, with approximately $48 \%$ reporting back pain (52). Overall, literature has overwhelmingly and consistently described the prevalence of chronic pain in children, adults, and elderly (53-59).

In a 4-year follow-up study, it was concluded that chronic pain is a common, persistent problem in the community with relatively high incidence and low recovery rates (53). In a cross sectional study of prevalence of musculoskeletal symptoms in single and multiple body regions, it was demonstrated that musculoskeletal symptoms for multiple body regions ( 2 or more) were more prevalent ( $64 \%$ of all workers) than those for single body regions (19\%) (54). They showed that approximately $85 \%$ of lower back symptoms were associated with dis- orders in other body regions.

\subsection{Spinal Pain}

Among chronic pain disorders, pain arising from various structures of the spine constitutes the majority of problems. The lifetime prevalence of spinal pain has been reported as $54 \%$ to $80 \%$ (1, $53,56-80)$. Studies of the prevalence of low back pain and neck pain $(60,64)$ and impact on general health showed $25 \%$ of patients reporting grade II to IV low back pain (high pain intensity with disability) vs $14 \%$ with neck pain. The studies evaluating chronic low back pain estimated the average age related prevalence of persistent low back pain as $12 \%$ in children and adolescents, $15 \%$ in adults, and $27 \%$ in the elderly $(1,56,57,60)$.

\subsection{Chronicity}

Duration of pain and its chronicity have been topics of controversy. Conventional beliefs are that most episodes of low back pain will be short-lived, with $80 \%$ to $90 \%$ of attacks resolving in about 6 weeks irrespective of the administration or type of treatment, and $5 \%$ to $10 \%$ of patients developing persistent back pain. However, this concept has been questioned, as the condition tends to relapse, so most patients will experience recurrent episodes. Modern evidence has shown that chronic persistent low back pain and neck pain in children and adults are seen in up to $60 \%$ of patients, 5 years or longer after the initial episode $(1,72-78)$.

\subsection{Health and Economic Impact}

Spinal pain is associated with significant economic, societal, and health impact (79-98). Estimates and patterns of direct healthcare expenditures among individuals with back pain in the United States have reached $\$ 90.7$ billion for the year 1998 (84). On average, individuals with back pain incurred healthcare expenditures about $60 \%$ higher than individuals without back pain $(\$ 3,498$ versus $\$ 2,178$ ). It was estimated that the cost of healthcare for patients with chronic pain might exceed the combined cost of treating patients with coronary artery disease, cancer, and AIDS (94). In the United States, it was estimated that the cost of treatment in the first year after failed back surgery for pain was approximately $\$ 18,883$ in 1997 (95). Even further, annual healthcare cost incurred by chronic pain patients, excluding cost for surgical procedures, may range from $\$ 500$ to as high as $\$ 35,400$, with the average ranging from $\$ 12,900$ to $\$ 18,883$ annually (95, 96). However, the majority of the costs are associated with disability compensation, lost productivity, and lost tax revenue. Disability secondary to spinal pain is enormous $(84,88-98)$.

\subsection{Structural Basis}

Chronic spinal pain is a multifactorial disorder with many possible etiologies. The biopsychosocial model, which emerged in the 1980s, views chronic spinal pain as a biopsychosocial phenomenon, in which biological, psychological and social factors dynamically interact with each other. In the 1990s, the biopsychosocial approach dominated chronic spinal pain management, at least among academicians, with the introduction of "psychosocial" approaches.

Proponents of a structural basis claim that proponents of psychopathologic basis should provide empirical evidence to prove that psychopathology causes pain and specify the mechanisms by which it is generated (99). Modern technology, including magnetic resonance imaging (MRI), computed tomographic axial scanning (CT), neurophysiologic testing, and comprehensive physical examination with psychological evaluation, can identify the cause of low back pain in only $15 \%$ of patients in the absence of disc herniation and neurological deficit $(1,100)$.

The majority of painful conditions 
include various types of pain originating from the spine with pain in the neck, upper back, mid back, low back and upper or lower extremities. It was postulated that, for any structure to be deemed a cause of back pain (101):

- The structure should have a nerve supply;

- The structure should be capable of causing pain similar to that seen clinically, ideally demonstrated in normal volunteers;

- The structure should be susceptible to diseases or injuries that are known to be painful; and,

- The structure should have been shown to be a source of pain in patients, using diagnostic techniques of known reliability and validity.

Kuslich et al (102) identified intervertebral discs, facet joints, ligaments, fascia, muscles, and nerve root dura as tissues capable of transmitting pain in the low back. Facet joint pain, discogenic pain, and sacroiliac joint pain also have been proven to be common causes of pain with proven diagnostic techniques $(1,32$, $33,100,101)$. In contrast, vertebrae, muscles and ligaments have not been proven to be common sources of spinal pain with proven diagnostic techniques. In one prospective evaluation (103), consecutive adult patients with intractable low back pain (who had failed conservative therapy) of undetermined etiology (by medical history, physical examination, x-ray, CT, MRI, EMG/NCV) had pain from facet joint(s) in $24 \%$, combined lumbar nerve root and facet disease in $24 \%$, combined facet(s) and sacroiliac joint(s) in 4\%, lumbar nerve root irritation in $20 \%$, internal disc disorder in $7 \%$, sacroiliac joint in $6 \%$, and sympathetic dystrophy in $2 \%$. In a second study (104), the relative contributions of various structures in patients with chronic low back pain who failed to respond to conservative modalities of treatments (physical therapy, chiropractic and drug therapy), with lack of radiological evidence to indicate disc protrusion or radiculopathy, were evaluated utilizing controlled, comparative, double diagnostic blocks. In this study, $40 \%$ of the patients were shown to have facet joint pain, $26 \%$ discogenic pain, 2\% sacroiliac joint pain, and possibly $13 \%$ segmental dural/ nerve root pain. No cause was identified in $13 \%$ (103) and 19\% (104) of the patients.

\subsection{Facet Joint}

The facet or zygapophysial joints are paired diarthrodial articulations between posterior elements of adjacent vertebrae (105). Spinal facet joints have been shown to be a source of pain in the neck and referred pain in the head and upper extremities (106-110); upper back, mid back and referred pain in chest wall (111); and the low back and referred pain in the lower extremity (112-117) in normal volunteers.

Facet joints are well innervated by the medial branches of the dorsal rami (118-127), contain free and encapsulated nerve endings $(116,119,121,127)$, and nociceptors and mechanoreceptors (119, 128-133).

Based on controlled diagnostic blocks of facet joints, in accordance with the criteria established by the International Association for the Study of Pain (IASP) (134), facet joints have been implicated as responsible for spinal pain in $15 \%$ to $45 \%$ of patients with low back pain $(104,135$ $143), 54 \%$ to $67 \%$ of patients with neck pain $(141,143-146)$, and $42 \%$ to $48 \%$ of patients with thoracic pain $(141,147)$.

\subsection{Intervertebral Disc}

The human intervertebral disc (IVD) is a complex structure, which is macroscopically composed of the nucleus pulposus (NP), the annulus fibrosus (AF), and the endplates (EP) (148). Intervertebral discs are innervated (116, $119,149-170)$. The outer annulus is innervated $(116,119,149,150)$ to a depth of up to $3.5 \mathrm{~mm}(161,162)$, but nerves may grow into the inner annulus and nucleus (163), particularly if the disc is degenerated or painful (152-154). IVD innervation density is concentrated in the periannular connective tissue and the endplates (159). These nerve fibers transmit both nociceptive and non-nociceptive information $(116,119,149-151,164-167)$. In addition, many of these nerve fibers, identifiable by immunochemistry, are accompanied by blood vessels; this process of neovascularization is associated with inflammation. Neural structures that express substance $\mathrm{P}$ and have the morphology of nociceptive nerve terminals are found in the nucleus of painful discs; this may distinguish painful versus painless disc degeneration (168).

Clinically, the IVD, depending on location, can produce pain in the neck, upper extremities, posterior thorax, chest wall, abdominal wall, low back, and lower extremities (102, 171-174). IVD-related pain can be caused by structural abnormalities, such as disc degeneration or disc herniation; correspondingly, biochemical effects, such as inflammation, and neurobiological processes may play a role. Nerve growth factor (NGF) dependent neurons are the main neuronal subgroup, within the dorsal root ganglion (DRG), that transmit and modulate pain in response to inflammation. This subgroup is responsible for sensitizing the DRG to NGF and is present in the painful IVD. NGF may play an important role in discogenic back pain $(169,175-178)$. The nucleus pulposus is a biologically active tissue that can respond to pro-inflammatory stimuli (178).

The first to create widespread interest in the disc as a source of pain in American literature were Mixter and Barr (173) with their 1934 hallmark description of the herniated nucleus pulposus. However, soon after, Mixter and Ayers (174) in 1935 demonstrated that radicular pain can occur without disc herniation. Consequently, the pathophysiology of spinal radicular pain is a subject of ongoing research and controversy and discogenic pain has assumed a major role as a cause of nonspecific low back pain, beyond the more specific disc herniation. Thus, in addition to the mechanical component, inflammation of the compressed nerve root is an important factor in the pathophysiology of radicular and discogenic pain (148, 179-184). Other proposed etiologies include neural compression with dysfunction and vascular compromise (185-189). While neurotoxicity has been attributed to many agents including phospholipase $\mathrm{A}_{2}\left(\mathrm{PLA}_{2}\right)$, metalloproteinases, and interleukin-6, prostaglandin E2 (177, 179-183, 190-196), tumor necrosis factor (TNF- $\alpha$ ) has been shown to have an essential role in intervertebral disc-induced nerve root damage (197-200).

The etiology of discogenic pain is unclear $(101,148,201)$. Internal disc disruption (IDD) is a condition in which the internal architecture of the disc is disrupted, but its external surface remains essentially normal (202). IDD can be experimentally induced by endplate damage (203). Likewise, experimentally induced annular tears can lead to adverse and progressive mechanical changes in the disc. Annular degeneration has been shown to appear early in lumbar discs and 
clearly related to back pain (204). Disrupted discs do not exhibit either bulging or herniation. These features with a normal or near normal contour of discs producing back pain, but with no evidence of herniation or prolapse were described by Crock (202) as internal disc disruption. It has been suggested that endplate damage would precede disc degeneration (205). Further, diminution of blood supply in the endplate initiates tissue breakdown, first in the endplate and thereafter in the nucleus in the first half of the second life decade (206), with visible tears in the nucleus in the age group of 11 to 16 years. The removal of proteoglycans from the endplate, which regulates the movement of solutes into and out of the disc, accelerates the loss of proteoglycans from the nucleus (207). It also has been shown that reduced lumbar artery blood flow may diminish nutrition through the endplates leading to an increased incidence of disc degeneration (208). Discs with internal disc disruption are rendered painful by either chemical nociception or mechanical stimulation. Explanted discs, following posterior lumbar interbody fusion in patients with lumbar discogenic pain demonstrated a vascularized strip lesion extending from the NP to the AF; this lesion was accompanied by extensive innervation in the posterior disc (209).

In a controlled study, the prevalence of pain due to internal disc disruption was reported as $39 \%$ in patients suffering with chronic low back pain (210). Primary discogenic pain was reported in $7 \%$ (103) to $26 \%$ (104) when no other cause was suspected. The prevalence of cervical discogenic pain in patients with chronic neck pain of traumatic origin in informal studies was estimated to be $61 \%$ (211). Discogenic and radicular pain syndromes continue to pose challenges to patients, physicians, and the society-at-large.

\subsection{Dorsal Root Ganglion}

The dorsal root ganglion plays an important role in the mechanism of spinal pain. This holds true, when the DRG itself is injured or when other spinal structures are injured. Experiments have suggested that edema in the dorsal root ganglion underlies the production of nerve root pain in patients with disc herniation (212221). Mechano- and chemosensitivity of dorsal root ganglia have been described (192, 193, 215-217). Experimentally applied nucleus pulposus from healthy and degenerative discs reduces nerve root conduction velocity, suggesting a pathomechanism of neural injury (218). The NP can induce excitatory changes, rising endoneurial pressures-compartment syndrome, and cause intraneural thrombi in the DRG or the nerve roots $(193,197$, 219). Anti-inflammatory agents, such as tumor-necrosis factor alpha inhibitors, may protect against NP-induced DRG and nerve root injury (192).

\subsection{Sacroiliac Joint}

The sacroiliac joint is a diarthrodial, synovial joint. The sacroiliac joint is well innervated receiving myelinated and unmyelinated axons capable of nociception (222-230). Referral patterns of sacroiliac joint provocation or irritation have been published (231-233).

Utilizing single diagnostic blocks, the prevalence of sacroiliac pain would appear to be at least $13 \%$ and perhaps as high as $30 \%$ in the United States (234) and 10\% in Taiwan (103). Utilizing controlled, comparative local anesthetic blocks in patients with low back pain in whom there was a high index of suspicion for pathology, frequency of sacroiliac joint dysfunction was established as $18.5 \%$ (235), or $10 \%$ (104) in suspected patients. High prevalence may be seen in patients with lumbar fusion $(236,237)$.

\subsection{Postlaminectomy Syndrome}

Postlaminectomy syndrome and other synonyms, such as failed back surgery syndrome, represent a cluster of syndromes wherein the expectations of the patient and spine surgeon are not met, following spine surgery (238-243). Persistent pain following spine surgery is common (238-252). Since discectomies, decompressions, and spinal fusions and more recently, minimally invasive surgical and interventional therapies, represent the largest portion of the US spine market (with expenditures of $\$ 2.5$ billion in the United States in 2003 of the estimated \$3 billion for the worldwide spine market), one may reasonably anticipate that the costs of persistent pain following spine surgery will increase substantially (253$258)$. In the year 2002 , more than 1 million spinal procedures were performed in the USA. Six hundred thousand cases were not instrumented, but 400,000 were instrumented (255-257). The estimated yearly growth rate of uninstrumented cases ranged from $3 \%$ to $5 \%$; in contrast, the growth rate of instrumented cases from $6 \%$ to $8 \%$ (257). The spine market may compound at $22 \%$ annually (257). Lieberman (253) cautioned that all parties involved in the spine market must be vigilant in not letting the spine market turn into a cancer, or even worse, allowing the "disc bulge bubble" to burst. A surgeon's assessment of adverse post-operative outcomes may seriously underreport a patient's self-assessment of surgical outcomes (259).

Animal models of postlaminectomy syndrome demonstrate paraspinous muscle spasms, tail contractures, behavioral pain behaviors, tactile allodynia, epidural and perineural scarring, and nerve root adherence to the underlying disc and pedicle (260). Speculated causes of postlaminectomy syndrome include acquired stenosis, adjacent segment degeneration, internal disc disruption, recurrent disc herniation, retained disc fragment, spondylolisthesis, epidural or intraneural fibrosis, degenerative disc disease, radiculopathy, radicular pain, deconditioning, facet joint pain, sacroiliac joint pain, discitis, arachnoiditis, pseudoarthrosis, segmental instability, and others (238-252). Among these, etiologies such as epidural fibrosis, facet joint dysfunction, sacro-iliac dysfunction, internal disc dysfunction, recurrent disc herniation, and spinal stenosis can be treated by interventional pain methods (251, 261-264). Ultimately, many of these etiologies are interrelated. Epidural fibrosis may occur following an annular tear, disc herniation, hematoma, infection, surgical trauma, vascular abnormalities, or intrathecal contrast media $(251,261,263$ 273). Epidural fibrosis may account for as much as $20 \%$ to $36 \%$ of all cases of failed back surgery syndrome (FBSS) $(239,246$, 247, 261, 263, 264, 274-276). Alternatively, there may be a final common pathway with all these etiologies, which results in peripheral and central facilitation potentiated by inflammatory and nerve injury mechanisms (260). Paraspinal muscles may become denervated and involved in the pathogenesis of FBSS (277).

\subsection{Spinal Stenosis}

Spinal stenosis can be defined as a narrowing of the spinal canal, resulting in symptoms and signs caused by entrapment and compression of the intraspinal vascular and nervous structures (278). Disc bulging, protrusion and herniation 
in the cervical, as well as lumbar area, combined with osteophytes and arthritic changes of the facet joints can cause narrowing of the spinal canal, encroachment on the contents of the dural sac, or localized nerve root canal stenosis (279-283).

The pain and disability associated with lumbar spinal stenosis can interfere with a patient's lifestyle. Treatment options for low back pain and neurogenic claudication related to lumbar spinal stenosis include surgery, but also, nonoperative modalities including conservative treatment and interventional techniques.

\subsection{Interventional Techniques}

Various types of injection techniques have been described with multiple benefits including pain relief that outlasts by days, weeks, or months the relatively short duration of pharmacologic action of the local anesthetics and other agents used. No clear-cut explanations for these prolonged improvements are currently available.

\subsection{Mechanism of Action}

Neural blockade has been postulated to alter or interrupt nociceptive input, reflex mechanisms of the afferent limb, selfsustaining activity of neuron pools and neuraxis, and the pattern of central neuronal activities (284). Improvements may be explained in part based on the pharmacological and physical actions of local anesthetics, corticosteroids, and other agents. Local anesthetics interrupt the pain-spasm cycle and reverberating nociceptor transmission, whereas corticosteroids reduce inflammation either by inhibiting the synthesis or release of a number of pro-inflammatory substances and by causing a reversible local anesthetic effect $(1,28,30,215,285-296)$.

Various modes of action of corticosteroids include membrane stabilization; inhibition of neural peptide synthesis or action; blockade of phospholipase $\mathrm{A}_{2}$ activity; prolonged suppression of ongoing neuronal discharge; and suppression of sensitization of dorsal horn neurons. Local anesthetics have been shown to produce prolonged dampening of C-fiber activity. Physical effects include clearing adhesions or inflammatory exudates from the vicinity of the nerve root sleeve. The scientific basis of some of these concepts, at least in part, is proven for spinal pain management with epidural injections of betamethasone and intravenous methyl- prednisolone (215, 288, 291-294).

Various mechanisms of benefits for longer periods of time than the duration of the anesthetics used have been described (297-300). Among the several theories listed include the influence on sympathetic nervous system (301); temporary abolition of spontaneous ectopic discharges, resulting in suppression of dynamically maintained central hyperexcitability, as well as reinforcing endogenous G-protein-couple receptor inhibition of $\mathrm{N}$-type voltage-sensitive calcium channels $(298,301)$; and glial inactivation (300).

\subsection{Diagnostic Interventional TECHNIQUeS}

It has been postulated that for any structure to be deemed a cause of back pain, the structure should have been shown to be a source of pain in patients, using diagnostic techniques of known reliability and validity $(32,101)$. The diagnostic blockade of a structure with a nerve supply with the ability to generate pain can be performed to test the hypothesis that the target structure is a source of a patient's pain. Evidence-based interventional diagnostic techniques include facet joint blocks, discography, sacroiliac joint injections, and transforaminal epidurals or selective nerve root blocks.

\subsubsection{Rationale}

The popularity of neural blockade as a diagnostic tool in painful conditions is due to multiple challenging clinical situations including the purely subjective nature of spinal pain and undetermined and uncertain pathophysiology in most painful spinal conditions. Precision diagnostic blocks are used to clarify these challenging clinical situations, in order to determine the pathophysiology of clinical pain, the site of nociception and the pathway of afferent neural signals. Precise anatomical diagnosis in low back pain has been described not only as elusive, but also the diagnostic evaluation is often frustrating for both physicians and patients $(1,32,33$, $99,100,101,103,104,302-304)$. History, physical examination, and imaging provide limited information.

\subsubsection{Reliability and Validity}

Clinical studies of precision diagnostic techniques are variable in sensitivity, specificity, accuracy and quality. Falsepositive rate (how often patients without a condition will nonetheless have a positive test), false-negative rate (how often a patient with disease will have a negative test), and placebo response are crucial. Since none of the tests available in clinical medicine are ideal, there is a degree of uncertainty regarding the accuracy of each and every diagnostic test as applied to an individual clinical case.

The accuracy of a diagnostic test is best determined by comparing it to an appropriate reference standard (gold standard) such as biopsy, surgery, autopsy, or long-term follow-up. Tissue confirmation of the presence or absence of a disease at surgery, with a biopsy, or autopsy, which has served as the accepted gold standard across multiple medical disciplines, is not applicable to interventional pain management. Consequently, most pain provocative or relieving tests used to diagnose painful conditions of the spine are more closely related to the physical examination than to a laboratory test (36). Stability of the diagnosis over a long period of time with long-term follow-up may be also used as a gold standard. These facts are especially true in the diagnosis of facet joint pain, discogenic pain, and sacroiliac joint pain.

In interventional pain management, a diagnostic blockade of a structure with a nerve supply, which can generate pain is performed to test the hypothesis that the target structure is the source of a patient's pain. Pain provocation in any structure is an unreliable criterion, except in provocative discography $(1,22-24,32,33,36,37$, $168,234,304-306)$. In an ideal world, all controlled blocks would include placebo injections of normal saline. However, in practical terms, it may be neither logistical, nor ethical to use placebo injections of normal saline in conventional practice. It would be necessary to perform three diagnostic blocks of the same structure with application of placebo. Consequently, the use of two local anesthetics with different durations of action, on two separate occasions, has been proposed. The use of comparative local anesthetic blocks with facet joint injections has been validated against challenge with placebo $(307,308)$.

\subsubsection{Environment}

The requirements for safe use of diagnostic interventional techniques include a sterile operating room or a procedure room, appropriate monitoring equipment, radiological equipment, sterile preparation, resuscitative equipment, needles, gowns, injectable drugs, intrave- 
nous fluids, anxiolytic medications, and trained personnel for preparation and monitoring of patients. Minimum requirements include history and physica examination, informed consent, and appropriate documentation of the procedure.

\subsubsection{Contraindications}

Contraindications include ongoing bacterial infection, possible pregnancy, bleeding diathesis, and anticoagulant therapy. Precautions are warranted in patients with antiplatelet or anticoagulant therapy, diabetes mellitus and artificial heart valves.

\subsection{Facet or Zygapophysial Joint Blocks}

Diagnostic blocks of a facet or zygapophysial joint can be performed by anesthetizing the joint by intraarticular injections of local anesthetic or the medial branches of the dorsal rami that innervate the target joint, to test whether the joint is the source of pain. Valid information is only obtained by performing controlled blocks, either in the form of placebo injections of normal saline or comparative local anesthetic blocks, in which on two separate occasions, the same joint is anesthetized using local anesthetics with different durations of action.

The rationale for using facet joint blocks for diagnosis is based on the fact that facet joints are capable of causing pain and they have a nerve supply. They have been shown to be a source of pain in patients using diagnostic techniques of known reliability and validity. Further, various patterns of referred pain described for facet joints in the spine are similar to other structures, such as discs (32, 33, 101, 106-117); most maneuvers used in physical examination are likely to stress several structures simultaneously, especially the discs, muscles, and facet joints, thus failing to provide any reasonable diagnostic criteria, and the evidence thus far on physical examination and diagnosis has been controversial (32, $33,100,101,135-140,144,145,309-315)$; demographic features, pain characteristics, and other signs and symptoms may not correlate and are unreliable $(32,33$, 100, 101, 135-140, 144, 145, 302-315); and medical imaging provides little useful information (315) with radiographic investigations, including magnetic resonance imaging (MRI), revealing only some con- ditions with certainty (315-321).

\subsubsection{Validity}

Controlled diagnostic blocks with two local anesthetics (or placebo-controlled) are the only means of confirming the diagnosis of facet joint pain. The face validity of medial branch blocks has been established by injecting small volumes of local anesthetic onto the target points for these blocks and by determining the spread of contrast medium in posteroanterior and lateral radiographs (123, $125,126)$. Construct validity of facet joint blocks is important to eliminate placebo effect as the source of confounding results and secure true positive results $(304,308)$. The hypothesis that testing a patient first with lidocaine and subsequently with bupivacaine provides a means of identifying the placebo response has been tested and proven $(304,307,308)$.

The specificity of the effect of cervical and lumbar facet joint blocks was demonstrated in controlled trials (123, 125, 126). Provocation response was shown to be unreliable in one study (305). The false-negative rate of diagnostic facet joint blocks was shown to be $8 \%$ due to unrecognized intravascular injection of local anesthetic (125). False-positive rates were evaluated in multiple investigations (104, 138-143, 146, 147, 262, 322-335). Reported false-positive rates varied from $27 \%$ to $63 \%$ in the cervical spine, $55 \%$ to $58 \%$ in the thoracic spine, and $17 \%$ to $47 \%$ in the lumbar spine.

The validity of comparative local anesthetic blocks was determined not only by short-term relief with controlled diagnostic blocks, and ability to perform movements which were painful prior to the blocks, but also with application of another appropriate reference standard (long-term follow-up) as described in the literature (326-328). Minimal effect of sedation $(326,327)$ in cervical and lumbar spine, and lack of influence of psychological factors on the validity of controlled diagnostic local anesthetic blocks of facet joints in the lumbar spine was demonstrated (329).

\subsubsection{Prevalence}

Based on numerous evaluations utilizing controlled diagnostic blocks, facet or zygapophysial joints have been implicated as the source of chronic spinal pain in $15 \%$ to $45 \%$ of heterogenous groups of patients with chronic low back pain (104, $135-143), 42 \%$ to $48 \%$ of the patients with thoracic pain $(141,147)$, and $54 \%$ to $67 \%$ of the patients with chronic neck pain (141, 143-146).

\subsubsection{Cost Effectiveness}

Diagnostic facet joint nerve blocks were not evaluated for cost effectiveness systematically. However, multiple authors (104, 330-332) described the feasibility and cost-effectiveness of appropriately performed controlled comparative local anesthetic blocks.

\subsubsection{Evidence}

The accuracy of facet joint nerve blocks was strong in the diagnosis of lumbar and cervical facet joint pain, whereas it was moderate in the diagnosis of thoracic facet joint pain.

\subsubsection{Safety And Complications}

Safety of facet joint interventions with intraarticular injections and medial branch blocks has been demonstrated. The most common and worrisome complications of facet joint injections or nerve blocks are related to needle placement and drug administration. These complications include hemorrhage, dural puncture, spinal cord trauma, infection, intraarterial or intravenous injection, chemical meningitis, neural trauma, paralysis, pneumothorax, radiation exposure, facet capsule rupture, hematoma formation, steroid side effects, and epidural, subdural or subarachnoid spread $(1,26,32,33$, 336-340).

\subsection{Provocative Discography}

Discography is a procedure that is used to characterize the pathoanatomy/ architecture of the intervertebral disc and to determine if the IVD is a source of chronic spinal pain. Implicitly, discography is an invasive diagnostic test that should only be applied to those chronic spinal pain patients in whom one suspects a discogenic etiology. Discography literally means the opacification of the nucleus pulposus of an intervertebral disc to render it visible under radiographs (306). The commonly practiced technical and evaluative components of discography include: sterile needle placement into the center of the IVD (nucleus pulposus), radiopaque contrast instillation to provoke pain, radiological assessment of disc morphology, and clinical assessment of the intensity and concordancy of evoked pain in relation to baseline pain. Discography has been used extensively in the study of lumbar discs, somewhat less so in cervical 
discs, and infrequently in thoracic discs.

\subsubsection{Rationale}

Formal studies have shown that the discs are innervated and can be a source of pain that has pathomorphologic correlates $(101,102,119,148-172)$. Even though the specific neurobiological events involved in how discography causes pain have not been elucidated, sound anatomic, histopathological, radiological, and biomechanical evidence suggests that lumbar discography may help to identify symptomatic and pathological IVDs. However, the cervical and thoracic discs differ from lumbar discs and do not appear to suffer the same pathology (306, 341-343).

Discography was performed in asymptomatic volunteers without spinal pain in the cervical spine (341), thoracic spine (342), and lumbar spine (343). It was shown that discographically normal discs were never painful in either symptomatic or asymptomatic groups.

The rationale is well established for lumbar discography $(37,306,343)$. Discography is helpful in patients with low back or lower extremity pain to acquire information about the structure and sensitivity of their lumbar intervertebral discs and to make informed decisions about treatment and modifications of activity (37). Although the clinical exam may demonstrate a favorable correlation with discography or disc-related pain (313, $344)$, this information may not be sufficient to guide invasive treatment for discogenic pain $(314,315)$. There is a significant overlap in evoked pain patterns among discs (345).

\subsubsection{Validity}

Examinations of cadaver discs typically confirm the presence of annular tears and disc degeneration, as revealed by discograms (204, 346-350). Multiple authors also have investigated the accuracy of discographic and CT/discographic findings based on the ability to demonstrate accurate pathology confirmed at the time of surgery. There is a high interand intra-observer agreement in assessing discographic morphology, i.e., the Adam's classification (351). While many authors (352-357) demonstrated significant correlation with confirmation of reliability of provocative discography, some $(358,359)$ have demonstrated poor correlation.

Discography was compared with myelography, CT, MRI, and results of surgical and conservative management. CT discography was reported to be more accurate than myelography $(345,353,354$, 359-365). On similar grounds, discography was shown to be superior to plain computed tomography $(362,365,366)$. While comparing the results of discography with MRI, some found discography to be as good as MRI, even though MRI was preferable as it was non-invasive and allowed assessment of more levels with one test, with minimal risk of complications and minimal discomfort $(367,368)$. However, others have identified advantages of discography with pain provocation, when MRIs were normal or equivocal (341, 342, 369-373). Alternatively, MR and CT/discography may provide complementary information. Strong correlation was demonstrated between MR/discography and CT/discography in assessing annular tears and degeneration (374). In the cervical spine, an MRI may have a false positive rate of $51 \%$ and a false negative rate of $27 \%$ in predicting which cervical spine levels to fuse, as compared to discography (375). Some authors have questioned the diagnostic accuracy of discography (376-381). The role of discography in a normal MRI is of questionable value and the routine performance of discography in this setting is not advised.

A good correlation between MRI, discography, and the high intensity zone (HIZ) has been established by some (382387 ), while others have reported poor correlation and limited value of discography $(388,389)$. Finally, the relationship of discography to outcomes, including conservative management, minimally invasive surgery, and open procedures remains controversial $(1,37)$.

While the accuracy of discography as an imaging test is high, with high specificity and sensitivity for the diagnosis of disc degeneration, the key question with discography is whether this test is accurate for the diagnosis of discogenic pain. An integral part of the problem is the lack of an adequate reference or gold standard. Surgical exposure can confirm the presence of disc degeneration or disruption, but it cannot definitely confirm the presence or absence of discogenic pain. However, the results from both surgical and minimally invasive treatment of discogenic pain in patients whose diagnosis was confirmed by discography should provide a reference standard for discogenic pain. Pressure controlled discography may reduce false-positives and enhance the value of discography (390).

The face validity of discography has been established by injecting small volumes of contrast into the disc and determining concordant pain, with spread of the contrast medium in posteroanterior and lateral radiographs and/or computed tomography. This 'face' validity can be challenged, since clinicians are relying on the transduction of a non-painful stimulus, pressure, into a painful stimulus. Nonetheless, discography may correlate with the use of frankly noxious intradiscal stimuli. Sixty-eight percent of patients undergoing intradiscal electrothermal therapy reported exact reproduction of their pain in quality and location; none reported unfamiliar pain (171). Construct validity of the discograms is also equally important to avoid a false-positive result and obtain a true positive response. Consequently, for a response to be considered positive, concordant pain must be produced; and for the test to be valid, there must be at least one disc (preferably two) that do not elicit pain upon injection, thereby serving as a control disc (134). Even then, some authors question the reliability of a patient's report of concordant pain (391).

Validity of cervical discography has been established in asymptomatic patients. However, there are no modern normative data that establish that cervical discography is a specific test for cervical discogenic pain (306). There is evidence indicating that up to $40 \%$ of the positive cervical discograms may be false-positive (211). With thoracic discography, unfamiliar or disconcordant pain may be produced in Schmorl's nodes, in lifelong asymptomatic individuals (342). Thoracic discography may demonstrate disc pathology that is not seen on MRI (342). The value of cervical and thoracic discography still warrants further investigation.

In the 1960's, Holt et al $(392,393)$ reported false-positive discograms in $37 \%$ of an asymptomatic prison population in the lumbar spine (392), with similar findings in the cervical spine (393). Simmons et al (394) reassessed Holt's data (392) and pointed out that discography as performed by Holt, although appropriate for its time, was quite different from discography as performed in 1988. Walsh et al (343), in a carefully controlled series of disc injections in asymptomatic volunteers, showed a $0 \%$ false-positive rate, refuting the findings of Holt (392). Stud- 
ies by Carragee et al $(391,395-399)$ have shown a higher rate of false-positives than the study of Walsh et al (343). Carragee et al (391), however, did not evaluate 'truly' asymptomatic volunteers.

The assumption that mild, intermittent low back pain cannot be discogenic in origin (397) can be challenged. Additionally, patients that undergo limited lumbar discectomy (396) often develop disc degeneration. A multitude of methodological flaws have been pointed out with each of these similarly structured studies (36, 400). It is noteworthy that provocative discography provided similar results in patients with or without somatization or combinations of the psychological triad of somatization disorder, depression, and generalized anxiety disorder (400).

\subsubsection{Indications}

Much of the controversy about discography has arisen because the results of discography have been used to help decide whether a certain patient should or should not have surgery, even though patients have usually undergone other diagnostic tests, the results of which were either equivocal or non-diagnostic. Thus, discography should be performed only if the patient has failed to respond to adequate attempts at non-operative care, and if diagnostic tests such as MRI have not provided sufficient diagnostic information. Generally, discography should be viewed as an invasive test to be used to seek abnormalities when results from other tests are equivocal or inconsistent, in a patient with symptoms severe enough to require further evaluation (37). Thus, specific uses for discography include, but are not limited to:

- Further evaluation of demonstrably abnormal discs to help assess the extent of abnormality or correlation of the abnormality with clinical symptoms (in case of recurrent pain from a previously operated disc and a lateral disc herniation);

- Patients with persistent, severe symptoms in whom other diagnostic tests have failed to reveal clear confirmation of a suspected disc as the source of pain;

- Assessment of patients who have failed to respond to surgical procedures to determine if there is painful pseudoarthrosis or a symptomatic disc in a posteriorly fused segment or to evaluate possible recurrent disc herniation;

- Assessment of discs before fusion to determine if the discs within the proposed fusion segment are symptomatic and to determine if discs adjacent to this segment are normal; and

- Assessment of minimally invasive surgical candidates to confirm a contained disc herniation or to investigate contrast distribution pattern before intradiscal procedures.

\subsubsection{Prevalence}

Prevalence of pain due to internal disc disruption was reported as $39 \%$ of patients suffering with chronic low back pain (210) in the United States and 7\% (103) in Taiwan. In contrast, primary discogenic pain was reported in $26 \%$ of patients suffering with chronic low back pain in the United States (104).

\subsubsection{Cost Effectiveness}

There are no cost effectiveness studies of provocative discography available in the literature.

\subsubsection{Evidence}

The evidence for cervical and thoracic discography is limited. The evidence for lumbar discography was strong for discogenic pain provided that lumbar discography is performed based on the history, physical examination, imaging data, and analysis of other precision diagnostic techniques. There is no evidence to support discography without other non-invasive or less invasive modalities of treatments or other precision diagnostic injections.

\subsubsection{Safety and Complications}

Complications related to discography include discitis, subdural abscess, spinal cord injury, vascular injury, epidural and prevertebral abscess (1, 37, 401-409). Complications are less frequent with lumbar discography compared to cervical discography. Lack of permanent effects from discography has been reported (410-413). A review of lumbar discography and prophylactic antibiotics (414) concluded that with lumbar discography using a twoneedle technique without prophylactic antibiotics, the risk of post discography discitis is minimal, and there is not enough support from the literature to justify the routine use of prophylactic antibiotics. They reported an overall incidence of $0.24 \%$ by patient, and $0.091 \%$ by disc. However, other studies have shown effective prevention of discitis with intrave- nous cefazolin or vancomycin (415), and the combination of cefoperazone and sulbactam (416). The administration of intradiscal antibiotics accidentally into the intrathecal space can have significant complications (417).

\subsection{Transforaminal Epidural Injections or Selective Nerve Root Blocks}

Transforaminal epidural injection (modern nomenclature) or a selective nerve root block (old nomenclature) consists of injection of contrast, local anesthetic, or other substances around spinal nerves under fluoroscopy $(1,22,23)$. Purists insist on describing them as two separate and distinct techniques. However, over the years authors have used them interchangeably. Consequently, we considered transforaminal epidural and selective nerve root blocks as the same procedure. Both the provocative response and analgesic response provide clinically useful information (418-436). The validity of provocative and analgesic spinal injections was recognized as early as 1938 (422). In 1971, the value of diagnostic, selective nerve root blocks in the preoperative evaluation of patients with negative or inconclusive imaging studies and clinical findings of root irritation was reported (423). Nerve blocks were utilized to diagnose the source of radicular pain when imaging studies suggested possible compression of several nerve roots $(421,424$ 433). The relief of usual symptoms following the injection of local anesthetic, $1 \mathrm{~mL}$ of $2 \%$ lidocaine, was the main determinant. Numerous authors $(421,424-$ $428,434)$ described results of diagnostic transforaminal epidural injections or selective nerve root blocks. The pattern of provoked symptoms from mechanical stimulation of nerve roots during selective nerve root blocks was described $(418,419$, 427). The literature on diagnostic selective nerve root blocks in the evaluation of low back pain was analyzed with the conclusion that selective nerve root blocks provide important prognostic information about surgical outcomes (437).

\subsubsection{Rationale}

Diagnostic selective nerve block is typically performed in a patient with persistent pain when history, examination, imaging, and other precision diagnostic injections and electrophysiologic testing do not identify the pain generator. 


\subsubsection{Validity}

The reported sensitivity of a diagnostic selective nerve root block ranges from $45 \%$ to $100 \%(421,424,427,428$, $432,438)$. The face validity of selective nerve root blocks may be accomplished by providing the blockade under fluoroscopic visualization utilizing contrast and small volume of local anesthetic with provocative and analgesic response. However, thus far, there are no means to eliminate false positives and establish construct validity for selective nerve root blocks. North et al (438), examined the specificity and sensitivity of a battery of local anesthetic blocks. They evaluated lumbosacral nerve root blocks, medial branch blocks, sciatic nerve blocks, and compared to lumbar subcutaneous injection of an identical volume of $3 \mathrm{~mL}$ of $0.5 \%$ bupivacaine. They showed that false-positive results were common and specificity was low. They concluded that there was only a limited role for uncontrolled local anesthetic blocks in the diagnostic evaluation of sciatica and referred pain syndromes in general.

On the other hand, properly performed, controlled diagnostic selective nerve root blocks or transforaminal epidural injections can be an effective technique in evaluating patients with multilevel pathology to help identify the pain generator. Similarly, they are useful when the location of symptoms seems to conflict with abnormalities identified with imaging findings $(433,439)$ or when no other cause was found based on evaluation and application of precision diagnostic techniques $(103,104,210)$.

\subsubsection{Cost Effectiveness}

Cost effectiveness of diagnostic transforaminal epidural injections or selective nerve root blocks has not been evaluated. However, several authors (104, 330-332) described the feasibility and cost-effectiveness of appropriately performed controlled comparative local anesthetic blocks.

\subsubsection{Evidence}

The evidence was moderate for transforaminal epidural injections or selective nerve root blocks in the preoperative evaluation of patients with negative or inconclusive imaging studies and clinical findings of nerve root irritation.

\subsubsection{Safety and Complications}

The most common and worrisome complications of transforaminal epidur- al injections are related to dural puncture, infection, intravascular injection, air embolism, vascular trauma, particulate embolism, cerebral thrombosis, epidural hematoma, neural or spinal cord damage, and complications related to administration of steroids $(1,25,30,38,440-450)$. Recent reports of paraplegia, vertebral artery dissection, neurological disorders, and death are concerning.

\subsection{Sacroiliac Joint Blocks}

The sacroiliac joint is accepted as a potential source of low back and/or buttock pain with or without lower extremity pain (222-233). Diagnostic blocks of a sacroiliac joint can be performed to determine whether the sacroiliac joint is the source of the patient's pain $(103,104,234$, 235). The sacroiliac joint can be anesthetized with intraarticular injection of local anesthetic.

\subsubsection{Rationale}

The rationale for sacroiliac joint blocks for diagnosis is based upon the fact that sacroiliac joints are innervated and have been shown capable of being a source of low back pain and referred pain in the lower extremity (222-233). There are no definite historical, physical, or radiological features to provide definite diagnosis of sacroiliac joint pain $(234,235$, $312,313,451-455)$. Nevertheless, many authors $(312,313,454-456)$ have advocated provocative maneuvers, which may enter into the differential diagnosis of sacroiliac joint pain. However, these signs may not be accurate in making a definitive diagnosis of sacroiliac joint syndrome. Many studies have evaluated the accuracy of plain films (457), computed tomography (458), single photon emission computed tomography (459), bone scans (460, 461), nuclear imaging (462-465), and magnetic resonance imaging (466) with variable results.

\subsubsection{Validity}

The face validity of sacroiliac joint block has been established by injecting small volumes of local anesthetic with contrast into the joint and determining contrast spread in posterior, anterior and lateral radiographs. Construct validity of sacroiliac joint blocks has been established by determining the false-positive rate of single, uncontrolled, sacroiliac joint injections of 20\% (235). Falsepositive injection may occur with extrava- sation of anesthetic agent out of the joint due to defects in the joint capsule. Falsenegative results may occur from faulty needle placement, intravascular injection or inability of the local anesthetic to reach the painful portion of the joint due to loculations $(24,467,468)$.

\subsubsection{Prevalence}

Several authors have shown the sacroiliac joint to be a source of pain in 10\% to $30 \%$ of cases by a single block (103, 234 ) and $10 \%$ to $19 \%$ by a double block paradigm $(104,235)$.

\subsubsection{Cost Effectiveness}

There are no studies evaluating the cost effectiveness of diagnostic sacroiliac joint blocks. However, the feasibility and cost-effectiveness of appropriately performed controlled comparative local anesthetic blocks has been described (104, 330-332).

\subsubsection{Evidence}

The evidence for the accuracy of sacroiliac joint diagnostic injections was moderate for the diagnosis of sacroiliac joint pain.

\subsubsection{Safety and Complications}

Complications of sacroiliac joint injection include infection, trauma to the sciatic nerve, embolic phenomena, and complications related to drug administration. Without fluoroscopy, successful joint injection is low (467-469). Epidural spread was noted in $24 \%$ and foraminal filling in 44\% (467).

\subsection{Therapeutic InTERVENTIONAL TeChNiques}

Therapeutic interventional techniques in the management of chronic spinal pain include various types of neural blockade and minimally invasive surgical procedures. These include epidural injections, facet joint injections, neuroablation techniques, intradiscal thermal therapy, nucleoplasty, morphine pump implantation, and spinal cord stimulation.

\subsubsection{Rationale}

The rationale for therapeutic interventional techniques in the spine is based upon the following considerations.

- Cardinal source(s) of chronic spinal pain, particularly discs and joints, are accessible to neural blockade,

- Removal or correction of structural abnormalities of the spine may fail to cure and may worsen painful spinal 
conditions,

- Degenerative processes of the spine and the origin of spinal pain are complex,

- The effectiveness of a large variety of therapeutic interventions used to manage chronic spinal pain has not been demonstrated conclusively, and

- There is increasing evidence supporting use of interventional techniques in managing spinal pain.

\subsubsection{Environment}

The requirements for safe use of therapeutic interventions include a sterile operating room or a procedure room appropriate monitoring equipment, radiological equipment, special instruments based on technique, sterile preparation with all the resuscitative equipment, needles, gowns, injectable drugs, intravenous fluids, anxiolytic medications, and trained personnel for preparation and monitoring of the patients. Minimum requirements include history and physical examination, informed consent, appropriate documentation of the procedure.

\subsubsection{Contraindications}

Contraindications include ongoing bacterial infection, possible pregnan- cy, bleeding diathesis, and anticoagulant therapy. Precautions are warranted in patients with anticoagulant or antiplatelet therapy, diabetes mellitus and artificial heart valves.

\subsection{Facet Joint Interventions}

A preponderance of the evidence supports the existence of facet joint pain (1, $26,32,33,39,100,101,103-147,262,304-$ $317,322-335)$, although there are a few detractors (470-472). Based on a detailed review of the literature, the general consensus appears to be that facet joint pain can be diagnosed with reasonable certainty only on the basis of controlled diagnostic local anesthetic blocks. Therefore, assessment of the efficacy of interventional procedures for the treatment of facet joint pain requires that studies only employ controlled diagnostic medial branch blocks or intraarticular injections as selection criteria for such studies.

Facet joint pain may be managed by intraarticular injections, medial branch blocks, or neurolysis of medial branches.

Relief with intraarticular injections or medial branch blocks was considered as short-term if documented for less than 6 weeks, and long-term, if documented for 6 weeks or longer. Relief with medial branch neurotomy was considered shortterm if it was less than 3 months, and long-term if it was 3 months or longer.

\subsubsection{Intraarticular Blocks}

Therapeutic benefit has been reported with the injection of corticosteroids, local anesthetics, or normal saline into the facet joints. The literature describing the effectiveness of these interventions is abundant. The only systematic review (4) in the literature evaluated intraarticular injections in conjunction with other interventional techniques. Five randomized clinical trials offer data on the use of intraarticular injections in the spine (26, 473-477). Open, controlled and uncontrolled clinical studies that evaluated the long term relief of back and leg pain from intraarticular facet joint injections are abundant $(26,478-482)$. Table 2 illustrates published results.

The effectiveness of intraarticular corticosteroid lumbar facet joint injections $(473,475-477)$ and cervical facet joint injections (474) was studied comparing the results to those of a similar group not receiving intraarticular steroids. Of these, two randomized trials, one by Carette et al (473) involving lum-

Table 2. Results of published reports of effectiveness of intraarticular injections of cervical and lumbar facet joints

\begin{tabular}{|c|c|c|c|c|c|c|c|c|c|}
\hline \multirow[b]{3}{*}{ Study } & \multirow[b]{3}{*}{$\begin{array}{c}\text { Study Charac- } \\
\text { teristics }\end{array}$} & \multicolumn{2}{|c|}{$\begin{array}{l}\text { Methodological } \\
\text { Quality Score }(s)\end{array}$} & \multirow[b]{3}{*}{$\begin{array}{c}\text { No. of } \\
\text { Patients }\end{array}$} & \multirow{3}{*}{$\begin{array}{c}\begin{array}{c}\text { Initial } \\
\text { Relief }\end{array} \\
\\
<6 \\
\text { weeks }\end{array}$} & \multirow{2}{*}{\multicolumn{2}{|c|}{ Long-term Relief }} & \multirow{2}{*}{\multicolumn{2}{|c|}{ Results }} \\
\hline & & & & & & & & & \\
\hline & & $\begin{array}{l}\text { AHRQ } \\
\text { Score }(s)\end{array}$ & $\begin{array}{l}\text { Cochrane } \\
\text { Score }(s)\end{array}$ & & & $\begin{array}{c}3 \\
\text { months }\end{array}$ & $\begin{array}{c}6 \\
\text { months }\end{array}$ & $\begin{array}{l}\text { Short- } \\
\text { term }<6 \\
\text { weeks }\end{array}$ & $\begin{array}{c}\text { Long- } \\
\text { term } \\
\text { relief } \geq \\
6 \text { weeks }\end{array}$ \\
\hline \multicolumn{10}{|l|}{ Lumbar Spine } \\
\hline $\begin{array}{l}\text { Carette et al } \\
(473)\end{array}$ & PC, RA, DB & $10 / 10$ & $10 / 10$ & $\begin{array}{l}\mathrm{C}=50 \\
\mathrm{~T}=51\end{array}$ & $\begin{array}{c}33 \% \text { vs } \\
42 \%\end{array}$ & NA & $\begin{array}{c}15 \% \text { vs } \\
42 \%\end{array}$ & $N$ & $N$ \\
\hline $\begin{array}{l}\text { Lynch and Taylor } \\
(480)\end{array}$ & $\mathrm{P}$ & $6 / 8$ & --- & $\begin{array}{l}\text { Extraarti. }=15 \\
\text { Intraarti. }=35\end{array}$ & $\begin{array}{c}53 \% \text { vs } \\
89 \%\end{array}$ & $62 \%$ & $56 \%$ & $P$ & $P$ \\
\hline Murtagh (478) & $\mathrm{P}$ & $6 / 8$ & --- & 100 & N/A & $54 \%$ & $54 \%$ & $P$ & $P$ \\
\hline $\begin{array}{l}\text { Desoutet et al } \\
(479)\end{array}$ & $\mathrm{P}$ & $6 / 8$ & --- & 54 & $54 \%$ & $38 \%$ & $38 \%$ & $P$ & $N$ \\
\hline Lippit (481) & $\mathrm{R}$ & $5 / 8$ & --- & 99 & $42 \%$ & $51 \%$ & $14 \%$ & $N$ & $N$ \\
\hline Lau et al (482) & $\mathrm{R}$ & $6 / 8$ & --- & 34 & $56 \%$ & $44 \%$ & $35 \%$ & $P$ & $N$ \\
\hline \multicolumn{10}{|l|}{ Cervical Spine } \\
\hline $\begin{array}{l}\text { Barnsley et al } \\
(474)\end{array}$ & RA, DB & $10 / 10$ & $9 / 10$ & 41 & $50 \%$ & N/A & N/A & $N$ & $N$ \\
\hline
\end{tabular}

$\mathrm{R}=$ Retrospective; $\mathrm{P}=$ prospective; $\mathrm{RA}=$ randomized $\mathrm{PC}=$ placebo controlled; $\mathrm{DB}=$ double blind $\mathrm{C}=$ control; $\mathrm{T}=$ treatment;

$\mathrm{N} / \mathrm{A}=$ not available; $\mathrm{SI}-$ significant improvement; $P=$ positive; $N=$ negative 
bar facet joint injections and the second one by Barnsley et al (474) involving cervical facet joint injections were included (26). Even then, Carette et al (473) failed to exclude placebo responders, which may account for the relatively high incidence of patients in their study with presumed facet joint pain $(58 \%)$, diluting the findings of true responses, making detection of differences between the study and control groups more difficult. Barnsley et al (474) included a small number of patients, a total of 41 patients, whose origin of neck pain was posttraumatic following whiplash. Consequently, these results, although from randomized trials, may not be applied across a heterogenous population.

Among the other 3 randomized trials, Marks et al (475) and Nash (476) compared the effects of intraarticular injections with medial branch blocks with a single injection, with only short-term evaluation. Lilius et al (477) used overly broad criteria for inclusion without confirming the diagnosis by controlled diagnostic blocks, and used excessive injectate volumes $(3 \mathrm{~mL}$ to $8 \mathrm{~mL}$ ) of active agents (26).

Both well-controlled trials of Carette et al (473) and Barnsley et al (474) were described as negative by the authors. Carette et al (473) showed that $42 \%$ of the methylprednisolone group (20 patients), whereas $33 \%$ of the saline group (16 patients) achieved significant relief at one month follow up. However, at 6month follow-up, $46 \%$ of the patients in the methylprednisolone group compared to $15 \%$ of the patients in the saline group continued to experience marked pain relief, with a statistically significant difference. Barnsley et al (474) showed that the time to return to $50 \%$ of baseline pain was
3 days in the steroid group and 3.5 days in the local anesthetic group. Less than half of the patients reported relief of pain for more than 1 week, and fewer than 1 in 5 patients reported relief for more than 1 month, regardless of whether the injection was with steroids or local anesthetic.

Among the non-randomized trials, multiple observational studies were evaluated for inclusion. Among these, three prospective evaluations (478-480) and two retrospective evaluations (481, 482) met the inclusion criteria. Among the prospective trials included in the evidence synthesis, Lynch and Taylor (480) reported initial pain relief in 31 of 35 patients receiving intraarticular steroids, whereas 8 of 15 patients receiving extraarticular steroids reported initial pain relief. Long-term pain relief was reported in $62 \%$ at 3 months, and $56 \%$ at 6 months. Destouet et al (479) reported significant pain relief for 1 to 3 months in 54\% of the patients and 3 to 6 months in $38 \%$ of the 54 patients. Murtagh (478) reported long-term relief of up to 6 months in $54 \%$ of the 100 patients. Among the retrospective evaluations, Lippitt (481) reported greater than $50 \%$ relief initially in $42 \%$ of patients, which declined to $14 \%$ at 6 months and $8 \%$ at 12 months in 99 patients. Lau et al (482) also reported initial relief in $56 \%$ of the patients, which declined to $44 \%$ at 3 months, and $35 \%$ at 6 to 12 months.

\subsubsection{Cost Effectiveness}

No studies were performed evaluating cost effectiveness of therapeutic intraarticular facet joint injections.

\subsubsection{Evidence}

For intraarticular injections of local anesthetics and steroids, there was moderate evidence for short-term and limited evidence for long-term improvement in managing low back pain and the evidence was negative in managing neck pain.

\subsubsection{Medial Branch Blocks}

The therapeutic role of medial branch blocks was evaluated in four randomized clinical trials $(475,476,483,484)$ and one prospective controlled trial (485). Table 3 shows particulars of the included studies.

Among the randomized trials, Marks et al (475) and Nash (476) compared the effectiveness of intraarticular injections and medial branch blocks with one injection, without any long-term followup. Manchikanti et al (484) compared the effect of Sarapin on various types of nerve blocks including epidurals and medial branch blocks in a random manner. However, this was not a specific study of effectiveness of medial branch blocks. Thus, three $(475,476,484)$ of four studies were excluded. One study by Manchikanti et al (483) met the inclusion criteria. In this study, 73 patients positive for lumbar facet joint pain by means of controlled, comparative local anesthetic blocks were randomly allocated into two groups, either receiving therapeutic medial branch blocks with a local anesthetic and Sarapin or with a mixture of local anesthetic, Sarapin, and methylprednisolone. Significant improvement was documented in both groups in various parameters of pain relief, functional status, opioid intake, return to work, and psychological status. Significant pain relief was seen with 1 to 3 injections in $100 \%$ of the patients up to 1 to 3 months, $82 \%$ of the patients for 4 to 6 months, and $21 \%$ for 7 to 12 months. The mean relief was $6.5 \pm 0.76$ months. Consequently, this study provided evidence of both short-term and long-term benefit with therapeutic medial branch blocks.

Table 3. Results of published reports of effectiveness of cervical and lumbar medial branch blocks

\begin{tabular}{|c|c|c|c|c|c|c|c|c|c|}
\hline \multirow[b]{3}{*}{ Study } & \multirow[b]{3}{*}{$\begin{array}{c}\text { Study } \\
\text { Character- } \\
\text { istics }\end{array}$} & \multicolumn{2}{|c|}{$\begin{array}{l}\text { Methodological } \\
\text { Quality Score(s) }\end{array}$} & \multirow[b]{3}{*}{$\begin{array}{l}\text { No. of } \\
\text { Patients }\end{array}$} & \multirow{3}{*}{$\begin{array}{c}\text { Initial } \\
\text { Relief }\end{array}$} & \multirow{2}{*}{\multicolumn{2}{|c|}{ Long-term Relief }} & \multirow{2}{*}{\multicolumn{2}{|c|}{ Results }} \\
\hline & & \multirow[b]{2}{*}{$\begin{array}{c}\text { AHRQ } \\
\text { Score }(s)\end{array}$} & \multirow[b]{2}{*}{$\begin{array}{l}\text { Cochrane } \\
\text { Score }(s)\end{array}$} & & & & & & \\
\hline & & & & & & $\begin{array}{c}3 \\
\text { months }\end{array}$ & $\begin{array}{c}6 \\
\text { months }\end{array}$ & $\begin{array}{c}\text { Short- } \\
\text { term relief } \\
<6 \text { weeks }\end{array}$ & $\begin{array}{c}\text { Long-term } \\
\text { relief } \\
\geq 6 \text { weeks } \\
\end{array}$ \\
\hline $\begin{array}{l}\text { Manchikanti et al } \\
\text { (483) }\end{array}$ & RA & $8 / 10$ & $6 / 10$ & 73 & $100 \%$ & $100 \%$ & $82 \%$ & $P$ & $P$ \\
\hline $\begin{array}{l}\text { Manchikanti et al } \\
\text { (485) }\end{array}$ & $\mathrm{P}$ & $8 / 8$ & --- & 100 & $92 \%$ & $92 \%$ & $82 \%$ & $P$ & $P$ \\
\hline
\end{tabular}

$\mathrm{P}=$ prospective $; \mathrm{RA}=$ randomized $P=$ positive $N=$ negative 
Manchikanti et al (485) evaluated the therapeutic effectiveness of cervical facet joint nerve blocks in chronic neck pain in a prospective outcome study. They evaluated 100 consecutive patients meeting the diagnostic criteria of facet joint pain by means of comparative, controlled diagnostic blocks. There were significant differences in numeric pain scores and pain relief $(\geq 50 \%)$ at 3 months $(92 \%)$, 6 months (82\%), and 12 months (56\%) compared to baseline measurements. There was significant improvement in functional status, psychological status and employment among patients eligible for employment (employed and unemployed) from baseline to 12 months.

\subsubsection{Cost Effectiveness}

The cost effectiveness of lumbar facet joint nerve blocks was evaluated by Manchikanti et al (483) with 1-year improvement of quality of life at $\$ 3,461$. The cost of one-year improvement was similar to various investigations with neural blockade, but also was significantly better than the cost-effectiveness with intrathecal morphine delivery or lumbar laminectomy, with or without instrumented fusion.

\subsubsection{Evidence}

The evidence for lumbar and cervical medial branch blocks in managing chronic low back and neck pain was moderate.

\subsubsection{Medial Branch Neurotomy}

Percutaneous radiofrequency neurotomy of medial branches is a procedure that offers pain relief by denaturing the nerves that innervate a painful joint. There have been three systematic reviews of medial branch neurotomy (57). Geurts et al (5) concluded that there was moderate evidence that radiofrequency lumbar facet denervation was more effective for chronic low back pain than

Table 4. Results of published reports on effectiveness of facet joint (medial branch) radiofrequency neurolysis

\begin{tabular}{|c|c|c|c|c|c|c|c|c|c|}
\hline \multirow[b]{2}{*}{ Study } & \multirow[b]{2}{*}{$\begin{array}{l}\text { Study } \\
\text { Character- } \\
\text { istics }\end{array}$} & \multicolumn{2}{|c|}{$\begin{array}{l}\text { Methodological } \\
\text { Quality Score(s) }\end{array}$} & \multirow[b]{2}{*}{$\begin{array}{l}\text { No. of } \\
\text { Patients }\end{array}$} & \multirow[b]{2}{*}{$\begin{array}{c}\text { Initial } \\
\text { Relief } \\
<3 \\
\text { months }\end{array}$} & \multicolumn{2}{|c|}{ Long-term Relief } & \multicolumn{2}{|c|}{ Results } \\
\hline & & $\begin{array}{c}\text { AHRQ } \\
\text { Score(s) }\end{array}$ & $\begin{array}{l}\text { Cochrane } \\
\text { Score }(s)\end{array}$ & & & $\begin{array}{c}6 \\
\text { months }\end{array}$ & $\begin{array}{c}12 \\
\text { months }\end{array}$ & $\begin{array}{c}\text { Short- } \\
\text { term } \\
\text { relief } \\
<3 \\
\text { months }\end{array}$ & $\begin{array}{c}\text { Long- } \\
\text { term } \\
\text { relief } \\
\geq 3 \\
\text { months }\end{array}$ \\
\hline \multicolumn{10}{|l|}{ Lumbar Spine } \\
\hline Van Kleef et al (487) & PC, RA, DB & $9 / 10$ & $7 / 10$ & $\begin{array}{l}\mathrm{C}=16 \\
\mathrm{~T}=15\end{array}$ & $\begin{array}{c}38 \% \text { vs } \\
67 \%\end{array}$ & $\begin{array}{c}19 \% \text { vs } \\
47 \%\end{array}$ & $\begin{array}{c}13 \% \text { vs } \\
47 \%\end{array}$ & $P$ & $P$ \\
\hline Dreyfuss et al (493) & $\mathrm{P}$ & $8 / 8$ & --- & 15 & $93 \%$ & $87 \%$ & $87 \%$ & $P$ & $P$ \\
\hline Vad et al (495) & $\mathrm{P}$ & $8 / 8$ & --- & 12 & $83 \%$ & $83 \%$ & $83 \%$ & $P$ & $P$ \\
\hline $\begin{array}{l}\text { Schofferman and Kine } \\
(496)\end{array}$ & $\mathrm{R}$ & $7 / 8$ & --- & 20 & $85 \%$ & $85 \%$ & $85 \%$ & $P$ & $P$ \\
\hline Schaerer (499) & $\mathrm{R}$ & $6 / 8$ & --- & 117 & NA & NA & $68 \%$ & $N$ & $N$ \\
\hline Tzaan and Tasker (500) & $\mathrm{R}$ & $6 / 8$ & --- & 90 & NA & $41 \%$ & NA & $N$ & $N$ \\
\hline North et al (501) & $\mathrm{R}$ & $7 / 8$ & --- & 42 & $45 \%$ & $45 \%$ & $45 \%$ & $N$ & $N$ \\
\hline \multicolumn{10}{|l|}{ Cervical Spine } \\
\hline Lord et al (486) & PC, RA, DB & $9 / 10$ & $9 / 10$ & $\begin{array}{c}\mathrm{LA}=12 \\
\mathrm{RFTN}=12\end{array}$ & $\begin{array}{c}50 \% \text { vs } \\
67 \%\end{array}$ & $\begin{array}{c}8 \% \text { vs } \\
58 \%\end{array}$ & $\begin{array}{c}8 \% \text { vs } \\
58 \%\end{array}$ & $P$ & $P$ \\
\hline McDonald et al (492) & $\mathrm{P}$ & $7 / 8$ & --- & 28 & $71 \%$ & $71 \%$ & $71 \%$ & $P$ & $P$ \\
\hline Sapir and Gorup (494) & $\mathrm{P}$ & $7 / 8$ & --- & 46 & NA & NA & NA & $P$ & $P$ \\
\hline Schaerer (499) & $\mathrm{R}$ & $6 / 8$ & --- & 117 & NA & NA & $68 \%$ & $N$ & $N$ \\
\hline Tzaan and Tasker (500) & $\mathrm{R}$ & $6 / 8$ & --- & 90 & NA & $41 \%$ & NA & $N$ & $N$ \\
\hline \multicolumn{10}{|l|}{ Thoracic Spine } \\
\hline Stolker et al (497) & $\mathrm{P}$ & $7 / 8$ & --- & 40 & $83 \%$ & $83 \%$ & $83 \%$ & $P$ & $P$ \\
\hline Tzaan and Tasker $(500)$ & $\mathrm{R}$ & $6 / 8$ & --- & 90 & NA & $41 \%$ & NA & $N$ & $N$ \\
\hline
\end{tabular}

$\mathrm{R}=$ Retrospective $\mathrm{P}=$ prospective $\mathrm{RA}=$ randomized $; \mathrm{PC}=$ placebo controlled $; \mathrm{DB}=$ double blind $\mathrm{C}=$ control $; \mathrm{T}=$ treatment; N/A = not available; $P=$ positive; $N=$ negative; LA = Local Anesthetic; RFTN: Radiofrequency neurotomy 
placebo, and there was only limited evidence existent for effectiveness of radiofrequency neurotomy for chronic cervical zygapophysial joint pain after flexion/ extension injury. Manchikanti et al (6) evaluated medial branch neurotomy for the management of chronic spinal pain utilizing AHRQ criteria with inclusion of randomized and observational reports. They concluded that there was strong evidence for short-term relief and moderate evidence for long-term relief of facet joint pain. Niemesto et al (7) performed a systematic review of radiofrequency denervation for neck and back pain within the framework of the Cochrane Collaboration Back Review Group. The reviewers concluded that there was limited evidence that radiofrequency denervation had a positive short-term effect on chronic cervical zygapophysial joint pain, and a conflicting short-term effect on chronic low back pain.

The systematic review by Manchikanti et al (6) met inclusion criteria. Due to several deficiencies $(1,26)$, two systematic reviews $(5,7)$ were excluded. The evaluation for guidelines yielded a total of 6 randomized trials (486-491), and 10 observational studies (492-501). Among these, as illustrated in Table 4, two randomized trials $(486,487)$ and 9 observational studies $(492-497,499-501)$ were included. Four of six randomized trials were excluded because of inappropriate inclusion criteria, inappropriate interventions, or inadequate follow-up (26). However, only 1 of 10 observational studies was excluded (Table 4).

Lord et al (486) evaluated percutaneous radiofrequency neurotomy in patients with cervical facet joint pain with controlled local anesthetic blocks, in a double-blind, placebo-controlled trial. The results showed that the median time that elapsed before the pain returned to at least $50 \%$ of the preoperative level was 263 days in the active treatment group and 8 days in the control group. The authors concluded that in patients with chronic cervical facet joint pain, percutaneous radiofrequency neurotomy with multiple lesions of target nerves can provide long lasting relief. In the second study, Van Kleef et al (487) showed that after 3, 6, and 12 months, the number of successes in the lesion and sham groups was 9 and 4,7 and 3 , and 7 and 2, respectively. These results demonstrated that radiofrequency denervation of the lumbar facet joints can be effective for pain reduction in patients with lumbar facet joint pain.

Among the non-randomized or observational studies, McDonald et al (492) determined the long-term efficacy of percutaneous radiofrequency medial branch neurotomy in the treatment of chronic neck pain in 28 patients diagnosed as having cervical zygapophysial joint pain, on the basis of controlled diagnostic blocks. They reported complete relief of pain in $71 \%$ of patients after an initial procedure. The median duration of relief after a first procedure was 219 days when failures were included, but 422 days when only the successes were considered. Dreyfuss et al (493) described lumbar facet joint radiofrequency neurotomy in 15 patients utilizing strict criteria and procedural considerations, and noted $60 \%$ of the patients were improved at 1 year. Sapir and Gorup (494) studied 46 patients reporting overall reduction in cervical whiplash symptoms and visual analog pain scores in a significant proportion of patients at 1 year in both litigant and non-litigant patients. Vad et al (495) described the role of lumbar radiofrequency denervation in baseball pitchers. They reported a median pain relief of 1.3 years (range: 1 to 2.1 years) and improved function in $83 \%$, or 10 of 12 patients. Stolker et al (497) studied thoracic facet joint neurolysis in 40 patients and reported positive results, with $47.5 \%$ of the patients being pain-free and an additional $35 \%$ having relief greater than $50 \%$ at 2 -months follow-up. After a follow up of 18 to 54 months, they reported $83 \%$ of the patients with greater than $50 \%$ pain relief.

Among the retrospective evaluations, Schofferman and Kine (496), in a chart review of 20 patients, reported 10.5 months of mean relief (range: 4-9 months) following lumbar radiofrequency neurotomy. Tzaan and Tasker (500) evaluated 118 consecutive percutaneous radiofrequency facet rhizotomies performed on 90 patients. They reported that with the first procedure, $41 \%$ of patients had greater than $50 \%$ subjective reduction of pain. The study included cervical, thoracic and lumbosacral facets. North et al (501) evaluated radiofrequency lumbar facet denervation with long-term outcome assessment by disinterested third party interview. Forty-five percent of patients undergoing denervation reported at least $50 \%$ relief of pain at long-term follow-up. Schaerer (499) evaluated radiofrequency facet rhizotomy in 117 consecutive patients with chronic neck and low back pain and reported that overall results were fair to excellent in $68 \%$ of patients, with an average follow-up of 13.7 months.

\subsubsection{Cost Effectiveness}

No cost effectiveness evaluations were performed with medial branch neurotomy.

\subsubsection{Evidence}

Evidence for radiofrequency neurotomy of medial branches was moderate to strong for short-term and long-term relief of lumbar and cervical facet joint pain.

\subsubsection{Safety and Complications}

The most common and worrisome complications of facet joint interventions are related to needle placement, drug administration, and neurolysis $(1,26,32,33$, 336-340, 502-521). Complications include dural puncture, spinal cord trauma, infection, intraarterial or intravenous injection, spinal anesthesia, chemical meningitis, neural trauma, pneumothorax, radiation exposure, facet capsule rupture, hematoma formation, and steroid side effects. In addition, potential side effects with radiofrequency denervation include painful cutaneous dysesthesias, increased pain due to neuritis or neurogenic inflammation, anesthesia dolorosa, cutaneous hyperesthesia, pneumothorax and deafferentation pain.

\subsection{Epidural Injections}

Several approaches are available to access the lumbar epidural space: caudal, interlaminar, and transforaminal $(1,23$, $25,28,30)$. There are substantial differences between the three approaches. The interlaminar entry is directed more closely to the assumed site of pathology requiring less volume than the caudal route. The caudal entry is relatively easily achieved, with minimal risk of inadvertent dural puncture. The transforaminal approach is target specific with smallest volume in fulfilling the aim of reaching the primary site of pathology; namely ventrolateral epidural space.

Due to the inherent variations, differences, advantages, and disadvantages applicable to each technique (including the effectiveness and outcomes), caudal epidural injections; interlaminar epidural injections (cervical, thoracic, and lumbar epidural injections); and transforaminal epidural injections (cervical, thoracic, and lumbosacral) are considered as sep- 
arate entities within epidural injections and are discussed as such below.

In this evaluation, we considered all relevant systematic reviews along with randomized, and non-randomized trials for each category, including caudal, interlaminar, and transforaminal epidural injections. Short-term effect was defined as a significant relief of less than 6 weeks and long-term effect was defined as 6 weeks or longer relief.

\subsubsection{Caudal Epidural Injections}

Several systematic reviews have evaluated the effectiveness of epidural steroids in general and interlaminar epidural steroids in particular $(1,4,25,28,29,30,35)$. While all the reviews included caudal epi- dural steroid injections, they failed to separate caudal and interlaminar techniques, arriving at erroneous conclusions (4, 29, 35). Of importance are systematic reviews performed by Nelemans et al (4), Koes et al (29), and Van Tulder et al (35). All these studies included essentially the same criteria as well as the same studies arriving at inaccurate conclusions, uniformly. In contrast, Boswell et al (28) in a systematic review and Bogduk et al (30) in a comprehensive review evaluated caudal epidural steroid injections as a separate procedure reaching opposite conclusions. They concluded that the effectiveness of caudal epidural injections in managing lumbar radiculopathy was moderate.
Among the multitude of trials, there were 9 randomized trials $(522-529,533)$, 5 prospective evaluations $(530-532,534$, 535), and many retrospective evaluations $(1,536)$. The results of published reports of the randomized trials and prospective trials of caudal epidurals utilized in evidence synthesis and guideline preparation are shown in Table 5.

Of the 9 randomized trials, two studies were excluded $(525,526)$ from evidence synthesis, due to non-availability of analyzable information (526), and due to lack of data at 3 months (525). Of the 7 randomized trials, 3 trials evaluated predominantly patients with radiculopathy or sciatica (522-524), two trials evaluat-

Table 5. Results of published reports on caudal epidural steroid injections

\begin{tabular}{|c|c|c|c|c|c|c|c|c|c|}
\hline \multirow[b]{3}{*}{ Study } & \multirow[b]{3}{*}{$\begin{array}{l}\text { Study } \\
\text { Charac- } \\
\text { teristics }\end{array}$} & \multicolumn{2}{|c|}{$\begin{array}{l}\text { Methodological } \\
\text { Quality Score(s) }\end{array}$} & \multirow[b]{3}{*}{ No. of Patients } & \multirow{3}{*}{$\begin{array}{c}\begin{array}{c}\text { Initial } \\
\text { Relief }\end{array} \\
<6 \\
\text { weeks }\end{array}$} & \multirow{2}{*}{\multicolumn{2}{|c|}{ Long-term Relief }} & \multirow{2}{*}{\multicolumn{2}{|c|}{ Results }} \\
\hline & & & & & & & & & \\
\hline & & $\begin{array}{c}\text { AHRQ } \\
\text { Score }(s)\end{array}$ & $\begin{array}{l}\text { Cochrane } \\
\text { Score }(s)\end{array}$ & & & $\begin{array}{c}3 \\
\text { months }\end{array}$ & 6 months & $\begin{array}{l}\text { Short- } \\
\text { term } \\
\text { relief }<6 \\
\text { weeks }\end{array}$ & $\begin{array}{l}\text { Long- } \\
\text { term } \\
\text { relief } \geq 6 \\
\text { weeks }\end{array}$ \\
\hline Breivik et al (522) & RA, DB & $8 / 10$ & $7 / 10$ & $\begin{array}{l}\mathrm{C}=19 \\
\mathrm{~T}=16\end{array}$ & $\begin{array}{c}25 \% \text { vs. } \\
63 \%\end{array}$ & $\begin{array}{c}20 \% \text { vs } \\
50 \%\end{array}$ & $\begin{array}{c}20 \% \text { vs. } \\
50 \%\end{array}$ & $P$ & $P$ \\
\hline $\begin{array}{l}\text { Bush and Hillier } \\
\text { (523) }\end{array}$ & RA, DB & $8 / 10$ & $8 / 10$ & $\begin{array}{l}\mathrm{C}=11 \\
\mathrm{~T}=12\end{array}$ & $100 \%$ & N/A & $\begin{array}{c}64 \% \text { vs } \\
83 \%\end{array}$ & $P$ & $N$ \\
\hline $\begin{array}{l}\text { Matthews et al } \\
(524)\end{array}$ & RA, DB & $8 / 10$ & $7 / 10$ & $\begin{array}{l}\mathrm{C}=34 \\
\mathrm{~T}=23\end{array}$ & $\begin{array}{c}56 \% \text { vs } \\
67 \%\end{array}$ & SMPR & N/A & $N$ & $P$ \\
\hline $\begin{array}{l}\text { Helsa and Breivik } \\
\text { (527) }\end{array}$ & $\mathrm{RA}, \mathrm{DB}$ & $7 / 10$ & $7 / 10$ & $\begin{array}{c}69 \\
\text { crossover }\end{array}$ & NA & NA & $\begin{array}{c}59 \% \text { vs } \\
25 \%\end{array}$ & $P$ & $P$ \\
\hline Revel et al (528) & RA & $7 / 10$ & $6 / 10$ & $\begin{array}{c}\text { Forceful } \\
\text { injection }=29 \\
\text { Regular }=31\end{array}$ & NA & NA & $\begin{array}{c}49 \% \text { vs } \\
19 \%\end{array}$ & $P$ & $N$ \\
\hline Meadeb et al (529) & RA & $6 / 10$ & $6 / 10$ & $\begin{array}{c}D=16 \\
D+G=15 \\
G=16\end{array}$ & N/A & N/A & N/A & $N$ & $N$ \\
\hline $\begin{array}{l}\text { McGregor et al } \\
\text { (533) }\end{array}$ & RA & $6 / 10$ & $5 / 10$ & $\begin{array}{c}\text { Caudal=14 } \\
\text { Interlaminar } \\
=16\end{array}$ & N/A & N/A & N/A & $N$ & $N$ \\
\hline $\begin{array}{l}\text { Manchikanti et al } \\
\text { (531) }\end{array}$ & $\mathrm{P}$ & $5 / 8$ & --- & $\begin{array}{l}\mathrm{ND}=45 \\
\mathrm{PD}=17\end{array}$ & $\begin{array}{c}71 \% \text { vs } \\
65 \%\end{array}$ & $\begin{array}{c}67 \% \text { vs } \\
65 \%\end{array}$ & $\begin{array}{c}47 \% \text { vs } \\
41 \%\end{array}$ & $P$ & $P$ \\
\hline Yates (532) & $\mathrm{P}$ & $5 / 8$ & --- & 20 & N/A & N/A & N/A & $P$ & $P$ \\
\hline Waldman (534) & $\mathrm{P}$ & $5 / 8$ & --- & 53 & $63 \%$ & $67 \%$ & $71 \%$ & $P$ & $P$ \\
\hline Ciocon et al (535) & $\mathrm{P}$ & $5 / 8$ & --- & 30 & SI & SI & SI & $P$ & $P$ \\
\hline $\begin{array}{l}\text { Manchikanti et al } \\
\text { (530) }\end{array}$ & $\mathrm{P}$ & $5 / 8$ & --- & $\begin{array}{l}\mathrm{G} 1=15 \\
\mathrm{G} 2=22 \\
\mathrm{G} 3=33\end{array}$ & $\begin{array}{c}0 \% \\
100 \% \\
97 \%\end{array}$ & $\begin{array}{c}0 \% \\
59 \% \\
55 \%\end{array}$ & $\begin{array}{c}0 \% \\
19 \% \\
15 \%\end{array}$ & $P$ & $P$ \\
\hline
\end{tabular}

$\mathrm{P}=$ prospective; $\mathrm{RA}=$ randomized $\mathrm{PC}=$ placebo controlled $\mathrm{DB}=$ double blind $\mathrm{C}=$ control $\mathrm{T}=$ treatment; $\mathrm{N} / \mathrm{A}=$ not available; $P=$ positive; $N$

= negative; $\mathrm{ND}=$ Negative Discography; $\mathrm{PD}=$ Positive Discography; $\mathrm{D}=$ Disruption, $\mathrm{G}=$ Glucocorticoid 
Table 6. Results of published reports of cervical and lumbar interlaminar epidural steroid injections

\begin{tabular}{|c|c|c|c|c|c|c|c|c|c|}
\hline \multirow[b]{3}{*}{ Study } & \multirow[b]{3}{*}{$\begin{array}{l}\text { Study Char- } \\
\text { acteristics }\end{array}$} & \multicolumn{2}{|c|}{$\begin{array}{c}\text { Methodological Quality } \\
\text { Score }(s)\end{array}$} & \multirow[b]{3}{*}{ No. of Patients } & \multirow{3}{*}{$\begin{array}{c}\begin{array}{c}\text { Initial } \\
\text { Relief }\end{array} \\
<6 \text { weeks }\end{array}$} & \multirow{2}{*}{\multicolumn{2}{|c|}{ Long-term Relief }} & \multirow{2}{*}{\multicolumn{2}{|c|}{ Results }} \\
\hline & & \multirow[b]{2}{*}{$\begin{array}{l}\text { AHRQ } \\
\text { Score }(s)\end{array}$} & \multirow[b]{2}{*}{$\begin{array}{l}\text { Cochrane } \\
\text { Score }(s)\end{array}$} & & & & & & \\
\hline & & & & & & $\begin{array}{c}3 \\
\text { months }\end{array}$ & $\begin{array}{c}6 \\
\text { months }\end{array}$ & $\begin{array}{c}\text { Short- } \\
\text { term relief } \\
<6 \text { weeks }\end{array}$ & $\begin{array}{c}\text { Long-term } \\
\text { relief } \geq 6 \\
\text { weeks }\end{array}$ \\
\hline \multicolumn{10}{|l|}{ Cervical Spine } \\
\hline $\begin{array}{l}\text { Castagnera et al } \\
(546)\end{array}$ & RA & $7 / 10$ & $6 / 10$ & $\begin{array}{c}\text { Local anesthetic } \\
+ \text { steroids }=14 \\
\text { Local anesthetic } \\
+ \text { steroids }+ \\
\text { Morphine }=10\end{array}$ & $\begin{array}{l}75 \% \text { vs } \\
96 \%\end{array}$ & $79 \%$ & $79 \%$ & $P$ & $P$ \\
\hline Stav et al (550) & RA & $6 / 10$ & $5 / 10$ & $\begin{array}{l}\mathrm{C}=17 \\
\mathrm{~T}=25\end{array}$ & $\begin{array}{c}36 \% \text { vs } \\
76 \%\end{array}$ & $\begin{array}{c}12 \% \text { vs } \\
68 \%\end{array}$ & $\begin{array}{c}12 \% \text { vs } \\
68 \%\end{array}$ & $P$ & $P$ \\
\hline \multicolumn{10}{|l|}{ Lumbar Spine } \\
\hline $\begin{array}{l}\text { Carette et al } \\
(537)\end{array}$ & RA, DB, PC & $10 / 10$ & $10 / 10$ & $\begin{array}{l}\mathrm{C}=80 \\
\mathrm{~T}=78\end{array}$ & SIT & NSD & NSD & $P$ & $N$ \\
\hline $\begin{array}{l}\text { Snoek et al } \\
(538)\end{array}$ & RA & $7 / 10$ & $6 / 10$ & $\begin{array}{l}\mathrm{C}=24 \\
\mathrm{~T}=27\end{array}$ & NSD & NSD & NSD & $N$ & $N$ \\
\hline $\begin{array}{l}\text { Cuckler et al } \\
(539)\end{array}$ & RA, DB & $9 / 10$ & $9 / 10$ & $\begin{array}{l}\mathrm{C}=31 \\
\mathrm{~T}=42\end{array}$ & NSD & NSD & NSD & $N$ & $N$ \\
\hline Dilke et al (540) & RA & $7 / 10$ & $7 / 10$ & $\begin{array}{l}\mathrm{C}=48 \\
\mathrm{~T}=51\end{array}$ & $\begin{array}{c}31 \% \text { vs } \\
60 \%\end{array}$ & SI & NA & $P$ & $P$ \\
\hline $\begin{array}{l}\text { Ridley et al } \\
\text { (544) }\end{array}$ & RA & $9 / 10$ & $8 / 10$ & $\begin{array}{l}\mathrm{C}=16 \\
\mathrm{~T}=19\end{array}$ & $\begin{array}{c}19 \% \text { vs } \\
90 \%\end{array}$ & $\begin{array}{c}19 \% \text { vs } \\
90 \%\end{array}$ & NA & $P$ & $N$ \\
\hline $\begin{array}{l}\text { Rogers et al } \\
(545)\end{array}$ & $\mathrm{RA}, \mathrm{SB}$ & $6 / 10$ & $5 / 10$ & $\begin{array}{l}\mathrm{C}=15 \\
\mathrm{~T}=15\end{array}$ & SI & NSD & NSD & $P$ & $N$ \\
\hline $\begin{array}{l}\text { Kraemer et al } \\
(553)\end{array}$ & RA & $6 / 10$ & $5 / 10$ & $\begin{array}{l}\mathrm{C}=46 \\
\mathrm{~T}=40\end{array}$ & SI & NA & NA & $P$ & $N$ \\
\hline $\begin{array}{l}\text { Pirbudak et al } \\
\text { (554) }\end{array}$ & RA & $6 / 10$ & $6 / 10$ & $\begin{array}{l}\text { steroid }=46 \\
\text { steroid + ami- } \\
\text { triptyline }=40\end{array}$ & $\begin{array}{c}\text { SI } \\
(\mathrm{AM})\end{array}$ & $\begin{array}{c}\text { SI } \\
(\mathrm{AM})\end{array}$ & $\begin{array}{c}\text { SI } \\
(\mathrm{AM})\end{array}$ & $P$ & $P$ \\
\hline $\begin{array}{l}\text { McGregor et al } \\
\text { (533) }\end{array}$ & RA & $6 / 10$ & $5 / 10$ & $\begin{array}{c}14=\text { caudal } \\
16=\text { interlaminar }\end{array}$ & NSD & NSD & NA & $N$ & $N$ \\
\hline Rull et al (556) & $\mathrm{P}$ & $5 / 8$ & -- & 149 & $66 \%$ & $66 \%$ & $66 \%$ & $P$ & $P$ \\
\hline $\begin{array}{l}\text { Caglar et al } \\
(557)\end{array}$ & $\mathrm{P}$ & $5 / 8$ & -- & 25 & SI & NA & NA & $P$ & $N$ \\
\hline $\begin{array}{l}\text { Koning et al } \\
(560)\end{array}$ & $\mathrm{P}$ & $5 / 8$ & -- & 74 & $54 \%$ & NA & $33 \%$ & $P$ & $N$ \\
\hline
\end{tabular}

$\mathrm{P}=$ prospective $\mathrm{RA}=$ randomized $\mathrm{DB}=$ double blind $\mathrm{PC}=$ placebo controlled $\mathrm{NA}=$ not available $\mathrm{SI}=$ significant improvement; $\mathrm{SIT}=$ significant improvement in treatment group; $\mathrm{AM}=$ amitriptyline; $\mathrm{NSD}=$ no significant difference; $\mathrm{vs}=$ versus, $\mathrm{C}=$ control, $\mathrm{T}=$ treatment; $\mathrm{P}=$ positive; $\mathrm{N}=$ negative

ed post lumbar laminectomy syndrome two trials (528) was positive for post lum$(528,529)$, one study (527) evaluated a bar laminectomy syndrome for shortmixed population with one half with post term relief. The study of a mixed populalumbar laminectomy syndrome and the tion (527) was positive for long-term reother half with sciatica, and one study lief. Thus, overall 3 of 4 studies were posevaluated similarities between interlam- itive for pain of radiculopathy, and 1 of 3 inar and caudal. Two of the 3 trials of were positive for post lumbar laminectoradiculopathy were positive for long-term my syndrome. relief $(522,524)$, whereas, only one of the
Among the 5 prospective evaluations (530-532, 534, 535), the role of caudal epidural steroids was evaluated in two studies in patients with radiculopathy or sciatica $(532,534)$, in two studies in patients with chronic low back pain $(530,531)$, and in one study (535) with spinal stenosis. All showed positive results for short-term and long-term pain relief. 


\subsubsection{Cost Effectiveness}

The cost effectiveness of epidural steroids was evaluated $(530,536)$. The cost-effectiveness of caudal epidural steroids was $\$ 3,635$ and that of transforaminal steroids was $\$ 2,927$ per year. In a prospective evaluation, the cost for 1-year improvement for quality-of-life, was $\$ 2,550$, in patients treated with caudal epidural with local anesthetic and Sarapin or steroids under fluoroscopy (530).

\subsubsection{Evidence}

The evidence for caudal epidural steroid injections with randomized trials and prospective trials was strong for short-term relief and moderate for longterm relief, in managing chronic low back and radicular pain. The evidence in postlumbar laminectomy syndrome and spinal stenosis was limited.

\subsubsection{Interlaminar Epidural Injections}

Multiple systematic reviews provided conflicting opinions $(1,4,8,25,29$ $31,35)$. Further, most of the systematic reviews $(4,8,29)$ utilized combined caudal and interlaminar epidural steroid injections. Consequently, no reasonable definitive conclusions may be drawn from these systematic reviews, and their conclusions may not be applied in clinical practice settings. Thus far, all the systematic reviews noted concluded that interlaminar epidural steroid injections lacked long-term effectiveness.

Nineteen randomized trials (533, 537-554), 9 prospective evaluations (555563 ), and numerous other observational studies (564-573) were identified. Among the 19 randomized trials, 11 met inclusion criteria and were utilized for evidence synthesis with exclusion of 8 studies (25, $541-543,547-549,551,552)$. Of the 8 prospective evaluations, 3 studies (556, 557, 560) were utilized for evidence synthesis. For evaluation of cervical pain and radiculopathy, 2 randomized trials (546, 550 ), one (555) prospective trial, and 8 retrospective evaluations were available (564-573).

Of the 11 randomized trials included in the evidence synthesis, 8 of them evaluated the effectiveness of interlaminar epidural steroid injections, either on disc herniation, sciatica, or radiculopathy in the lumbar spine $(533,537-540,544,545,553$, 554), whereas, 2 randomized evaluations included cervical disc herniation with radiculitis or brachialgia $(546,550)$. Of the 8 randomized trials evaluating lumbar ra- diculitis, 5 were positive for short-term relief $(537,540,544,545,553,554)$, whereas only one study was positive for long-term relief (540). In the evaluation of cervical interlaminar epidural steroids in managing cervical radiculopathy, both randomized trials were positive $(546,550)$. None of the randomized evaluations were performed in managing either axial neck pain or low back pain. Among the negative studies, Cuckler et al (539) included patients suffering with post lumbar laminectomy syndrome. Results of included studies are illustrated in Table 6.

Of the 9 prospective evaluations, 3 studies in the lumbar spine $(556,557$, $560)$ were included. In the only prospective study of the cervical spine (555), patients received cervical interlaminar epidural steroid injections for cervical radiculopathy and cervical transforaminal epidural steroid injections if they failed to respond to the interlaminar epidural steroid injections. Thus, it was difficult to assess the outcomes. Among the 3 prospective trials in the lumbar spine, 2 studies were positive for short-term relief $(556,560)$, whereas only one study was positive for long-term relief (556). A study evaluating management of lumbar radiculopathy (557), a study evaluating effect in spinal stenosis (564), and a study evaluating correlation of epidural steroid injection as a predictor of surgical outcome were negative (562).

\subsubsection{Cost Effectiveness}

In the evaluation of cost effectiveness, Manchikanti et al (536) showed that caudal epidural steroid injections, as well as lumbar transforaminal epidural steroid injections were significantly cost effective compared to blind interlaminar epidural steroid injections.

\subsubsection{Evidence}

The evidence of interlaminar epidural steroid injections in managing lumbar radiculopathy was strong for shortterm relief and limited for long-term relief. In managing cervical radiculopathy, the evidence was moderate for short-term and long-term relief. The evidence was inconclusive in the management of neck pain, low back pain, and lumbar spinal stenosis.

\subsubsection{Transforaminal Epidural Injections}

Transforaminal epidural injections have emerged as a target-specific modality of treatment for management of spinal pain. Review of the literature showed one systematic review (38), 8 randomized trials $(553,574-580), 14$ prospective evaluations (555, 581-593), and multiple retrospective reports (594-608).

Among the 8 randomized controlled trials, 5 trials were included in evidence synthesis $(574,576,577,579,580)$, whereas of 14 prospective evaluations, 6 were included $(555,581,588-590,593)$. A summary of reported studies is listed in Table 7.

Among the 5 randomized trials included in the evidence synthesis meeting inclusion criteria, 4 of them evaluated effectiveness in lumbar disc herniation and radiculopathy $(574,576,579,580)$, showing positive results in 3 of the 4 , both in short-term and long-term with one negative study $(575,576)$. The fifth trial $(577)$ studied effectiveness in post lumbar laminectomy syndrome with negative results. Among the 6 prospective evaluations included for evaluation, 2 studies evaluated the effectiveness of cervical transforaminal epidurals $(555,590)$, showing positive results. The remaining 4 studies $(581,588$, $589,593)$ evaluated lumbar transforaminal epidural steroid injections. One study (589) compared effectiveness of transforaminal epidural steroid injections in lumbar spine with discectomy. One evaluation reported the effect on spinal stenosis (593). Multiple retrospective evaluations also showed positive results.

\subsubsection{Cost Effectiveness}

Cost effectiveness of transforaminal epidural steroid injections in the management of chronic low back pain showed that cost per 1 year improvement of quality of life was $\$ 2,927$ per year (536). Further, in patients treated with transforaminal steroids, operations were avoided for contained herniations, costing $\$ 12,666$ less per responder in the steroid group (576). Cost effectiveness was also demonstrated by avoiding surgical intervention in $77 \%$ of the patients (574).

\subsubsection{Evidence}

The evidence for lumbar transforaminal epidural steroid injections in managing lumbar nerve root pain was strong for short-term and moderate for long-term improvement. The evidence was moderate in managing cervical nerve root pain. The evidence was limited in lumbar post laminectomy syndrome, and lumbar spinal stenosis. The effectiveness of transforaminal epidural steroid injections in ax- 
Table 7. Results of published reports on lumbar and cervical transforaminal epidural steroid injections

\begin{tabular}{|c|c|c|c|c|c|c|c|c|c|}
\hline \multirow[b]{3}{*}{ Study } & \multirow[b]{3}{*}{$\begin{array}{c}\text { Study } \\
\text { Characteristics }\end{array}$} & \multicolumn{2}{|c|}{$\begin{array}{l}\text { Methodological } \\
\text { Quality Score(s) }\end{array}$} & \multirow[b]{3}{*}{$\begin{array}{l}\text { No. of } \\
\text { Patients }\end{array}$} & \multirow{3}{*}{$\begin{array}{l}\text { Initial Relief } \\
<6 \text { weeks }\end{array}$} & \multirow{2}{*}{\multicolumn{2}{|c|}{ Long-term Relief }} & \multirow{2}{*}{\multicolumn{2}{|c|}{ Results }} \\
\hline & & \multirow[b]{2}{*}{$\begin{array}{l}\text { AHRQ } \\
\text { Score(s) }\end{array}$} & \multirow[b]{2}{*}{$\begin{array}{l}\text { Cochrane } \\
\text { Score }(s)\end{array}$} & & & & & & \\
\hline & & & & & & $\begin{array}{c}3 \\
\text { months }\end{array}$ & $\begin{array}{c}6 \\
\text { months }\end{array}$ & $\begin{array}{c}\text { Short- } \\
\text { term }<6 \\
\text { weeks }\end{array}$ & $\begin{array}{c}\text { Long- } \\
\text { term } \geq 6 \\
\text { weeks }\end{array}$ \\
\hline \multicolumn{10}{|l|}{ Lumbar Spine } \\
\hline Riew et al (574) & $\mathrm{RA}, \mathrm{DB}$ & $8 / 10$ & $7 / 10$ & $\begin{array}{l}\mathrm{LA}=27 \\
\mathrm{La}=\mathrm{S}=28\end{array}$ & $\begin{array}{c}33 \% \text { vs } \\
77 \%\end{array}$ & $\begin{array}{c}33 \% \text { vs } \\
77 \%\end{array}$ & $\begin{array}{c}33 \% \text { vs } \\
77 \%\end{array}$ & $P$ & $P$ \\
\hline $\begin{array}{l}\text { Karppinen et al } \\
(575,576)\end{array}$ & RA, DB, PC & $9 / 10$ & $8 / 10$ & $\begin{array}{l}\mathrm{C}=80 \\
\mathrm{~T}=80\end{array}$ & NA & NA & NA & $N$ & $N$ \\
\hline Devulder et al (577) & RA & $6 / 10$ & $5 / 10$ & 60 & NS & NS & NS & $N$ & $N$ \\
\hline Vad et al (579) & RA & $7 / 10$ & $7 / 10$ & 48 & $\begin{array}{c}48 \% \text { vs } \\
84 \%\end{array}$ & $\begin{array}{l}8 \% \text { vs } \\
84 \%\end{array}$ & $\begin{array}{l}8 \% \text { vs } \\
84 \%\end{array}$ & $P$ & $P$ \\
\hline Thomas et al (580) & RA & $6 / 10$ & $5 / 10$ & $\begin{array}{l}\mathrm{C}=15 \\
\mathrm{~T}=16\end{array}$ & SI & SI & SI & $P$ & $P$ \\
\hline Lutz et al (581) & $\mathrm{P}$ & $4 / 8$ & --- & 69 & $75 \%$ & $75 \%$ & $75 \%$ & $P$ & $P$ \\
\hline Butterman (588) & $\mathrm{P}$ & $4 / 8$ & --- & 232 & SI & SI & SI & $P$ & $P$ \\
\hline Buttermann (589) & $\mathrm{P}$ & $4 / 8$ & --- & 169 & NA & NA & $\begin{array}{l}42 \%- \\
56 \%\end{array}$ & $P$ & $P$ \\
\hline Botwin (593) & $\mathrm{P}$ & $4 / 8$ & --- & 34 & $75 \%$ & $75 \%$ & $75 \%$ & $P$ & $P$ \\
\hline \multicolumn{10}{|l|}{ Cervical Spine } \\
\hline $\begin{array}{l}\text { Bush and Hillier } \\
\text { (555) }\end{array}$ & $\mathrm{P}$ & $4 / 8$ & --- & 68 & $93 \%$ & $93 \%$ & $93 \%$ & $P$ & $P$ \\
\hline Cyteval et al (590) & $\mathrm{P}$ & $4 / 8$ & --- & 30 & $60 \%$ & $60 \%$ & $60 \%$ & $P$ & $P$ \\
\hline
\end{tabular}

$\mathrm{P}=$ prospective; $\mathrm{PC}=$ placebo controlled; $\mathrm{RA}=$ randomized; $\mathrm{DB}$ - double blind; $\mathrm{LA}=$ Local Anesthetic; $\mathrm{S}=$ Steroids $\mathrm{SI}=$ significant improvement $\mathrm{C}=$ control; $\mathrm{T}=$ treatment $\mathrm{NA}=$ not available; $P=$ positive; $N=$ negative; vs $=$ versus

ial low back pain, lumbar disc extrusions, and axial neck pain was indeterminate.

\subsubsection{Safety and Complications}

The most common and worrisome complications of caudal, interlaminar, and transforaminal epidural injections are of two types: those related to needle placement and those related to drug administration $(1,25,30,336,340,440-450$, 502, 511, 514, 517, 518, 609-639). Complications include dural puncture, spinal cord trauma, infection, hematoma formation, abscess formation, subdural injection, intracranial air injection, epidural lipomatosis, pneumothorax, nerve damage, headache, death, brain damage, increased intracranial pressure, intravascular injection, vascular injury, cerebral vascular or pulmonary embolus and effects of steroids. Spinal cord trauma and spinal cord or epidural hematoma formation are catastrophic complications, but rarely seen following epidural injections.

\subsection{Epidural Adhesiolysis}

Percutaneous epidural adhesiolysis or lysis of epidural adhesions or epidural adhesiolysis with a spinal endoscope (myeloscope) are interventional pain management techniques that play an active role in managing chronic intractable low back pain $(1,27,263,264,640)$.

The purpose of percutaneous epidural lysis of adhesions is to eliminate the deleterious effects of scar formation, which can physically prevent direct application of drugs to nerves or other tissues to treat chronic back pain. Epidural lysis of adhesions and direct deposition of corticosteroids in the spinal canal are also achieved with a 3-dimensional view provided by epiduroscopy or spinal endoscopy.

Duration of relief of less than 3 months was considered as short-term and longer than 3 months was considered as long-term.

\subsubsection{Percutaneous Adhesiolysis}

Clinical effectiveness of percutaneous adhesiolysis was evaluated in 4 randomized controlled trials (641-644) and 7 retrospective evaluations (645-651). Of these 11 relevant articles, 3 randomized trials $(641,643,644)$, and 3 retrospective evaluations (645-647) were included in the analysis. The remaining studies failed to meet inclusion criteria and were excluded from the evidence synthesis (27).

Three randomized trials $(641,643$, 644) and one of the two retrospective studies (645) included patients with and without previous surgery. One study (646) included only post lumbar laminectomy syndrome patients. All the studies included patients with chronic, refractory low back pain and lower extremity pain.

Of the 3 randomized trials $(641,643$, 644), all were positive for short-term and long-term pain relief. Among the two retrospective evaluations $(645,646)$, both were positive for short-term relief. How- 
Table 8. Results of published reports of percutaneous lysis of lumbar epidural adhesions and hypertonic saline neurolysis

\begin{tabular}{|c|c|c|c|c|c|c|c|c|c|c|}
\hline \multirow[b]{3}{*}{ Study } & \multirow{3}{*}{$\begin{array}{c}\text { Study } \\
\text { Charac- } \\
\text { teristics }\end{array}$} & \multicolumn{2}{|c|}{$\begin{array}{l}\text { Methodological } \\
\text { Quality Score(s) }\end{array}$} & \multirow[b]{3}{*}{$\begin{array}{c}\text { No. of } \\
\text { Patients }\end{array}$} & \multirow{3}{*}{$\begin{array}{c}\begin{array}{c}\text { Initial } \\
\text { Relief }\end{array} \\
<3 \\
\text { months }\end{array}$} & \multirow{2}{*}{\multicolumn{3}{|c|}{ Long-term Relief }} & \multirow{2}{*}{\multicolumn{2}{|c|}{ Results }} \\
\hline & & \multirow[b]{2}{*}{$\begin{array}{c}\text { AHRQ } \\
\text { Score }(s)\end{array}$} & \multirow[b]{2}{*}{$\begin{array}{c}\text { Cochrane } \\
\text { Score }(s)\end{array}$} & & & & & & & \\
\hline & & & & & & $\begin{array}{c}3 \\
\text { months }\end{array}$ & $\begin{array}{c}6 \\
\text { months }\end{array}$ & $\begin{array}{c}12 \\
\text { months }\end{array}$ & $\begin{array}{l}\text { Short-term } \\
<3 \text { months }\end{array}$ & $\begin{array}{l}\text { Long-term } \\
\geq 3 \text { months }\end{array}$ \\
\hline Manchikanti et al (643) & RA, DB & $10 / 10$ & $10 / 10$ & $\begin{array}{l}\mathrm{G} 1=25 \\
\mathrm{G} 2=25 \\
\mathrm{G} 3=25\end{array}$ & $\begin{array}{l}33 \% \\
64 \% \\
72 \%\end{array}$ & $\begin{array}{c}0 \% \\
64 \% \\
72 \%\end{array}$ & $\begin{array}{c}0 \% \\
60 \% \\
72 \%\end{array}$ & $\begin{array}{c}0 \% \\
60 \% \\
72 \%\end{array}$ & $P$ & $P$ \\
\hline Heavner et al (641) & RA, DB & $7 / 10$ & $7 / 10$ & 59 & $83 \%$ & $49 \%$ & $43 \%$ & $49 \%$ & $P$ & $P$ \\
\hline Manchikanti et al (644) & RA & $5 / 10$ & $6 / 10$ & $\begin{array}{l}C=15 \\
T x=30\end{array}$ & $\begin{array}{l}\text { NSI } \\
97 \%\end{array}$ & $\begin{array}{l}\text { NSI } \\
97 \%\end{array}$ & $\begin{array}{l}\text { NSI } \\
93 \%\end{array}$ & $\begin{array}{l}\text { NSI } \\
47 \%\end{array}$ & $P$ & $P$ \\
\hline Manchikanti et al (645) & $\mathrm{R}$ & $4 / 8$ & --- & 129 & $79 \%$ & $68 \%$ & $36 \%$ & $13 \%$ & $P$ & $N$ \\
\hline Manchikanti et al (646) & $\mathrm{R}$ & $4 / 8$ & --- & 60 & $100 \%$ & $90 \%$ & $72 \%$ & $52 \%$ & $P$ & $P$ \\
\hline
\end{tabular}

$\mathrm{RA}=$ randomized $\mathrm{DB}=$ double blind $; \mathrm{R}=$ retrospective $\mathrm{NA}=$ not available $; \mathrm{NSI}$ - no significant improvement $P=$ positive N $=$ negative

ever, only one study (646) was positive for long-term relief. The summary of the five studies included in the evidence synthesis is described in Table 8.

\subsubsection{Cost Effectiveness}

Cost effectiveness of percutaneous epidural adhesiolysis was determined in 3 separate groups of patients (644-646). Cost effectiveness for 1-year of improvement in the quality of life varied from $\$ 2,028$ to $\$ 5,564$.

\subsubsection{Evidence}

The evidence was strong in managing chronic low back and lower extremity pain.

\subsubsection{Endoscopic Adhesiolysis}

Spinal endoscopic adhesiolysis and target delivery of steroids were evaluated in two randomized trials $(652,653)$, 3 prospective evaluations (654-656) and 3 retrospective trials $(646,657,658)$ and multiple case reports.

There was one randomized double-blind trial meeting inclusion criteria (653). In addition, 3 prospective evaluations, and 2 of the 3 retrospective evaluations were included. One randomized trial (653) included in the analysis showed significant short-term and long-term improvement. Among the 3 prospective, observational studies, one study (655) evalu- ated the effectiveness of spinal endoscopic adhesiolysis in lumbar spinal stenosis showing good short-term and long-term improvement in patients with low back pain, however, long-term improvement of leg pain was seen only in the mono-segmental group. The other 2 prospective evaluations $(654,656)$ also showed positive results. Both the retrospective evaluations $(646,647)$ showed positive shortterm and long-term relief. Table 9 illustrates the results of various studies of spinal endoscopy. The majority of the studies included a heterogenous group of patients, most with post lumbar laminectomy syndrome or epidural fibrosis.

Table 9. Results of published reports of spinal endoscopy

\begin{tabular}{|c|c|c|c|c|c|c|c|c|c|c|}
\hline \multirow[b]{3}{*}{ Study } & \multirow{3}{*}{$\begin{array}{l}\text { Study } \\
\text { Charac- } \\
\text { teristics }\end{array}$} & \multicolumn{2}{|c|}{$\begin{array}{l}\text { Methodological } \\
\text { Quality Score }(s)\end{array}$} & \multirow[b]{3}{*}{$\begin{array}{l}\text { No. of Pa- } \\
\text { tients }\end{array}$} & \multirow{3}{*}{$\begin{array}{l}\text { Initial Relief } \\
<3 \text { months }\end{array}$} & \multirow{2}{*}{\multicolumn{3}{|c|}{ Long-term Relief }} & \multirow{2}{*}{\multicolumn{2}{|c|}{ Results }} \\
\hline & & \multirow[b]{2}{*}{$\begin{array}{c}\text { AHRQ } \\
\text { Score(s) }\end{array}$} & \multirow{2}{*}{$\begin{array}{c}\text { Co- } \\
\text { chrane } \\
\text { Score }(s)\end{array}$} & & & & & & & \\
\hline & & & & & & $\begin{array}{c}3 \\
\text { months }\end{array}$ & $\begin{array}{c}6 \\
\text { months }\end{array}$ & $\begin{array}{c}12 \\
\text { months }\end{array}$ & $\begin{array}{l}\text { Short-term } \\
<3 \text { months }\end{array}$ & $\begin{array}{l}\text { Long-term } \\
\geq 3 \text { months }\end{array}$ \\
\hline $\begin{array}{l}\text { Manchikanti } \\
\text { et al (653) }\end{array}$ & RA, DB & $10 / 10$ & $10 / 10$ & $\begin{array}{l}\mathrm{C}=33 \\
\mathrm{Tx}=50\end{array}$ & $\begin{array}{c}33 \% \text { vs } \\
90 \%\end{array}$ & $\begin{array}{c}0 \% \text { vs } \\
80 \%\end{array}$ & $\begin{array}{c}0 \% \text { vs } \\
56 \%\end{array}$ & $\begin{array}{c}0 \% \text { vs } \\
48 \%\end{array}$ & $P$ & $P$ \\
\hline $\begin{array}{l}\text { Igarashi et al } \\
(655)\end{array}$ & $\mathrm{P}$ & $5 / 8$ & --- & $\begin{array}{l}\text { Mono }=34 \\
\text { Multi }=24\end{array}$ & SI & SI & $\begin{array}{l}\text { SI in } \\
\text { mono }\end{array}$ & $\begin{array}{l}\text { SI in } \\
\text { mono }\end{array}$ & $P$ & $P$ \\
\hline $\begin{array}{l}\text { Geurts et al } \\
(654)\end{array}$ & $\mathrm{P}$ & $6 / 8$ & --- & 20 & $55 \%$ & $55 \%$ & $40 \%$ & $35 \%$ & $P$ & $P$ \\
\hline $\begin{array}{l}\text { Richardson } \\
\text { et al (656) }\end{array}$ & $\mathrm{P}$ & $4 / 8$ & --- & 34 & SI & SI & SI & SI & $P$ & $P$ \\
\hline $\begin{array}{l}\text { Manchikanti } \\
\text { et al (646) }\end{array}$ & $\mathrm{R}$ & $4 / 8$ & --- & 60 & $100 \%$ & $75 \%$ & $40 \%$ & $22 \%$ & $P$ & $P$ \\
\hline $\begin{array}{l}\text { Manchikanti } \\
\text { et al (657) }\end{array}$ & $\mathrm{R}$ & $4 / 8$ & --- & 85 & $100 \%$ & $77 \%$ & $52 \%$ & $21 \%$ & $P$ & $P$ \\
\hline
\end{tabular}

$\mathrm{P}=$ prospective $\mathrm{R}=$ retrospective $\mathrm{PC}=$ placebo controlled; $\mathrm{RA}=$ randomized; $\mathrm{DB}=$ double blind; $\mathrm{NA}=$ not available; $N=$ negative; $P=$ positive SI=Significant Improvement; Mono: monosegmental; Multi: multisegmental 
Table 10. Results of published reports of therapeutic sacroiliac joint injections

\begin{tabular}{|c|c|c|c|c|c|c|c|c|c|}
\hline \multirow[b]{3}{*}{ Study } & \multirow[b]{3}{*}{$\begin{array}{c}\text { Study } \\
\text { Character- } \\
\text { istics }\end{array}$} & \multicolumn{2}{|c|}{$\begin{array}{l}\text { Methodological } \\
\text { Quality Score(s) }\end{array}$} & \multirow[b]{3}{*}{ No. of Patients } & \multirow{3}{*}{$\begin{array}{l}\begin{array}{c}\text { Initial } \\
\text { Relief }\end{array} \\
<6 \text { wks }\end{array}$} & \multirow{2}{*}{\multicolumn{2}{|c|}{ Long-term Relief }} & \multirow{2}{*}{\multicolumn{2}{|c|}{ Results }} \\
\hline & & & & & & & & & \\
\hline & & $\begin{array}{c}\text { AHRQ } \\
\text { Score }(s)\end{array}$ & $\begin{array}{c}\text { Co- } \\
\text { chrane } \\
\text { Score }(s)\end{array}$ & & & 3 months & 6 months & $\begin{array}{c}\text { Short-term } \\
\text { relief }<6 \\
\text { weeks }\end{array}$ & $\begin{array}{l}\text { Long-term re- } \\
\text { lief } \geq 6 \text { weeks }\end{array}$ \\
\hline $\begin{array}{l}\text { Maugars et al } \\
(670)\end{array}$ & RA & $6 / 10$ & $6 / 10$ & $\begin{array}{c}10 \text { patients/ } \\
13 \mathrm{w} / \\
\text { articulations }\end{array}$ & $62 \%$ & $62 \%$ & $58 \%$ & $P$ & $P$ \\
\hline $\begin{array}{l}\text { Hanly et al } \\
(673)\end{array}$ & $\mathrm{P}$ & $5 / 8$ & --- & 19 & SI & SI & $\mathrm{NI}$ & $P$ & $N$ \\
\hline $\begin{array}{l}\text { Slipman et al } \\
(674)\end{array}$ & $\mathrm{R}$ & $6 / 8$ & --- & 31 & $\mathrm{P}$ & N/A & $\mathrm{N} / \mathrm{A}$ & $P$ & $P$ \\
\hline
\end{tabular}

$\mathrm{P}=$ prospective $\mathrm{R}=$ retrospective $\mathrm{RA}=$ randomized $\mathrm{SI}=$ significant improvement $\mathrm{NI}=$ no improvement $\mathrm{NA}=$ not available; $P=$ positive; $N=$ negative

\subsubsection{Cost Effectiveness}

The cost effectiveness of spinal endoscopy and adhesiolysis was determined in two separate groups of patients (646). The cost effectiveness of spinal endoscopy in patients failing to respond to all conservative modalities of treatments including percutaneous lysis with a springguided catheter was shown to be $\$ 7,020$ to $\$ 8,127$.

\subsubsection{Evidence}

Evidence for spinal endoscopy was strong for short-term relief and moderate for long-term relief, in managing chronic refractory low back and lower extremity pain.

\subsubsection{Complications}

The most common and worrisome complications of adhesiolysis and spinal endoscopy with lysis of adhesions are related to dural puncture, spinal cord compression, catheter shearing, infection, steroids, hypertonic saline, hyaluronidase, instrumention with endoscope, and administration of high volumes of fluids potentially resulting in excessive epidural hydrostatic pressures $(1,27,30,440-450,511$, $514,517,518,613-668)$. This may cause spinal cord compression, excessive intraspinal and intracranial pressures, epidural hematoma, bleeding, infection, increased intraocular pressures with resultant visual deficiencies, and even blindness and dural puncture. Unintended subarachnoid or subdural puncture with injection of local anesthetic or hypertonic saline is one of the major complications of the procedure with catheter adhesiolysis. Hypertonic saline injected into the subarachnoid space has been reported to cause cardiac ar- rhythmias, myelopathy, paralysis, and loss of sphincter control.

\subsection{Sacroiliac Joint Interventions}

The present evidence supports the existence of sacroiliac joint pain (222233). Based on a detailed review of the literature, the general consensus appears to be that sacroiliac joint pain can be diagnosed with reasonable certainty with controlled comparative local anesthetic diagnostic blocks (24).

Sacroiliac joint pain may be managed by intraarticular injections, or neurolysis of the sacroiliac joint. Relief with intraarticular injections was considered short-term if less than 6 weeks and longterm if 6 weeks or longer. Relief with radiofrequency neurotomy was considered short-term if less than 3 months, and long-term 3 months or longer.

\subsubsection{Intraarticular Injections}

Two randomized trials $(669,670), 3$ prospective evaluations (671-673), and one retrospective evaluation (674) were identified. However, only one randomized trial (670), one prospective evaluation (673), and one retrospective evaluation (674) met the inclusion criteria (Table 10). Two of the studies evaluated spondyloarthropathy $(670,673)$. The retrospective evaluation (674) included patients with 6 weeks of pain. Due to lack of studies evaluating non-inflammatory SI joint arthritis, the above studies were included.

Maugars et al (670), in a doubleblind study of evaluation of 10 patients suffering with painful sacroiliitis reported improvement in 5 of the 6 sacroiliac joints injected with corticosteroid with $70 \%$ relief at 1 -month and 0 of the 7 of the placebo joint injections reporting any significant relief. There was significant improvement in $62 \%$ of the patients at 3 months and $58 \%$ of the patients at 6 months. Hanley et al (673) showed only transient improvement with pain relief and spinal mobility, which was most pronounced at 1 to 3 months after intraarticular therapy. However, by 6 months, all outcome variables reverted to pre-therapy levels in both groups. Slipman et al (674) in a retrospective study with independent clinical review of 31 patients receiving an average of 2.1 therapeutic injections concluded that fluoroscopically guided therapeutic sacroiliac joint injections are a clinically effective intervention in the treatment of patients with sacroiliac joint syndrome.

\subsubsection{Cost Effectiveness}

No studies were performed evaluating the cost effectiveness of therapeutic intraarticular injections.

\subsubsection{Evidence}

The evidence for intraarticular sacroiliac joint injections was moderate for short-term relief and limited for longterm relief.

\subsubsection{Radiofrequency neurotomy}

Percutaneous radiofrequency neurotomy of sacroiliac joints has been reported to provide long-term relief (229, 675-677).

Of all the evaluations performed on radiofrequency neurotomy in managing sacroiliac joint pain, one report was prospective $(675)$ and 3 were retrospective $(229,676,677)$. However, the prospective evaluation only had 3-months follow-up 
Table 11. Results of published reports of sacroiliac joint radiofrequency thermoneurolysis

\begin{tabular}{|c|c|c|c|c|c|c|c|c|c|}
\hline \multirow[b]{2}{*}{ Study } & \multirow[b]{2}{*}{$\begin{array}{l}\text { Study } \\
\text { Charac- } \\
\text { teristics }\end{array}$} & \multirow[b]{2}{*}{$\begin{array}{c}\text { Methodological } \\
\text { Quality Criteria } \\
\text { AHRQ Score }\end{array}$} & \multirow[b]{2}{*}{$\begin{array}{c}\text { No. of } \\
\text { Patients }\end{array}$} & \multirow{2}{*}{$\begin{array}{c}\begin{array}{c}\text { Initial } \\
\text { Relief }\end{array} \\
<3 \\
\text { months }\end{array}$} & \multicolumn{3}{|c|}{ Long-term Relief } & \multicolumn{2}{|c|}{ Results } \\
\hline & & & & & $\begin{array}{c}3 \\
\text { months }\end{array}$ & $\begin{array}{c}6 \\
\text { months }\end{array}$ & $\begin{array}{c}1 \\
\text { year }\end{array}$ & $\begin{array}{c}\text { Short-term } \\
\text { relief }<3 \text { months }\end{array}$ & $\begin{array}{c}\text { Long-term } \\
\text { relief } \geq 3 \\
\text { months }\end{array}$ \\
\hline Yin et al (229) & $\mathrm{R}$ & $4 / 8$ & 14 & $64 \%$ & $64 \%$ & $64 \%$ & $64 \%$ & $P$ & $P$ \\
\hline $\begin{array}{l}\text { Ferrante et al } \\
(676)\end{array}$ & $\mathrm{R}$ & $4 / 8$ & 33 & $35 \%$ & $35 \%$ & $35 \%$ & NA & $N$ & $N$ \\
\hline $\begin{array}{l}\text { Cohen and } \\
\text { Abdi (677) }\end{array}$ & $\mathrm{R}$ & $4 / 8$ & 9 & $89 \%$ & $89 \%$ & $89 \%$ & NA & $P$ & $P$ \\
\hline
\end{tabular}

$\mathrm{R}=$ retrospective $\mathrm{NA}=$ not available $P=$ positive $;=$ negative

and consequently failed to meet inclusion criteria, as it reported only short-term relief. Hence, all 3 retrospective evaluations were included in the evidence synthesis (Table 11). Among the retrospective reports, Ferrante et al (676) evaluated effectiveness of sacroiliac joint radiofrequency denervations in 33 patients. They reported that only $36 \%$ of the patients met the criteria for successful denervation at 6 months.

Yin et al (229) in a retrospective evaluation of 14 patients reported that $64 \%$ of the patients experienced a successful outcome. Finally, Cohen and Abdi (677) evaluated radiofrequency lesioning on 9 patients and reported that $89 \%$ obtained $\geq 50 \%$ pain relief from this procedure that persisted at the 9-month follow-up.

\subsubsection{Cost Effectiveness}

No cost effectiveness evaluations were performed with radiofrequency neurotomy of sacroiliac joint innervation.

\subsubsection{Evidence}

Evidence synthesis of radiofrequency neurotomy of sacroiliac joints included only retrospective evaluations with small numbers of patients, providing indeterminate evidence for managing sacroiliac joint pain.

\subsubsection{Safety and Complications}

No complications have been reported in any of the studies included in this review. However, expected complications include infection, hematoma formation, neural damage, trauma to the sciatic nerve, potential gas and vascular particulate embolism, leakage of the drug from the joint, and other complications related to drug administration.

\subsection{Intradiscal Therapies}

Multiple percutaneously administered minimally invasive interventional techniques to achieve disc decompression have been described. Of these, intradiscal electrothermal therapy (IDET) and nucleoplasty are commonly employed minimally invasive techniques. Relief of less than 6 months was considered as shortterm relief and relief of 6 months or longer was considered as long-term relief.

\subsubsection{Intradiscal Electrothermal}

Therapy.

Intradiscal electrothermal therapy (IDET) is performed by introducing a flexible catheter, containing a resistive coil, into the disc.

One randomized trial (678) and multiple prospective and retrospective trials (172, 679-697) were available. Among the prospective evaluations, 8 studies were included. All the studies evaluated chronic, refractory, discogenic pain (Table 12).

Pauza et al (678) in evaluation of the effectiveness of intradiscal electrothermal therapy for the treatment of discogenic low back pain in a randomized, placebo-controlled trial reported significant improvements in pain, disability and depression in the group treated with IDET. However, only $40 \%$ of patients treated with IDET achieved greater than $50 \%$ relief of pain at 6 months.

Karasek and Bogduk (679) and Bogduk and Karasek (680) studied 53 patients with back pain and followed them for 2 years. They concluded that in carefully selected cases, IDET can eliminate or dramatically reduce the pain of internal disc disruption in a substantial proportion of patients and appears to be superior to conventional conservative care for internal disc disruption. At 24 months, 54\% of the patients had achieved at least $50 \%$ relief with functional improvement.

Saal and Saal $(681,685,691)$ reported results of their experience over a period of 6 months, 1 year, and 2 years, with overall improvement in $71 \%$ of the patients. They reported a VAS change for the entire group of 3.2 with a mean change on the SF-36 physical function subscale of 20 , and the mean change on the SF- 36 bodily pain subscale of 17.8

Derby et al (682) reported that $63 \%$ of the 32 patients had a favorable outcome, with no change in outcome measures at 6 month and 12-month followups.

A total of 8 prospective evaluations (679, 684-690) and one retrospective evaluation (682) were included in evidence synthesis, with 7 positive reports and 2 negative reports $(689,693)$.

\subsubsection{Cost Effectiveness}

Cost effectiveness of intradiscal electrothermal anuloplasty has not been evaluated.

\subsubsection{Evidence}

The evidence for intradiscal electrothermal therapy (IDET) was strong for short-term relief and moderate for longterm relief in managing chronic discogenic low back pain.

\subsubsection{Complications}

Complications include catheter breakage, nerve root injuries, post-IDET disc herniation, cauda equina syndrome, infection, epidural abscess, and spinal cord damage (698-699). 
Table 12. Results of published reports of IDET

\begin{tabular}{|c|c|c|c|c|c|c|c|c|c|}
\hline \multirow[b]{3}{*}{ Study } & \multirow[b]{3}{*}{$\begin{array}{l}\text { Study Char- } \\
\text { acteristics }\end{array}$} & \multicolumn{2}{|c|}{$\begin{array}{l}\text { Methodological } \\
\text { Quality Score(s) }\end{array}$} & \multirow[b]{3}{*}{$\begin{array}{c}\text { No. of } \\
\text { Patients }\end{array}$} & \multirow{3}{*}{$\begin{array}{c}\text { Initial } \\
\text { Relief }\end{array}$} & \multirow{2}{*}{\multicolumn{2}{|c|}{ Long-term Relief }} & \multirow{2}{*}{\multicolumn{2}{|c|}{ Results }} \\
\hline & & \multirow[b]{2}{*}{$\begin{array}{c}\text { AHRQ } \\
\text { Score(s) }\end{array}$} & \multirow{2}{*}{$\begin{array}{c}\text { Co- } \\
\text { chrane } \\
\text { Score }(s)\end{array}$} & & & & & & \\
\hline & & & & & & $\begin{array}{c}6 \\
\text { months }\end{array}$ & $\begin{array}{c}1 \\
\text { year }\end{array}$ & $\begin{array}{c}\text { Short-term relief } \\
<6 \text { months }\end{array}$ & $\begin{array}{l}\text { Long-term relief } \\
\geq 6 \text { months }\end{array}$ \\
\hline Pauza et al (678) & $\begin{array}{l}\mathrm{RA}, \mathrm{DB}, \\
\mathrm{PC}\end{array}$ & $10 / 10$ & $10 / 10$ & $\begin{array}{l}\mathrm{C}=27 \\
\mathrm{~T}=37\end{array}$ & Equal & $\begin{array}{l}50 \% \\
\text { Treat }\end{array}$ & NA & $P$ & $N$ \\
\hline $\begin{array}{l}\text { Karasek \& Bogduk } \\
(679,680)\end{array}$ & $\mathrm{P}$ & $9 / 10$ & --- & $\begin{array}{l}\mathrm{C}=17 \\
\mathrm{~T}=35\end{array}$ & $\begin{array}{c}6 \% \text { vs } \\
70 \%\end{array}$ & $53 \%$ & $53 \%$ & $P$ & $P$ \\
\hline $\begin{array}{l}\text { Saal and Saal (681, } \\
685,691)\end{array}$ & $\mathrm{P}$ & $6 / 10$ & --- & 58 & SI & SI & SI & $P$ & $P$ \\
\hline $\begin{array}{l}\text { Gerszten et al } \\
(684)\end{array}$ & $\mathrm{P}$ & $6 / 10$ & --- & 27 & $75 \%$ & $75 \%$ & $75 \%$ & $P$ & $P$ \\
\hline $\begin{array}{l}\text { Mekhail and } \\
\text { Kapural (686) }\end{array}$ & $\mathrm{P}$ & $5 / 10$ & --- & 32 & SI & SI & SI & $P$ & $P$ \\
\hline Lee et al (687) & $\mathrm{P}$ & $5 / 10$ & --- & 62 & $53 \%$ & $53 \%$ & $53 \%$ & $P$ & $P$ \\
\hline Lutz et al (688) & $\mathrm{P}$ & $5 / 10$ & --- & 33 & SI & SI & SI & $P$ & $P$ \\
\hline $\begin{array}{l}\text { Freedman et al } \\
(689)\end{array}$ & $\mathrm{P}$ & $6 / 10$ & --- & 36 & NA & $47 \%$ & $16 \%$ & $N$ & $N$ \\
\hline Spruit (693) & $\mathrm{P}$ & $5 / 10$ & --- & 20 & NSI & NSI & NSI & $N$ & $N$ \\
\hline Derby et al (682) & $\mathrm{R}$ & $5 / 10$ & --- & 99 & $64 \%$ & $64 \%$ & $64 \%$ & $P$ & $P$ \\
\hline
\end{tabular}

$\mathrm{P}=$ prospective $\mathrm{PC}=$ placebo controlled $\mathrm{RA}=$ randomized $\mathrm{R}=$ retrospective $; \mathrm{C}=$ control; $\mathrm{T}=$ treatment $\mathrm{SI}=$ significant improvement; $\mathrm{NA}=$ not available; NSI $=$ No significant improvement $P=$ positive $N=$ negative

\subsubsection{Nucleoplasty}

Percutaneous disc decompression (PDD) with nucleoplasty (coblation technology) is performed with RF energy to dissolve nuclear material through molecular dissociation. Bipolar RF coagulation denatures proteoglycans, changing the internal environment of the affected nucleus pulposus with reduction in intradiscal pressure (700-702).

The effectiveness of nucleoplasty has been reported in three prospective (702704) evaluations. There were no randomized trials evaluating the effectiveness of percutaneous disc decompression with nucleoplasty. However, all the observational studies showed significant improvement in short-term, as well as longterm, in multiple parameters with pain and functional status. All the studies were performed in patients either with discogenic pain or with small contained disc herniations (Table 13).

\subsubsection{Cost Effectiveness}

Cost effectiveness of percutaneous disc decompression with coblation nucleoplasty has not been evaluated.

\subsubsection{Evidence}

The evidence of nucleoplasty is limited in managing lumbar discogenic pain.

\subsubsection{Complications}

No significant complications have been described. However, possibilities include neural trauma, cauda equina syndrome and other neurological complications.

\subsection{Implantable Therapies}

Spinal cord stimulation systems and implantable intrathecal devices are frequently used in managing chronic intractable pain.

\subsubsection{Spinal Cord Stimulation}

In the United States, the primary indications for spinal cord stimulation are failed back surgery syndrome and complex regional pain syndromes type I and type II $(21,40,705,706)$. Significant improvements of less than one year were considered as short-term, whereas, one year or longer were considered as longterm.

Turner et al (40), in 2004, performed a systematic review of spinal cord stimulation for patients with failed back sur-

Table 13. Results of published reports of nucleoplasty

\begin{tabular}{|c|c|c|c|c|c|c|c|c|}
\hline \multirow[b]{2}{*}{ Study } & \multirow[b]{2}{*}{$\begin{array}{c}\text { Study } \\
\text { Characteristics }\end{array}$} & \multirow{2}{*}{$\begin{array}{c}\begin{array}{c}\text { Methodological } \\
\text { Quality Score }\end{array} \\
\text { AHRQ Score }\end{array}$} & \multirow[b]{2}{*}{$\begin{array}{c}\text { No. of } \\
\text { Patients }\end{array}$} & \multirow{2}{*}{$\begin{array}{c}\begin{array}{c}\text { Initial } \\
\text { Relief }\end{array} \\
<6 \text { months }\end{array}$} & \multicolumn{2}{|c|}{$\begin{array}{l}\text { Long-term } \\
\text { Relief }\end{array}$} & \multicolumn{2}{|c|}{ Results } \\
\hline & & & & & 6 months & 1 year & $\begin{array}{l}\text { Short-term relief } \\
<6 \text { months }\end{array}$ & $\begin{array}{l}\text { Long-term relief } \\
\geq 6 \text { monthss }\end{array}$ \\
\hline $\begin{array}{l}\text { Singh et al } \\
(702)\end{array}$ & $\mathrm{P}$ & $5 / 10$ & 67 & $82 \%$ & $59 \%$ & $56 \%$ & $P$ & $P$ \\
\hline $\begin{array}{l}\text { Sharps and } \\
\text { Isaac (703) }\end{array}$ & $\mathrm{P}$ & $5 / 10$ & 49 & $79 \%$ & $79 \%$ & $79 \%$ & $P$ & $P$ \\
\hline $\begin{array}{l}\text { Singh et al } \\
(704)\end{array}$ & $\mathrm{P}$ & $5 / 10$ & 47 & $80 \%$ & $63 \%$ & $53 \%$ & $P$ & $P$ \\
\hline
\end{tabular}

$\mathrm{P}=$ prospective $P=$ positive $;=$ negative 
gery syndrome or complex regional pain syndrome. Following an extensive review, they concluded that the literature on spinal cord stimulation for failed back surgery syndrome and complex regional pain syndrome remains inadequate to make definitive statements about efficacy in reducing physical disability, work disability, and medication consumption. They also concluded that there is moderate evidence (one high quality RCT) that spinal cord stimulation plus physical therapy is more effective than physical therapy alone for patients with CRPS Type I in relieving pain at 6- and 12-months. They further added that both the RCT and lowerquality studies suggested a modest painrelieving effect on average. They also felt that complications leading to the need for additional surgeries have been common. However, the same authors, in a previous systematic review in 1995 (706), which consisted mostly of retrospective case series, concluded that approximately $50 \%$ to $60 \%$ of patients with failed back surgery syndrome reported $\geq 50 \%$ pain relief with spinal cord stimulation.

Turner et al (40), in their recent review also excluded two commonly used randomized trials in the evidence synthesis $(707,708)$. They stated that North et al (708) failed to report either pain or functional outcomes. They also discussed North and Wetzel's report of 2002 (709) which reports SCS to be more effective than reoperation for $90 \%$ of patients at a 3-year follow-up, with significantly better outcomes and lower rates of crossover. They excluded a large prospective multicenter study (707) because only 70 of 182 failed back surgery syndrome patients who received a permanent spinal cord stimulator completed the follow-up.

Taylor et al (21), in a recent systematic review of spinal cord stimulation for chronic back and leg pain and failed back surgery syndrome, studied one randomized controlled trial, one cohort study, and 72 case studies. They concluded that there is moderate evidence for spinal cord stimulation effectiveness.

Five randomized controlled trials $(708,710-713)$, two prospective trials $(707,714)$, multiple case series (715-720), and other reports were identified (721).

For this evaluation, 3 of the 5 randomized trials were included $(710,711$, 713). Two reports by Kemlar et al (711, 712 ) and two studies by North et al (708, 713) were included as one each. Rapha- el et al (710) reported positive results of spinal cord stimulation in failed back surgery syndrome. Kemler et al $(711,712)$ evaluated the effectiveness in complex regional pain syndrome. They reported that pain, but not functional status or depression, improved significantly more in spinal cord stimulation with physical therapy than physical therapy alone at 6 months. However, at 1 year, pain and quality of life were improved more in the spinal cord stimulation group. In a second study, North et al $(708,713)$ studied failed back surgery syndrome patients as candidates for repeat laminectomy or spinal cord stimulation. They concluded that at long-term follow-up of 3 years, spinal cord stimulation continues to be more effective than reoperation, for $90 \%$ of the patients.

The two prospective trials included in the evidence synthesis $(707,714)$ showed positive results. Barolat et al (714), in a multicenter study, showed $83 \%$ to $92 \%$ of the patients had fair to excellent relief with either leg or back pain, and $69 \%$ to $88 \%$ of the patients fair to excellent relief in the legs or in the low back at 1 year, with significant improvement in function and quality of life. The second study by Burchiel et al (707) in a multicenter prospective study reported that at the 1-year follow-up evaluation of $70 \mathrm{pa}$ tients, quality-of-life measures showed statistically significant improvement during the treatment year.

Among the case series (715-721), all were positive for short-term and longterm benefit. Overall pain relief was better in the leg than in the low back.

\subsubsection{Cost Effectiveness}

Taylor et al (721) performed a systematic review of the literature. They reviewed 99 abstracts and found 14 studies that met the criteria of the review. They found across a range of health care institutions that the initial healthcare acquisition costs were offset by a reduction in post-implant healthcare resource demand and costs. Costs were $\$ 29,123$ in intervention group, compared to $\$ 38,029$ in the control group for failed back surgery syndrome. In contrast, for CRPS (722) in the lifetime analysis, spinal cord stimulation per patient was estimated to be $\$ 60,000$ cheaper than control therapy.

\subsubsection{Evidence}

The evidence for spinal cord stimulation in failed back surgery syndrome and complex regional pain syndrome was strong for short-term relief and moderate for long-term relief.

\subsubsection{Complications}

Complications with spinal cord stimulation range from infection, hematoma, nerve damage, lack of appropriate paraesthesia coverage, paralysis, nerve injury, and death (40).

\subsubsection{Implantable Intrathecal Drug Administration Systems}

Continuous infusion of intrathecal medication is used for control of chronic, refractory, malignant and non-malignant pain. In an exhaustive review of available literature, Bennett et al (723) concluded that clinical efficacy in large-scale randomized controlled trials utilizing intrathecal delivery of most compounds has not been demonstrated and variations between study designs make useful comparisons of existing studies difficult. In another review, Walker et al (724) concluded that the evidence for the safety and effectiveness of combination spinal analgesic therapies is moderate in acute pain, whereas, they found limited or no evidence to support the combination analgesics in chronic pain. Various guidelines also have been published on intrathecal infusion systems (725).

The literature supporting the use of intrathecal infusion systems includes four randomized trials (726-729), multiple prospective trials (730-735), and multiple retrospective evaluations (1, 736-739).

Among the randomized trials, Siddall et al (726) compared the effectiveness of intrathecal morphine or clonidine, alone or in combination, in the treatment of neuropathic pain after spinal cord injury. They concluded that the combination of morphine and clonidine produced significantly more pain relief than placebo 4 hours after administration. van Hilten et al (727) evaluated the use of intrathecal baclofen for the treatment of dystonia in patients with complex regional pain syndrome, in a double-blind, randomized, controlled, crossover trial of bolus intrathecal injections of baclofen in various doses. They concluded that in some patients, the dystonia associated with reflex sympathetic dystrophy responded markedly to intrathecal baclofen. Smith et al (728) reported significant improvement in patients treated with intrathecal infusion systems when compared to patients treated with conventional aggressive med- 
ical management in patients with malignant pain. Staats et al (729) in a multicenter, double-blind trial, reported that a neuron-specific calcium channel blocker delivered via an implanted intrathecal pump in patients with cancer and AIDSrelated pain syndromes significantly decreased pain scores in $51 \%$ of the patients compared to $18 \%$ in the placebo group at the 7-day follow-up. Thus, all the randomized trials were performed for neuropathic pain utilizing various types of drugs and short-term follow-up.

Among the prospective studies, Hassenbusch et al (730) reported favorable results in patients with long-standing nonmalignant neuropathic pain in a study of 14 patients, $61 \%$ reported good or fair pain control with a mean follow-up duration of 2.4 years. Angel et al (731) reported good to excellent analgesic response in $73 \%$ of 11 patients. Others (732-734) reported favorable results in chronic pain. In a recent evaluation, Deer et al (735) reported the results of the National Outcomes Registry for low back pain collected at 6- and 12-month follow-ups. They reported that in the implant group, numeric pain ratings dropped by more than $47 \%$ for back pain and more than $31 \%$ for leg pain at 12-month follow-up. They also reported improvement in Oswestry scores in $65 \%$ of the patients.

Retrospective reports dominate the literature on intrathecal pain management (736-740). Among the retrospective evaluations, the reports provided significant improvement at short-term and long-term follow-up.

\subsubsection{Cost Effectiveness}

In post lumbar laminectomy syndrome, it was shown that intrathecal morphine delivery resulted in lower cumulative 60 -month costs of $\$ 16,579$ per year and $\$ 1,382$ per month versus medical management at $\$ 17,037$ per year or $\$ 1,420$ per month (741).

In another study (96), the expected total cost of intrathecal morphine over 60 months was $\$ 82,893$ (an average of $\$ 1382$ per month).

\subsubsection{Evidence}

The evidence for implantable intrathecal infusion systems was strong for short-term improvement in pain of malignancy or neuropathic pain. The evidence was moderate for long-term management of chronic pain.

\subsubsection{Complications}

The complications include post-dural puncture headache, infection, nausea, urinary retention, pruritus, catheter and pump failure, pedal edema, hormonal changes, granuloma formation, and decreased libido.

\subsection{Evaluation and Management}

\subsection{Evaluation}

Appropriate history, physical examination, and medical decision making are essential (742). There are numerous acceptable medical methods to evaluate a chronic spinal pain patient. These methods vary from physician to physician and textbook to textbook. The guidelines established by the Centers for Medicare and Medicaid Services (CMS) aid the physician in performing a comprehensive and complete evaluation, and assist in complying with regulations. The CMS guidelines define five levels of services. The three crucial components of evaluation and management services are: history, physical examination, and medical decision-making. Other components include: counseling, coordination of care, nature of presenting problem, and time.

\subsection{Medical Necessity Management}

The following criteria should be considered carefully in performing interventional techniques:

1. Complete initial evaluation, including history and physical examination.

2. Physiological and functional assessment, as necessary and feasible.

3. Determination of indications and medical necessity:

- Suspected organic problem.

- Nonresponsiveness to less invasive modalities of treatments except in acute situations such as acute disc herniation, herpes zoster and postherpetic neuralgia, reflex sympathetic dystrophy, and intractable pain secondary to carcinoma.

- Pain and disability of moderateto-severe degree.

- No evidence of contraindications such as severe spinal stenosis resulting in intraspinal obstruction, infection, or predominantly psychogenic pain.
- Responsiveness to prior interventions with improvement in physical and functional status to justify repeat blocks or other interventions.

- Repeating interventions only upon return of pain and deterioration in functional status.

\subsection{Delivery of Interventional TECHNOLOGY}

There is no consensus among the interventional pain management specialists with regards to type, dosage, frequency, total number of injections, or other interventions. Yet significant attention in the literature seems to be focused on the complications attributed to the use of epidural steroids in the entire arena of interventional pain management. Thus, various limitations of interventional techniques, specifically neural blockade, have arisen from basically false impressions. Based on the available literature and scientific application, the most commonly used formulations of long-acting steroids, which include methylprednisolone (Depo-Medrol ${ }^{\circledR}$ ), triamcinolone diacetate (Aristocort ${ }^{\circledR}$ ), triamcinolone acetonide $\left(\right.$ Kenalog $\left.^{\circledR}\right)$, and betamethasone acetate and phosphate mixture (Celestone Soluspan $\left.{ }^{8}\right)$, appear to be safe and effective (1, $25,30,743-764)$. Based on the present literature, it appears that if repeated within two weeks, betamethasone may be the best choice in avoiding side effects; whereas, if treatment is carried out at six-week intervals or longer, any one of the four formulations will be safe and effective.

Frequency and total number of injections or interventions are key issues, although controversial and rarely addressed. Descriptions of the frequency of various types of interventional techniques are described here. These are based on available evidence and consensus regarding the safety, clinical effectiveness, and cost effectiveness. However, they are not based on evidence synthesis methodology. Descriptions are provided only for commonly used procedures. Medicare, Medicaid and third party payers in each region and state may have rules and regulations different from these guidelines. Interventions permitted per year and per region are also variable. 
8.1 Facet Joint Injections and Medial Branch Blocks

- In the diagnostic phase, a patient may receive two procedures at intervals of no sooner than 1 week or, preferably, 2 weeks.

- In the therapeutic phase (after the diagnostic phase is completed), the suggested frequency would be 2 months or longer between injections, provided that $\geq 50 \%$ relief is obtained for 6 weeks.

- If the interventional procedures are applied for different regions, they may be performed at intervals of no sooner than 1 week or preferably 2 weeks for most types of procedures. It is suggested that therapeutic frequency remain at 2 months for each region. It is further suggested that all regions be treated at the same time, provided all procedures can be performed safely.

- In the treatment or therapeutic phase, the interventional procedures should be repeated only as necessary according to the medical necessity criteria, and it is suggested that these be limited to a maximum of six times for local anesthetic and steroid blocks over a period of 1 year, per region.

- Under unusual circumstances with a re-current injury or cervicogenic headache, procedures may be repeated at intervals of 6 weeks after stabilization in the treatment phase.

\subsection{Medial Branch Neurotomy}

- The suggested frequency would be 3 months or longer between each procedure, provided that $\geq 50 \%$ relief is obtained for 10 to 12 weeks.

- The therapeutic frequency for medial branch neurotomy should remain at intervals of at least 3 months for each region. It is further suggested that all regions be treated at the same time, provided all procedures are performed safely.

\subsection{Epidural Injections}

- Epidural injections include caudal, interlaminar, and transforaminal.

- In the diagnostic phase, a patient may receive two procedures at intervals of no sooner than 1 week or preferably, 2 weeks, except in cancer pain or when a continuous administration of local anesthetic is employed for reflex sympathetic dystrophy.

- In the therapeutic phase (after the diagnostic phase is completed), the suggested frequency of interventional techniques should be 2 months or longer between each injection, provided that $\geq 50 \%$ relief is obtained for 6 to 8 weeks.

- If the neural blockade is applied for different regions, they may be performed at intervals of no sooner than 1 week and preferably 2 weeks for most type of procedures. The therapeutic frequency may remain at intervals of at least 2 months for each region. It is further suggested that all regions be treated at the same time, provided all procedures can be performed safely.

- In the treatment or therapeutic phase, the interventional procedures should be repeated only as necessary according to medical necessity criteria, and it is suggested that these be limited to a maximum of 6 times per year.

- Under unusual circumstances with a recurrent injury, carcinoma, or reflex sympathetic dystrophy, blocks may be repeated at intervals of 6 weeks after diagnosis/stabilization in the treatment phase.

\subsection{Percutaneous Adhesiolysis}

- The number of procedures are preferably limited to:

- With a 3-day protocol, 2 interventions per year,

- With a 1-day protocol, 4 interventions per year.

8.5 Spinal Endoscopic Adhesiolysis

- The procedures are preferably limited to a maximum of 2 per year provided the relief was $\geq 50 \%$ for $\geq 4$ months.

\subsection{Sacroiliac Joint Injections}

- In the diagnostic phase, a patient may receive two procedures at intervals of no sooner than 1 week or, preferably, 2 weeks.

- In the therapeutic phase (after the diagnostic phase is completed), the suggested frequency would be 2 months or longer between injections, provided that $\geq 50 \%$ relief is obtained for 6 weeks.
- If the procedures are done for different joints, they be performed at intervals of no sooner than 1 week or preferably 2 weeks. It is suggested that therapeutic frequency remain at 2 months for each joint. It is further suggested that both joints be treated at the same time, provided the injections can be performed safely.

- In the treatment or therapeutic phase, the interventional procedures should be repeated only as necessary according to the medical necessity criteria, and it is suggested that they be limited to a maximum of six times for local anesthetic and steroid blocks over a period of 1 year, per region.

- Under unusual circumstances with a re-current injury, procedures may be repeated at intervals of 6 weeks after stabilization in the treatment phase.

\subsection{Sacroiliac Joint Radiofrequency Neurotomy}

- The suggested frequency is 3 months or longer between each procedure, provided that $\geq 50 \%$ relief is obtained for 10 to 12 weeks.

- The therapeutic frequency for neurotomy should remain at intervals of at least 3 months for each region. It is further suggested that all regions be treated at the same time, provided all procedures are performed safely.

\subsection{An Algorithmic Approach}

In the changing paradigm of modern medicine, with its major focus on evidence-based medicine, interventional pain physicians may benefit from the practice of evidence-based interventional pain management. An algorithmic approach, if developed properly, may assist the physician in the clinical practice of interventional pain management.

An algorithmic approach was developed, based on the structural basis of spinal pain, and incorporated acceptable evidence of diagnostic and therapeutic interventional techniques available in managing chronic spinal pain. Consensus was utilized in the absence of specific evidence. Fig. 1 describes a proposed algorithmic approach for the diagnosis of chronic low back pain and Fig. 2 describes an algorithmic approach to management of chronic low back pain. Fig. 3 describes a proposed algorithmic approach for di- 


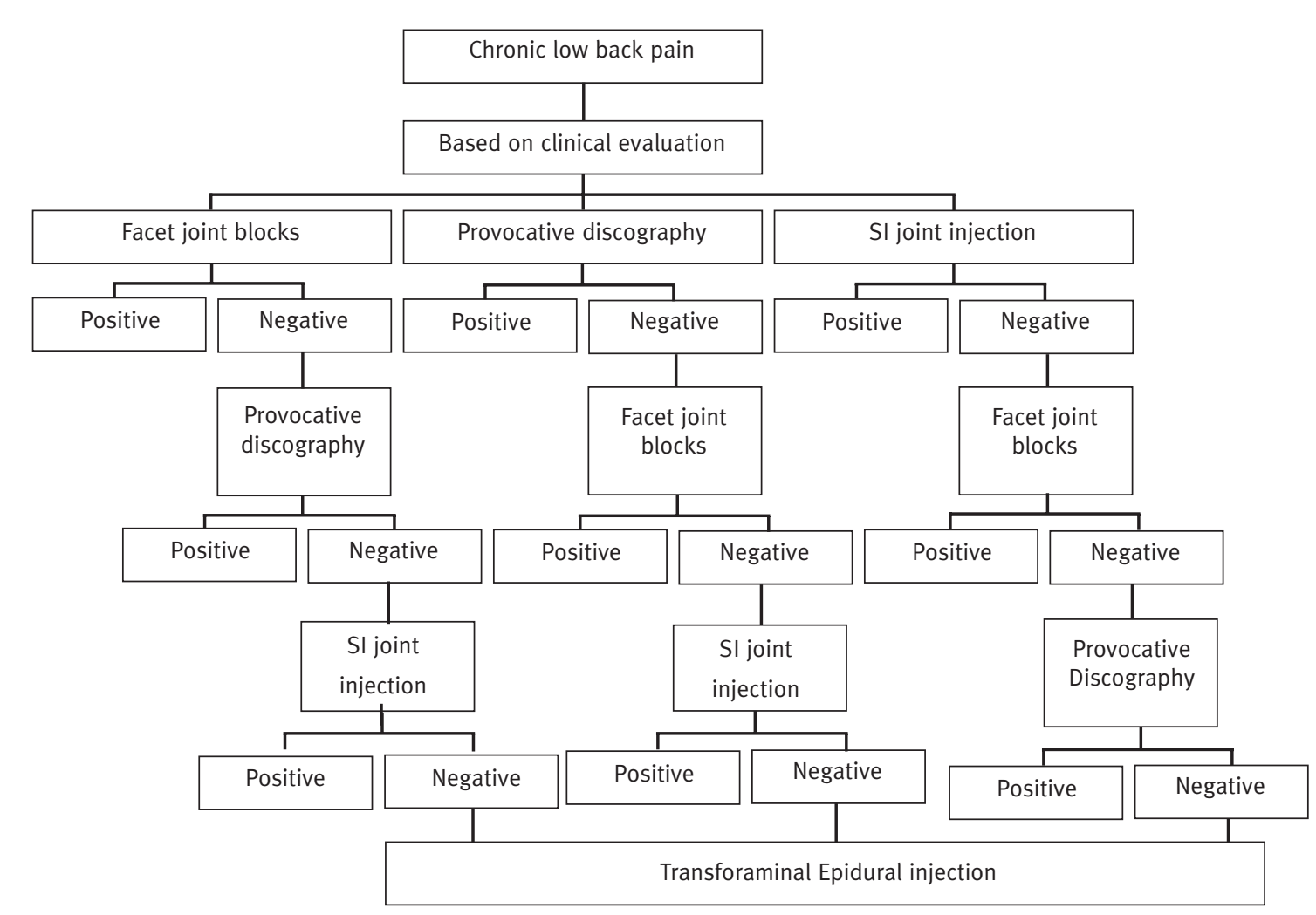

Fig. 1. An algorithmic approach to diagnosis of chronic low back pain without disc herniation

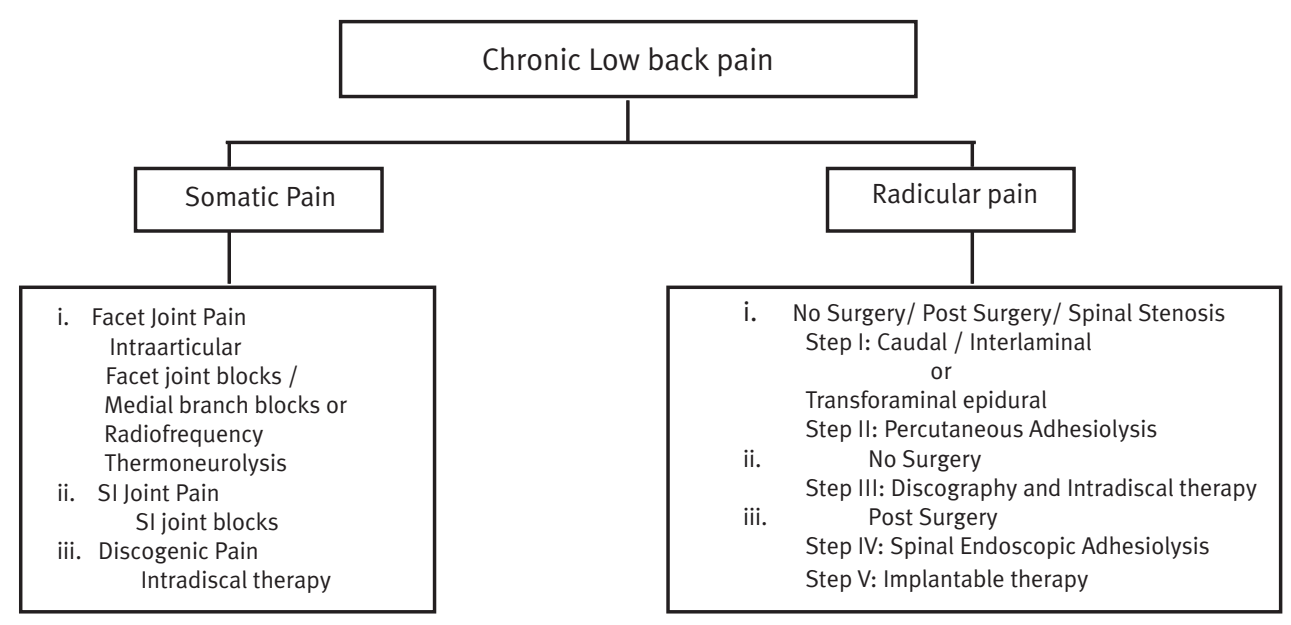

Fig. 2. A suggested algorithm for therapeutic interventional techniques in management of chronic low back pain 


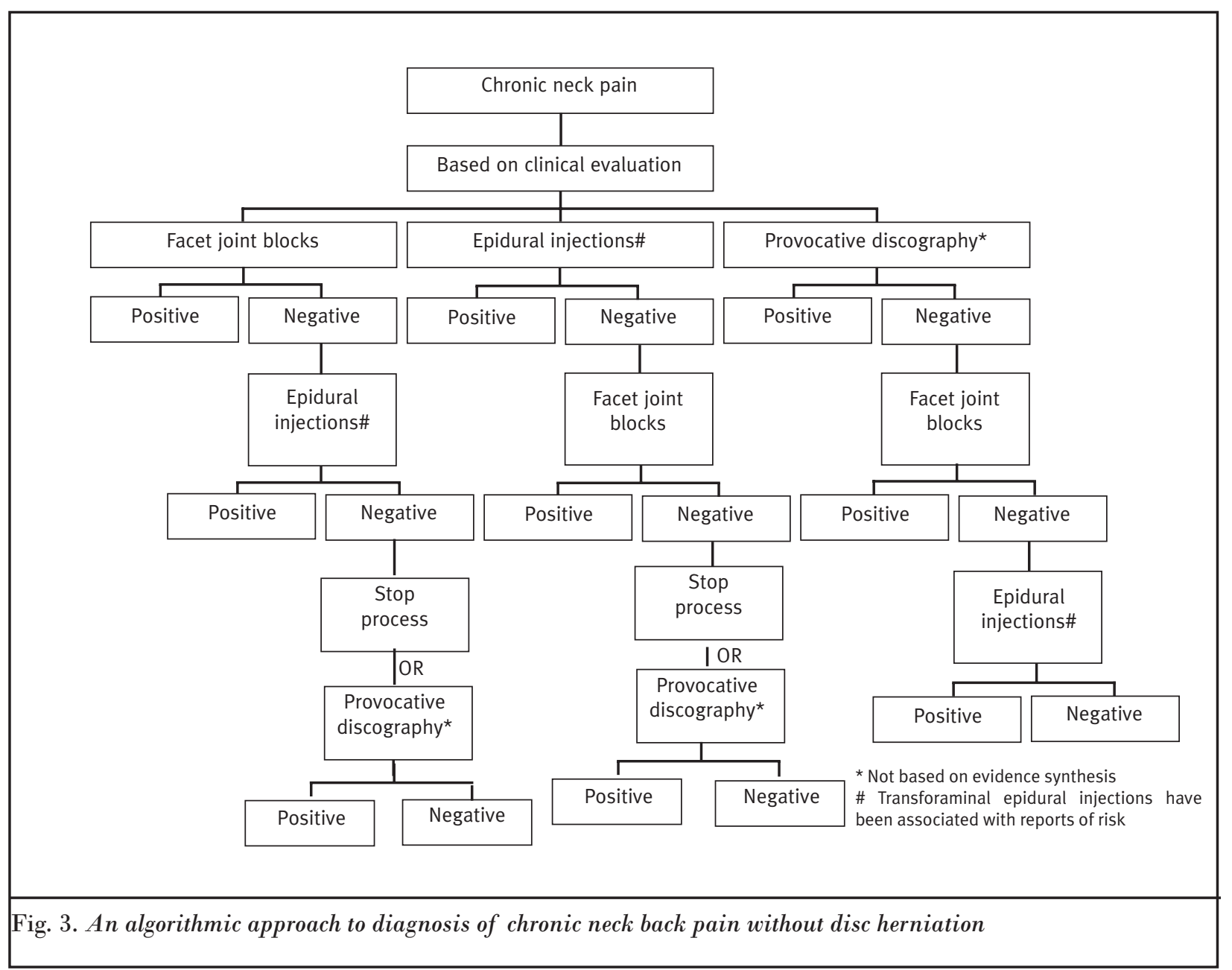

agnosis and management of chronic neck pain.

\section{Conclusion}

Evidence-based practice guidelines for interventional techniques in the management of chronic spinal pain were developed by the American Society of Interventional Pain Physicians utilizing the best available clinical evidence from systematic research. A policy committee with broad representation, consisting of academic and clinical practitioners recognized as experts in one or more interventional techniques under consideration and representing a variety of practices and geographic areas, assisted in preparation of these guidelines. All types of rele- vant and published evidence and consensus were utilized. These guidelines are a comprehensive review of interventional techniques for managing chronic spinal pain. It is hoped that these guidelines will assist both physicians and patients in making appropriate health care decisions for the diagnosis and treatment of chronic spinal pain. 
Author Affiliation

Mark V. Boswell, MD, PhD

Associate Professor of Anesthesiology

Chief, Pain Medicine Service

Director, Pain Medicine Fellowship

Department of Anesthesiology

University Hospitals of Cleveland

Case School of Medicine

11100 Euclid Avenue

Cleveland OH 44106

E-mail: boswellmv@earthlink.net

Rinoo V. Shah, MD

Assistant Professor

Department of Anesthesiology and

Pain Services, International Pain Institute

Texas Tech University Health Sciences

Center

4430 South Loop 289

Lubbock, TX 79414

E-mail: rinoo_shah@yahoo.com

Clifford R. Everett, MD

Assistant Professor, Department

of Orthopaedics and Physical

Medicine and Rehabilitation

University of Rochester Medical Center

601 Elmwood Avenue, Box 65

Rochester, NY 14642

clifford_everett@URMC.Rochester.edu

Nalini Sehgal, MD

Medical Director, Interventional Pain

Program

Assistant Professor, Department of

Orthopedics and Rehabilitation

University of Wisconsin School of

Medicine

600 Highland Avenue. Mail Code 2424

Madison, WI 53792

E-mail: n.sehgal@hosp.wisc.edu

Ann Marie McKenzie-Brown, MD

Assistant Professor of Anesthesiology

Division Director, Division of Pain

Medicine

Emory Department of Anesthesiology

Emory Center for Pain Medicine

550 Peachtree Street, NE

Atlanta GA 30308

anne_marie_mckenzie-brown@emory.org

Salahadin Abdi, MD, PhD

Director, Massachusetts General Hospital

Pain Center

Department of Anesthesiology and

Critical Care

15 Parkman Street, Suite 333B

Boston MA 02114

Department of Anesthesiology and

Critical Care

Harvard Medical School

Boston, Massachusetts, 02114

E-Mail: sabdi@partners.org
Richard C. Bowman II, MD

The Center for Pain Relief

400 Court Street, Suite 304

Charleston WV 25301

jgoodwin@centerforpainreleif.com

Timothy R. Deer, MD

Chairman, Chronic Pain Committee,

American Society of Anesthesiologists

Medical Director

The Center for Pain Relief

400 Court Street, Suite 304

Charleston WV 25301

E-mail: DocTDeer@aol.com

Sukdeb Datta, MD

Director, Pain Management Center

VA Tennessee Valley Healthcare System

$131024^{\text {th }}$ Avenue South

Nashville, TN 37212

sukdeb@hotmail.com

James D. Colson, MS, MD

Clinical Assistant Professor of

Anesthesiology

Attending Staff, Center for Interventional

Pain Medicine

University Of Michigan

1H247 UH, 1500 E. Medical Center Drive

Ann Arbor, MI 48130

E-mail: colsonj@umich.edu

William F. Spillane, MD

Anesthesiology/Neurology

Medical Director, Pain Control Center

Co-Director, Pain Fellowship Program

Assistant Clinical Professor

Department Of Anesthesiology

Wake Forest University Baptist Medical

Center

Medical Center Boulevard

Winston-Salem, NC 27157

E-mail: wspillan@wfubmc.edu

Howard S. Smith, MD

Associate Professor of Anesthesiology

Academic Director of Pain Management

Albany Medical College

47 New Scotland Avenue

Albany, NY 12208

E-mail: smithh@mail.amc.edu

Linda F. Levin, MD

Associate Professor

Department of Anesthesiology and

Perioperative Medicine

Director of Pain Management Fellowship

University of Louisville School of

Medicine

530 S. Jackson Street

Louisville, Kentucky 40202

E-Mail: 1fluca01@louisville.edu
Allen W. Burton, MD

Section Chief

Pain Management Services

Associate Professor of Anesthesiology

M.D. Anderson Cancer Center

Department Anesthesiology

Unit 042, 1515 Holcombe Blvd.

University of Texas

Houston, TX 77030

E-mail: awburton@mdanderson.org

Pradeep Chopra, MD

Assistant Professor of Medicine (Clinical)

Department of Medicine

Division of Biology and Medicine

Brown Medical School

Providence, RI

Assistant Professor of

Anesthesiology(Adjunct)

Boston University School of Medicine

Medical Director

Interventional Pain Management Center

Pawtucket, RI 02860

E-mail: painri@yahoo.com

Peter S. Staats, MD

Interventional Pain Management

160 Avenue at the Common

Shrewsbury, NJ 07702

E-mail: pstaats@JHMI.EDU

Ronald A. Wasserman, MD

Clinical Assistant Professor

Department of Anesthesiology

Director, Pain Clinic University of

Michigan

1500 E. Medical Center Drive

Ann Arbor MI 48109

E-mail: ronaldw@umich.edu

Laxmaiah Manchikanti, MD

Medical Director

Pain Management Center of Paducah

2831 Lone Oak Road

Paducah, Kentucky 42003

Assistant Clinical Professor of

Anesthesiology and Perioperative

Medicine

University of Louisville School of

Medicine

Louisville, Kentucky 40292

E-mail: drm@apex.net. 


\section{RefERENCES}

1. Manchikanti L, Staats PS, Singh V, Schultz DM, Vilims BD, Jasper JF, Kloth DS, Trescot AM, Hansen HC, Falasca TD, Racz GB, Deer T, Burton AW, Helm S, Lou L, Bakhit CE, Dunbar EE, Atluri SL, Calodney AK, Hassenbusch S, Feler CA. Evidence-based practice guidelines for interventional techniques in the management of chronic spinal pain. Pain Physician 2003; 6:3-80.

2. Practice guidelines for chronic pain management. A report by the American Society of Anesthesiologists Task Force on Pain Management, Chronic Pain Section. Anesthesiology 1997; 86:995-1004.

3. Sanders SH, Harden RN, Benson SE, Vicente PJ. Clinical practice guidelines for chronic non-malignant pain syndrome patients II: An evidence-based approach. J Back Musc Rehabil 1999; 13:47-58.

4. Nelemans PJ, Debie RA, DeVet HC, Sturmans F. Injection therapy for subacute and chronic benign low back pain. Spine 2001; 26:501-515.

5. Geurts JW, van Wijk RM, Stolker RJ, Groen GJ. Efficacy of radiofrequency procedures for the treatment of spinal pain: A systematic review of randomized clinical trials Reg Anesth Pain Med 2001; 26:394-400.

6. Manchikanti L, Singh V, Vilims B, Hansen HC, Schultz DM, Kloth DS. Medial branch neurotomy in management of chronic spinal pain: Systematic review of the evidence. Pain Physician 2002; 5:405-418.

7. Niemisto L, Kalso E, Malmivaara A, Seitsalo S, Hurri H; Cochrane Collaboration Back Review Group.. Radiofrequency denervation for neck and back pain: a sys tematic review within the framework of the Cochrane collaboration back review group. Spine 2003, 28:1877-1888.

8. Nachemson AL, Jonsson E (eds). Neck and Back Pain. The Scientific Evidence of Causes, Diagnosis, and Treatment. Lippincott Williams \&Wilkins, Philadelphia, 2000.

9. Shaneyfelt TM, Mayo-Smith MF, Rothwangl J. Are guidelines following guidelines? The methodological quality of clinical practice guidelines in the peerreviewed medical literature. JAMA 1999; 281:1900-1905

10. Gatchel RJ, McGeary D. Cochrane collaboration-based reviews of health-care interventions: Are they unequivocal and valid scientifically or simply nihilistic? Spine J 2002; 2:315-319.

11. Manchikanti L, Abdi S, Lucas LF. Evidence synthesis and development of guidelines in interventional pain management. Pain Physician 2005; 8:73-86.

12. Manchikanti L, Heavner J, Racz GB, Mekhail NA, Schultz DM, Hansen HC, Singh V. Methods for evidence synthesis in interventional pain management. Pain Physician 2003; 6:89-111.

13. Shekelle P, Woolf S, Grimshaw J. Clinical guidelines: Developing guidelines. BMJ 1999; 318:593-596.
14. Connis R, Nickinovich D, Caplan R, Arens J. The development of evidence-based clinical practice guidelines. Integrating medical science and practice. Int J Technol Assess Health Care 2000;16(4):1003-1012.

15. Sackett D, Richardson WS, Roseberg W, Haynes RB. Evidence Based Medicine. Churchill Livingstone, Philadelphia, 1996.

16. West S, King V, Carey T, Lohr K, McKoy $N$, Sutton S, Lux L. Systems to rate the strength of scientific evidence. Evidence Report/Technology Assessment No. 47 University of North Carolina: Agency for Healthcare Research and Quality. AHRQ Publication No. 02-E016; April 2002.

17. Tunis SR, Stryer DB, Clancy CM. Practical clinical trials: Increasing the value of clinical research for decision making in clinical and health policy. JAMA 2003; 290:16241632

18. Silagy C, Rubin G, Henderson-Smart D, Gross P. A guide to the development, implementation and evaluation of clinical practice guidelines. National Health and Medical Research Council, Canberra, Commonwealth of Australia, 1998, pp 1-79.

19. O’Brien P, Silagy C, McCallum J, O'Connell, D, Glasziou P, Hill A. How to use the evidence: Assessment and application of scientific evidence. National Health and Medical Research Council, Canberra, Commonwealth of Australia, 2000, pp 1-84.

20. van Tulder M, Assendelft W, Koes B, Bouter LM. Method guidelines for systematic reviews in the Cochrane Collaboration Back Review Group for Spinal Disorders. Spine 1997; 22:2323-2330.

21. Taylor RS, Van Buyten JP, Buchser E. Spinal cord stimulation for chronic back and leg pain and failed back surgery syndrome: A systematic review and analysis of prognostic factors. Spine 2005; 30:152160.

22. Manchikanti L. Transforaminal lumbar epidural steroid injections. Pain Physician 2000; 3:374-398.

23. O’Neill C, Derby R, Kenderes L. Precision injection techniques for diagnosis and treatment of lumbar disc disease. Semin Spine Surg 1999; 11:104-118.

24. McKenzie-Brown A, Shah RV, Sehgal N, Everett CR. A systematic review of sacroiliac joint interventions. Pain Physician 2005;8:115-125.

25. Abdi S, Lucas LF, Datta S. Role of epidural steroids in the management of chronic spinal pain: A systematic review of effectiveness and complications Pain Physician 2005;8:127-143.

26. Boswell MV, Colson JD, Spillane WF. Therapeutic facet joint interventions: A systematic review of their role in chronic spinal pain management and complications. Pain Physician 2005;8:101-114

27. Chopra P, Smith HS, Deer TR, Bowman RC. Systematic review of adhesiolysis in managing chronic low back pain. Pain Physician 2005;8:87-100.

28. Boswell M, Hansen H, Trescot A, Hirsch,
J. Epidural steroids in the management of chronic spinal pain and radiculopathy. Pain Physician 2003; 6:319-334.

29. Koes BW, Scholten RJ, Mens JMA, Bouter LM. Epidural steroid injections for low back pain and sciatica. An updated systematic review of randomized clinical trials. Pain Digest 1999; 9:241-247.

30. Bogduk N, Christophidis N, Cherry D. Epidural use of steroids in the management of back pain. Report of working party on epidural use of steroids in the management of back pain. National Health and Medical Research Council. Canberra, Commonwealth of Australia, 1994, pp 176.

31. Bigos SJ, Boyer OR, Braen GR, Brown K, Deyo R. Acute Low Back Problems in Adults. Clinical Practice Guideline Number 4. AHCPR Publication No. 95-0642. Agency for Health Care Policy and Research, Public Health Service, US Department of Health and Human Services, Rockville, December 1994.

32. Bogduk N. International Spinal Injection Society guidelines for the performance of spinal injection procedures. Part 1: Zygapophyseal joint blocks. Clin J Pain 1997; 13:285-302.

33. Boswell MV, Singh V, Staats PS, Hirsch JA. Accuracy of precision diagnostic blocks in the diagnosis of chronic spinal pain of facet or zygapophysial joint origin. Pain Physician 2003; 6:449-456.

34. American Geriatrics Society. The management of chronic pain in older persons: New guidelines from the American Geriatrics Society. J Am Geriatr Soc 1998; 46: 128-150.

35. van Tulder MWV, Koes BW, Bouter LM Conservative treatment of acute and chronic nonspecific low back pain. A systematic review of randomized controlled trials of the most common interventions. Spine 1997; 22:2128-2156.

36. Saal JS. General principles of diagnostic testing as related to painful lumbar spine disorders. Spine 2002; 27:2538-2545

37. Guyer R, Ohnmeiss D. Lumbar discography. Spine J 2003-3:11S-27S.

38. Slipman CW, Bhat AL, Gilchrist RV, Issac Z, Chou L, Lenrow DA. A critical review of the evidence for the use of zygapophysial injections and radiofrequency denervation in the treatment of low back pain. Spine J $2003 ; 3: 310-316$.

40. Turner J, Loeser J, Deyo R, Sanders SB Spinal cord stimulation for patients with failed back surgery syndrome or complex regional pain syndrome: A systemic review of effectiveness and complications. Pain 2004; 108:137-147.

41. Whiting P, Rutjes A, Reitsma J, Bossuyt P, Kleijnen J. The Development of QUADAS: A tools for the quality assessment of stud ies of diagnostic accuracy included in systematic reviews. BMC Med Res Methodol 2003; 3:25.

42. http://www.consort-statement.org/ 
QUOROM.pdf

43. Bossuyt PM, Reitsma JB, Bruns DE, Gatsonis CA, Glasziou PP, Irwig LM, Lijmer JG, Moher D, Rennie D, de Vet HC; Standards for Reporting of Diagnostic Accuracy. Towards complete and accurate reporting of studies of diagnostic accuracy: The STARD initiative. Clin Chem 2003; 49:16. http://www.clinchem.org/cgi/content/ full/49/1/1

44. Stroup DF, Berlin JA, Morton SC, Olkin I, Williamson GD, Rennie D, Moher D, Becker BJ, Sipe TA, Thacker SB. Meta-analysis of observational studies in epidemiology: A proposal for reporting. JAMA 2000; 283: 2008-2012.

45. Moher D, Schulz KF, Altman D, for the CONSORT Group. The CONSORT statement: revised recommendations for improving the quality of report of parallel-group randomized trials. JAMA. 2001; 285:19871991.

46. Verhaak PF, Kerssens JJ, Dekker J, Sorbi MJ, Bensing JM. Prevalence of chronic benign pain disorder among adults: A review of the literature. Pain 1998; 77:231-239.

47. Blyth FM, March LM, Brnabic AJ, Jorm LR, Williamson M, Cousins MJ. Chronic pain in Australia: A prevalence study. Pain 2001; 89:127-134.

48. Rustoen T, Wahl AK, Hanestad BR, Lerdal A, Paul S, Miaskowski C. Prevalence and characteristics of chronic pain in the general Norwegian population. Eur J Pain 2004; 8:555-565.

49. Buskila D, Abramov G, Biton A, Neumann L. The prevalence of pain complaints in a general population in Israel and its implications for utilization of health services. J Rheumatol 2000; 27:1521-1525.

50. Catala E, Reig E, Artes M, Aliaga L, Lopez JS, Segu JL. Prevalence of pain in the Spanish population: telephone survey in 5000 homes. Eur J Pain 2002; 6:133-140.

51. Ng KF, Tsui SL, Chan WS. Prevalence of common chronic pain in Hong Kong adults. Clin J Pain 2002; 18:275-281.

52. Gureje O, Von Korff M, Simon GE, Gater R. Persistent pain and well-being: a World Health Organization Study in Primary Care. JAMA 1998; 280:147-151.

53. Elliott AM, Smith BH, Hannaford PC, Smith WC, Chambers WA. The course of chronic pain in the community: Results of a 4-year follow-up study. Pain 2002; 99:299-307.

54. Yeung SS, Genaidy A, Deddens J, Alhe$\operatorname{mood}$ A, Leung PC. Prevalence of musculoskeletal symptoms in single and multiple body regions and effects of perceived risk of injury among manual handling workers. Spine 2002; 27:2166-2172.

55. Menefee LA, Cohen MJ, Anderson WR, Doghramji K, Frank ED, Lee H. Sleep disturbance and nonmalignant chronic pain: A comprehensive review of the literature. Pain Med 2000; 1:156-172.

56. Bressler HB, Keyes WJ, Rochon PA, Badley $E$. The prevalence of low back pain in the elderly. A systemic review of the litera- ture. Spine 1999; 24:1813-1819.

57. Lawrence RC, Helmick CG, Arnett FC. Estimates of the prevalence of arthritis and selected musculoskeletal disorders in the United States. Arthritis Rheum 1998; 41: 778-799.

58. Barajas C, Bosch F, Baños J. A pilot survey of pain prevalence in schoolchildren. Pain Clin 2001; 13:95-102.

59. Hakala P, Rimpela A, Salminen JJ, Virtanen SM, Rimpela M. Back, neck, and shoulder pain in Finnish adolescents: National cross sectional surveys. BMJ 2002; 325 : 743 .

6o. Cassidy JD, Carroll LJ, Cotê P: The Saskatchewan Health and Back Pain Survey. The prevalence of low back pain and related disability in Saskatchewan Adults. Spine 1998; 23:1860-1867.

61. Vingard E, Mortimer M, Wiktorin C, Pernold R P T G, Fredriksson K, Nemeth G, Alfredsson L; Musculoskeletal Intervention Center-Norrtalje Study Group.. Seeking care for low back pain in the general population: A two-year follow-up study: Results from the MUSIC-Norrtalje Study. Spine 2002; 27:2159-2165

62. Walker BF, Muller R, Grant WD. Low back pain in Australian adults: prevalence and associated disability. J Manipulative Physiol Ther 2004; 27:238-244.

63. Guo HR, Tanaka S, Halperin WE, Cameron LL. Back pain prevalence in US industry and estimates of lost workdays. Am J Public Health 1999; 89:1029-1035.

64. Côté P, Cassidy JD, Carroll L. The Saskatchewan Health and Back Pain Survey. The prevalence of neck pain and related disability in Saskatchewan adults. Spine 1998; 23:1689-1698.

65. Croft PR, Lewis M, Papageorgiou AC Thomas E, Jayson MI, Macfarlane GJ, Silman AJ. Risk factors for neck pain: A longitudinal study in the general population. Pain 2001; 93:317-325.

66. Leclerc A, Niedhammer I, Landre MF, Ozguler A, Etore P, Pietri-Taleb F. Oneyear predictive factors for various aspects of neck disorders. Spine 1999; 24:14551462.

67. Tousignant M, Duclos E, Lafleche S, Mayer A, Tousignant-Laflamme Y, Brosseau L, O'Sullivan J. Validity study for the cervical range of motion device used for lateral flexion in patients with neck pain. Spine 2002; 27:812-817.

68. Uhrenholt L, Grunnet-Nilsson N, Hartvigsen J. Cervical spine lesions after road traffic accidents: a systematic review. Spine 2002; 27:1934-1941.

69. Haldeman S, Dagenais S. Cervicogenic headaches: a critical review. Spine / 2001; 1:31-46.

70. Singer KP, Edmondston SJ. Introduction: The enigma of the thoracic spine. In Giles GF, Singer KP (eds). Clinical Anatomy and Management of Thoracic Spine Pain. Butternorth Heineman, Boston, 2000, pp 3 15.
71. Hartvigsen J, Christensen K, Frederiksen H. Back and neck pain exhibit many common features in old age: a population-based study of 4,486 Danish twins 70-102 years of age. Spine 2004; 29:576-580.

72. Enthoven P, Skargren E, Oberg B. Clinical course in patients seeking primary care for back or neck pain: A prospective 5-year follow-up of outcome and health care consumption with subgroup analysis. Spine 2004; 29:2458-2465.

73. Sjolie AN. Persistence and change in nonspecific low back pain among adolescents: a 3-year prospective study. Spine 2004; 29:2452-2457.

74. Brattberg G. Do pain problems in young school children persist into early adulthood? A 13-year follow-up. Eur J Pain 2004; 8:187-199.

75. Elders LA, Burdorf A. Prevalence, incidence, and recurrence of low back pain in scaffolders during a 3-year follow-up study. Spine 2004; 29:E101-E106.

76. Hoving JL, de Vet HC, Twisk JW, Deville WL, van der Windt D, Koes BW, Bouter LM. Prognostic factors for neck pain in general practice. Pain 2004; 110:639-645.

77. Smith BH, Elliott AM, Hannaford PC, Chambers WA, Smith WC. Factors related to the onset and persistence of chronic back pain in the community: results from a general population follow-up study. Spine 2004; 29:1032-1040.

78. Cote P, Cassidy JD, Carroll LI, Kristman V. The annual incidence and course of neck pain in the general population: a population-based cohort study. Pain 2004; 112: 267-273.

79. Picavet HS, Schouten JS. Musculoskeletal pain in the Netherlands: prevalences, consequences and risk groups, the DMC(3)study. Pain 2003; 102:167-178.

80. van der Windt D, Croft P, Penninx B. Neck and upper limb pain: more pain is associated with psychological distress and consultation rate in primary care. I Rheumatol 2002; 29:564-569.

81. Daffner SD, Hilibrand AS, Hanscom BS, Brislin BT, Vaccaro AR, Albert TJ. Impact of neck and arm pain on overall health status. Spine 2003; 28:2030-2035.

82. Latza U, Kohlmann T, Deck R, Raspe H. Can health care utilization explain the association between socioeconomic status and back pain? Spine 2004; 29:1561-1566.

83. Dionne CE, Chenard M. Back-related functional limitations among full-time homemakers: a comparison with women employed full-time outside the home. Spine 2004; 29:1375-1382.

84. Luo X, Pietrobon R, Sun SX, Liu GG, Hey L. Estimates and patterns of direct health care expenditures among individuals with back pain in the United States. Spine 2004; 29:79-86.

85. Reyes-Gibby CC, Aday L, Cleeland C. Impact of pain on self-rated health in the community-dwelling older adults. Pain 2002; 95:75-82. 
86. McGorry RW, Webster BS, Snook SH, Hsiang SM. The relation between pain intensity, disability, and the episodic nature of chronic and recurrent low back pain. Spine 2000; 25:834-841.

87. Oleske DM, Andersson GB, Lavender SA, Hahn JJ. Association between recovery outcomes for work-related low back disorders and personal, family, and work factors. Spine 2000; 25:1259-1265.

88. Leigh JP, Markowitz SB, Fahs M, Shin C, Landrigan PJ. Occupational injury and illness in the United States. Estimates of costs, morbidity, and mortality. Arch Intern Med 1997; 157:1557-1568.

89. Freedman VA, Martin LG, Schoeni RF. Recent trends in disability and functioning among older adults in the united states. JAMA 2002; 288:3137-3146.

90. Eriksen J, Sjogren P, Ekholm O, Rasmussen NK. Health care utilisation among individuals reporting long-term pain: an epidemiological study based on Danish National Health Surveys. Eur J Pain 2004; 8:517523.

91. Ohayon MM, Schatzberg AF. Using chronic pain to predict depressive morbidity in the general population. Arch Gen Psychiatry 2003; 60:39-47.

92. Hurwitz EL, Morgenstern H, Yu F. Crosssectional and longitudinal associations of low-back pain and related disability with psychological distress among patients enrolled in the UCLA Low-Back Pain Study. J Clin Epidemiol 2003; 56:463-471.

93. Turner JA, Franklin G, Heagerty PJ, Wu R, Egan K, Fulton-Kehoe D, Gluck JV, Wickizer TM. The association between pain and disability. Pain 2004; 112:307-314.

94. Hough J. Estimating the health care utilization costs associated with people with disabilities: Data from the 1996 Medical Expenditure Panel Survey (MEPS). Annual meeting of the Association for Health Services Research, Los Angeles, California, 2000.

95. Bell G, Kidd D, North R. Cost-effectiveness analysis of spinal cord stimulation in treatment of failed back surgery syndrome. Pain Symp Manage 1997; 13:286-295.

96. de Lissovoy G, Brown RE, Halpern M, Hassenbusch SJ, Ross E. Cost-effectiveness of long-term intrathecal morphine therapy for pain associated with failed back surgery syndrome. Clin Ther 1997; 19:96-112.

97. Turk DC. Clinical effectiveness and costeffectiveness of treatments for patients with chronic pain. Clin J Pain 2002; 18: 355-365.

98. Walker BF, Muller R, Grant WD. Low back pain in Australian adults: the economic burden. Asia Pac J Public Health 2003; 15: 79-87.

99. Gagliese L, Katz J. Medically unexplained pain is not caused by psychopathology. Pain Res Manage 2000; 5:251-257.

100. Bogduk N, McGuirk B (eds). Causes and sources of chronic low back pain. In Medical Management of Acute and Chronic Low
Back pain. An Evidence-Based Approach: Pain Research and Clinical Management, Vol. 13, Elsevier Science BV, Amsterdam, 2002, pp 115-126.

101. Bogduk N. Low back pain. In Clinical Anatomy of the Lumbar Spine and Sacrum, ed 3. Churchill Livingstone, New York, 1997, pp 187-214.

102. Kuslich SD, Ulstrom CL, Michael CJ. The tissue origin of low back pain and sciatica: A report of pain response to tissue stimulation during operation on the lumbar spine using local anesthesia. Orthop Clin North Am 1991; 22:181-187.

103. Pang WW, Mok MS, Lin ML, Chang DP, Hwang MH. Application of spinal pain mapping in the diagnosis of low back pain - analysis of 104 cases. Acta Anaesthesiol Sin 1998; 36:71-74.

104. Manchikanti L, Singh V, Pampati V, Damron K, Barnhill R, Beyer C, Cash K. Evaluation of the relative contributions of various structures in chronic low back pain. Pain Physician 2001; 4:308-316.

105. Bogduk N. The zygapophysial joints. In Clinical Anatomy of the Lumbar Spine and Sacrum, Third edition. Churchill Livingstone, New York, 1997, pp 33-41.

106. Fukui S, Ohseto K, Shiotani M, Ohno K, Karasawa H, Naganuma Y, Yuda Y. Referred pain distribution of the cervical zygapophyseal joints and cervical dorsal rami. Pain 1996; 68:79-83.

107. Dwyer A, Aprill C, Bogduk N. Cervical zygapophyseal joint pain patterns: A study in normal volunteers. Spine 1990; 15:453457.

108. Aprill C, Dwyer A, Bogduk N. The prevalence of cervical zygapophyseal joint pain patterns II: A clinical evaluation. Spine 1990; 15:458-461.

109. Pawl RP. Headache, cervical spondylosis, and anterior cervical fusion. Surg Ann 1977; 9:391-498.

110. Windsor RE, Nagula D, Storm S. Electrical stimulation induced cervical medial branch referral patterns. Pain Physician.2003; 6:411-418.

111. Dreyfuss P, Tibiletti C, Dreyer SJ. Thoracic zygapophyseal joint pain patterns: A study in normal volunteers. Spine 1994; 19:807-811.

112. Mooney V, Robertson J. The facet syndrome. Clin Orthop 1976; 115:149-156.

113. McCall IW, Park WM, O'Brien JP. Induced pain referral from posterior elements in normal subjects. Spine 1979; 4:441-446.

114. Marks R. Distribution of pain provoked from lumbar facet joints and related structures during diagnostic spinal infiltration. Pain 1989; 39:37-40.

115. Fukui S, Ohseto K, Shiotani M, Ohno K, Karasawa H, Naganuma Y. Distribution of referral pain from the lumbar zygapophyseal joints and dorsal rami. Clin J Pain 1997; 13:303-307.

116. Hirsch C, Ingelmark BE, Miller M. The anatomical basis for low back pain. Acta Or- thop Scand 1963; 33:1-17.

117. Windsor RE, King FJ, Roman SJ, Tata N, Cone-Sullivan LA, Thampi S, Acebey M, Gilhool JJ, Rao R, Sugar R. Electrical Stimulation Induced Lumbar Medial Branch Referral Patterns. Pain Physician 2002; 5: 347-353.

118. Bogduk N. The clinical anatomy of the cervical dorsal rami. Spine 1982; 7:319-330.

119. Cavanaugh JM, Ozaktay AC, Yamashita T, Avramov A, Getchell TV, King Al. Mechanisms of low back pain: A neurophysiologic and neuroanatomic study. Clin Orthop 1997; 335:166-180.

120. Bogduk N, Wilson AS, Tynan W. The human lumbar dorsal rami. J Anat 1982; 134: 383-397.

121. Ohtori S, Takahashi K, Chiba T, Yamagata M, Sameda H, Moriya H. Sensory innervation of the cervical facet joints in rats. Spine 2001; 26:147-150.

122. Chua WH, Bogduk N. The surgical anatomy of thoracic facet denervation. Acta Neurochir 1995; 136:140-144.

123. Barnsley L, Bogduk N. Medial branch blocks are specific for the diagnosis of cervical zygapophyseal joint pain. Reg Anesth 1993; 18:343-350.

124. Zhang J, Tsuzuki N, Hirabayashi S, Saiki K, Fujita K. Surgical anatomy of the nerves and muscles in the posterior cervical spine. Spine 2003; 1379-1384.

125. Dreyfuss P, Schwarzer AC, Lau P, Bogduk N. Specificity of lumbar medial branch and L5 dorsal ramus blocks. Spine 1997; 22:895-902.

126. Kaplan M, Dreyfuss P, Halbrook B, Bogduk $N$. The ability of lumbar medial branch blocks to anesthetize the zygapophysial joint. Spine 1998; 23:1847-1852.

127. Özaktay AC, Yamashita T, Cavanaugh JM, King Al. Fine nerve fibers and endings in the fibrous capsule of the lumbar facet joint. Trans Orthop Res Soc 1991; 16:353.

128. Inami S, Shiga T, Tsujino A, Yabuki T, Okado $\mathrm{N}$, Ochiai N. Immunohistochemical demonstration of nerve fibers in the synovial fold of the human cervical facet joint. J Orthop Res 2001; 19:593-596.

129. Kallakuri S, Singh A, Chen C, Cavanaugh JM. Demonstration of substance P, calcitonin gene-related peptide, and protein gene product 9.5 containing nerve fibers in human cervical facet joint capsules. Spine 2004; 29:1182-1186.

130. Igarashi A, Kikuchi S, Konno S, Olmarker K. Inflammatory cytokines released from the facet joint tissue in degenerative lumbar spinal disorders. Spine 2004; 29:20912095.

131. McLain RF, Pickar JG. Mechanoreceptor endings in human thoracic and lumbar facet joints. Spine 1998; 23:168-173.

132. McLain RF. Mechanoreceptors ending in human cervical facets joints. Spine 1994; 5:495-501.

133. Yamashita T, Cavanaugh JM, el-Bohy AA, Getchell TV, King Al. Mechanosensitive 
afferent units in the lumbar facet joint. J Bone Joint Surg (Am) 1990; 72:865-870.

134. Merskey H, Bogduk N. Classification of chronic pain: Descriptions of chronic pain syndromes and definitions of pain terms. Second Edition. IASP Press, Seattle, 1994.

135. Schwarzer AC, Aprill CN, Derby R, Fortin J, Kine G, Bogduk N. Clinical features of patients with pain stemming from the lumbar zygapophysial joints. Is the lumbar facet syndrome a clinical entity? Spine 1994; 19:1132-1137.

136. Schwarzer AC, Aprill CN, Derby R, Fortin J, Kine G, Bogduk N. The relative contributions of the disc and zygapophyseal joint in chronic low back pain. Spine 1994; 19: 801-806.

137. Schwarzer AC, Wang SC, Bogduk N, MCNaught PJ, Laurent R. Prevalence and clinical features of lumbar zygapophysial joint pain: A study in an Australian population with chronic low back pain. Am Rheum Dis 1995; 54:100-106.

138. Manchikanti L, Pampati V, Fellows B, Bakhit C. Prevalence of lumbar facet joint pain in chronic low back pain. Pain Physician 1999; 2:59-64.

139. Manchikanti L, Pampati V, Fellows B, Bakhit CE. The diagnostic validity and therapeutic value of medial branch blocks with or without adjuvants agents. Curr Rev Pain 2000; 4:337-344.

140. Manchikanti L, Pampati V, Fellows B, Baha AG. The inability of the clinical picture to characterize pain from facet joints. Pain Physician 2000; 3:158-166.

141. Manchikanti L, Boswell MV, Singh V, Pampati V, Damron KS, Beyer CD. Prevalence of facet joint pain in chronic spinal pain of cervical, thoracic, and lumbar regions. BMC Musculoskelet Disord 2004; 5:15.

142. Manchikanti L, Hirsch JA, Pampati V. Chronic low back pain of facet (zygapophysial) joint origin: is there a difference based on involvement of single or multiple spinal regions? Pain Physician 2003; 6:399-405.

143. Manchikanti L, Singh V, Pampati S, Damron K, Beyer C, Barnhill R. Is there correlation of facet joint pain in lumbar and cervical spine? Pain Physician 2002; 5:365371.

144. Barnsley L, Lord SM, Wallis BJ, Bogduk $\mathrm{N}$. The prevalence of chronic cervical zygapophyseal joint pain after whiplash. Spine 1995; 20:20-26.

145. Lord SM, Barnsley L, Wallis BJ, Bogduk N. Chronic cervical zygapophysial joint pain with whiplash: A placebo-controlled prevalence study. Spine 1996; 21:1737-1745.

146. Manchikanti L, Singh V, Rivera J, Pampati V. Prevalence of cervical facet joint pain in chronic neck pain. Pain Physician 2002; 5 : 243-249.

147. Manchikanti L, Singh, V, Pampati V, Beyer C, Damron K. Evaluation of the prevalence of facet joint pain in chronic thoracic pain. Pain Physician 2002; 5:354-359.

148. Wheeler AH, Murrey DB. Chronic lumbar spine and radicular pain: Pathophysiology and treatment. Curr Pain Headache Rep 2002; 6:97-105.

149. Bogduk N, Windsor M, Inglis A. The innervation of the cervical intervertebral discs. Spine 1988; 13:2-8.

150. Mendel T, Wink CS, Zimny ML. Neural elements in human cervical intervertebral discs. Spine 1992; 17:132-135.

151. Bogduk N, Tynan W, Wilson AS. The nerve supply to the human lumbar intervertebral discs. J Anat 1981; 132:39-56.

152. Freemont AJ, Peacock TE, Goupille P, Hoyland JA, O'Brien J, Jayson MI.. Nerve ingrowth into diseased intervertebral disc in chronic back pain. Lancet 1997; 350:178 181.

153. Coppes MH, Marani E, Thomeer RT, Oudega $M$, Groen GJ. Innervation of annulus fibrosus in low back pain. Lancet 1990; 336:189-190.

154. Coppes MH, Marani E, Thomeer RT, Groen GJ. Innervation of "painful" lumbar discs. Spine 1997; 22:2342-2350.

155. Nakamura S, Takahashi K, Takahashi Y, Morinaga T, Shimada Y, Moriya H. Origin of nerves supplying the posterior portion of lumbar intervertebral discs in rats. Spine 1996; 21:917-924.

156. Morinaga T, Takahashi K, Yamagata M, Chiba T, Tanaka K, Takahashi Y, Nakamura S, Suseki K, Moriya H. Sensory innervation to the anterior portion of lumbar intervertebral disc. Spine 1996; 21:1848-1851.

157. Ohtori S, Takahashi Y, Takahashi K, Yamagata M, Chiba T, Tanaka K, Hirayama J, Moriya $\mathrm{H}$. Sensory innervation of the dorsal portion of the lumbar intervertebral disc in rats. Spine 1999; 24:2295-2299.

158. Groen G, Baljet B, Drukker J. Nerves and nerve plexuses of the human vertebral column. Am J Anat 1990; 188:282-296.

159. Fagan A, Moore R, Vernon Roberts B, Blumbergs $P$, Fraser $R$. The innervation of the intervertebral disc: A quantitative analysis. Spine 2003; 28:2570-2576.

160. Cavanaugh JM, Kallakuri S, Ozaktay AC. Innervation of the rabbit lumbar intervertebral disc and posterior longitudinal ligament. Spine 1995; 20:2080-2085.

161. Palmgren T, Gronblad M, Virri J, Kaapa E, Karaharju E. An immunohistochemical study of nerve structures in the anulus fibrosus of human normal lumbar intervertebral discs. Spine 1999; 24:2075-2079.

162. Ashton IK, Roberts S, Jaffray DC, Polak $J M$, Eisenstein SM. Neuropeptides in the human intervertebral disc. J Orthop Res 1994; 12:186-192.

163. Shinohara H. Lumbar disc lesion, with special reference to the histological significane of nerve endings of the lumbar discs. J Jap Orthop Assoc 1970; 44:553570.

164. Roofe PG. Innervation of annulus fibrosis and posterior longitudinal ligament. Arch Neurol Psych 1940; 44:100-103.

165. Malinsky J. The ontogenetic development of nerve trigeminations in the intervertebral discs of man. Acta Anat 1959; 38:96113

166. Yoshizawa H, O’Brien JP, Smith WT, Trumper M. The neuropathology of intervertebral discs removed for low back pain. J Pathol 1980; 132:95-104

167. Roberts S, Eisenstein SM, Menage J, Evans EH, Ashton IK. Mechanoreceptors in intervertebral discs. Spine 1995; 24:26452651.

168. Hurri H, Karppinen J. Discogenic pain. Pain 2004; 112:225-228.

169. Aoki Y, Ohtori S, Takahashi K, Ino H, Takahashi Y, Chiba T, Moriya H. Innervation of the lumbar intervertebral disc by nerve growth factor-dependent neurons related to inflammatory pain. Spine $2004 ; 29$ : 1077-1081.

170. Ohtori S, Takahashi K, Chiba T, Yamagata $M$, Sameda H, Moriya H. Sensory innervation of the dorsal portion of the lumbar intervertebral discs in rats. Spine 2001; 26 : 946-950.

171. O'Neill CW, Kurgansky ME, Derby R, Ryan DP. Disc stimulation and patterns of referred pain. Spine 2002; 27:2776-2781.

172. Derby R, Eek B, Lee SH, Seo S, Kim BJ. Comparison of intradiscal restorative injections and intradiscal electrothermal treatment (IDET) in the treatment of low back pain. Pain Physician 2004; 7:63-66.

173. Mixter WJ, Barr JS. Rupture of the intervertebral disc with involvement of the spinal canal. N Eng J Med 1934; 211:210-215.

174. Mixter WJ, Ayers JB. Herniation or rupture of the intervertebral disc into the spinal canal. N Engl J Med 1935; 213:385-395.

175. Aoki Y, Takahashi Y, Ohtori S, Moriya H, Takahashi K. Distribution and immunocytochemical characterization of dorsal root ganglion neurons innervating the lumbar intervertebral disc in rats: a review. Life Sci 2004; 74:2627-2642.

176. Freemont AJ, Watkins A, Le Maitre C, Baird P, Jeziorska M, Knight MT, Ross ER, O'Brien JP, Hoyland JA. Nerve growth factor expression and innervation of the painful intervertebral disc. J Pathol 2002; 197:286292.

177. Burke JG, Watson RW, McCormack D, Dowling FE, Walsh MG, Fitzpatrick JM. Intervertebral discs which cause low back pain secrete high levels of proinflammatory mediators. J Bone Joint Surg Br 2002; 84:196201.

178. Burke JG, G Watson RW, Conhyea D, MCCormack D, Dowling FE, Walsh MG, Fitzpatrick JM. Human nucleus pulposis can respond to a pro-inflammatory stimulus. Spine 2003; 28:2685-2693.

179. McCarron RF, Wimpee MW, Hudkins PG, Laros GS. The inflammatory effects of nucleus pulposus: A possible element in the pathogenesis of low back pain. Spine 1987; 12:760-764.

180. Olmarker K, Blomquist J, Stromberg J, Nannmark U, Thomsen P, Rydevik B. Inflammatogenic properties of nucleus pulpo- 
sus. Spine 1995; 20:665-669.

181. Marshall LL, Trethewie ER, Curtain CC. Chemical radiculitis: A clinical, physiological, and immunological study. Clin Orthop Rel Res 1977; 190:61-67.

182. Olmarker K, Nordborg C, Larsson K, Rydevik B. Ultrastructural changes in spinal nerve roots induced by autologous nucleus pulposus. Spine 1996; 27:411-414.

183. Olmarker K, Rydevik B, Nordborg C. Autologous nucleus pulposus induces neurophysiologic and histologic changes in porcine cauda equina nerve roots. Spine 1993; 18:1425-1432.

184. Uchida K, Baba H, Maezawa Y, Kubota C. Progressive changes in neurofilament proteins and growth-associated protein-43 immunoreactivities at the site of cervical spinal cord compression in spinal hyperostotic mice. Spine 2002; 27:480-486.

185. Olmarker K, Rydevik B, Holm S. Edema formation in spinal nerve roots induced by experimental, graded compression: An experimental study on the pig cauda equina with special reference to differences in effects between rapid and slow onset of compression. Spine 1989; 14:569-573.

186. Olmarker K, Rydevik B, Holm S, Bagge U. Effects of experimental graded compression on blood flow in spinal nerve roots: $A$ vital microscopic study on the porcine cauda equina. J Orthop Res 1989; 7:817-823.

187. Olmarker K, Holm S, Rydevik B. Importance of compression onset rate for the degree of impairment of impulse propagation in experimental compression injury of the porcine cauda equina. Spine 1990; 35: 416-419.

188. Rydevik BL. The effects of compression on the physiology of nerve roots. I Manipul Physiol Ther 1992; 1:62-66.

189. Olmarker $\mathrm{K}$, Holm S, Rosenqvist $\mathrm{AL}$, Rydevik B. Experimental nerve root com pression. Presentation of a model for acute, graded compression of the porcine cauda equina, with analysis of neural and vascular anatomy. Spine 1992; 16:61-69.

190. Kawakami M, Tamaki T, Hashizume $H$, Weinstein JN, Meller ST. The role of phospholipase $A_{2}$ and nitric oxide in pain-related behavior produced by an allograft of intervertebral disc material to the sciatic nerve of the rat. Spine 1997; 22:1074 1079.

191. Saal JS, Franson RC, Dobrow R, Saal JA, White $\mathrm{AH}$, Goldthwaite N. High levels of inflammatory phospholipase A2 activity in lumbar disc herniations. Spine 1990; 15: 674-678.

192. Yabuki S, Kikuchi S, Olmarker K, Myers RR. Acute effects of nucleus pulposus on blood flow and endoneurial fluid pressure in rat dorsal root ganglia. Spine 1998; 23 : 2517-2523.

193. Yabuki S, Igarashi T, Kikuchi S. Application of nucleus pulposus to the nerve root simultaneously reduces blood flow in dorsal root ganglion and corresponding hindpaw in the rat. Spine 2000; 25:1471-1476.
194. Kang JD, Georgescu HI, Mclntyre-Larkin L, Stefanovic-Racic M, Donaldson WF zrd, Evans $\mathrm{CH}$. Herniated lumbar intervertebral discs spontaneously produce matrix metalloproteinases, nitric oxide, interleukin-6, and prostaglandin $E_{2}$. Spine 1996; 21:271-277.

195. Kang JD, Stefanovic-Racic M, McIntyre LA, Georgescu HI, Evans CH. Toward a biochemical understanding of human intervertebral disc degeneration and herniation. Contributions of nitric oxide, interleukins, prostaglandin $E_{2}$, and matrix metalloproteinases. Spine 1997; 22:1065-1073.

196. Takahashi H, Suguro T, Okazima Y, Motegi M, Okada Y, Kakiuchi T. Inflammatory cytokines in the herniated disc of the lumbar spine. Spine 1996; 21:218-224.

197. Olmarker K, Rydevik B. Selective inhibition of tumor necrosis factor-alpha prevents nucleus pulposus-induced thrombus formation, intraneural edema, and reduction of nerve conduction velocity: possible implications for future pharmacologic treatment strategies of sciatica. Spine 2001; 26:863-869.

198. Igarashi T, Kikuchi S, Shubayev V, Myers RR. 2000 Volvo Award winner in basic science studies: Exogenous tumor necrosis factor-alpha mimics nucleus pulposus-induced neuropathology. Molecular, histologic, and behavioral comparisons in rats. Spine 2000; 25:2975-2980.

199. Homma Y, Brull SJ, Zhang JM. A comparison of chronic pain behavior following local application of tumor necrosis factor alpha to the normal and mechanically compressed lumbar ganglia in the rat. Pain 2002; 95:239-246.

200. Miyamoto H, Saura R, Doita M, Kurosaka $M$, Mizuno K. The role of cyclooxygenase2 in lumbar disc herniation. Spine 2002; 27:2477-2483.

201. Milette PC, Fontaine S, Lepanto L, Breton G. Radiating pain to the lower extremities caused by lumbar disc rupture without spinal nerve root involvement. $A m$ J Neuroradiol 1995; 16:1605-1615.

202. Crock HV. Isolated lumbar disc resorption as a cause of nerve root canal stenosis. Clin Orthop 1976; 115:109-115.

203. Holm S, Holm AK, Ekstrom L, Karladani A, Hansson T. Experimental disc degeneration due to endplate injury. J Spinal Disord Tech 2004; 17:64-71.

204. Videman T, Nurminen M. The occurrence of anular tears and their relation to lifetime back pain history: a cadaveric study using barium sulfate discography. Spine 2004; 29:2668-2676.

205. Rajasekaran S, Babu JN, Arun R, Armstrong BR, Shetty AP, Murugan S. ISSLS prize winner: A study of diffusion in human lumbar discs: a serial magnetic resonance imaging study documenting the influence of the endplate on diffusion in normal and degenerate discs. Spine 2004; 29:26542667.

206. Boos N, Weissbach S, Rohrbach H, Weiler
C, Spratt KF, Nerlich AG. Classification of age-related changes in lumbar intervertebral discs: 2002 Volvo Award in basic science. Spine 2002; 27:2631-2644.

207. Roberts S, Urban JP, Evans H, Eisenstein SM. Transport properties of the human cartilage endplate in relation to its composition and calcification. Spine 1996; 21: 415-420.

208. Kauppila LI, McAlindon T, Evans S, Wilson PW, Kiel D, Felson DT. Disc degeneration/ back pain and calcification of the abdominal aorta. A 25-year follow-up study in Framingham. Spine 1997; 22:1642-1647.

209. Peng BG, Wu WW, Hou SX, Zhang CL, Yang $\mathrm{Y}$, Wang $\mathrm{XH}$, Fu XB. The pathogenesis of discogenic low back pain. Zhonghua Wai Ke Za Zhi 2004; 42:720-724.

210. Schwarzer AC, Aprill CN, Derby R, Fortin J, Kine G, Bogduk N. The prevalence and clinical features of internal disc disruption in patients with chronic low back pain. Spine 1995; 20:1878-1883.

211. Bogduk N, Aprill C. On the nature of neck pain, discography, and cervical zygapophyseal joint blocks. Pain 1993; 54:213-217.

212. Aota Y, Onari K, An HS, Yoshikawa K. Dorsal root ganglia morphologic features in patients with herniation of the nucleus pulposus. Assessment using magnetic resonance myelography and clinical correlation. Spine 2001; 26:2125-2132.

213. Rydevik BL, Myers RR, Powell HC. Pres sure increase in the dorsal root ganglion following mechanical compression: Closed compartment syndrome in nerve roots. Spine 1989; 14:574-576.

214. Weinstein J. Mechanisms of spinal pain The dorsal root ganglion and its role as a pain mediator of low-back pain. Spine 1986; 11:999-1001.

215. Byrod G, Otani K, Brisby H, Rydevik B, Olmarker K. Methylprednisolone reduces the early vascular permeability increase in spinal nerve roots induced by epidural nucleus pulposus application. J Orthop Res 2000; 18:983-987.

216. Harrington JF, Messier AA, Bereiter D, Barnes B, Epstein MH. Herniated lumbar disc material as a source of free glutamate available to affect pain signals through the dorsal root ganglion. Spine 2000; 25:929936.

217. Cavanaugh JM, Ozaktay AC, Vaidyanathan S. Mechano- and chemosensitivity of lumbar dorsal roots and dorsal root ganglia: An in vitro study. Trans Orthop Res Soc 1994; 19:109.

218. Iwabuchi M, Rydevik B, Kikuchi S, Olmark er K. Effects of anulus fibrosus and experimentally degenerated nucleus pulposus on nerve root conduction velocity: relevance of previous experimental investigations using normal nucleus pulposus. Spine 2001; 26:1651-1655.

219. Takebayashi T, Cavanaugh JM, Cuneyt Ozaktay A, Kallakuri S, Chen C. Effect of nucleus pulposus on the neural activity of dorsal root ganglion. Spine 2001; 26:940- 
945.

220. Aoki Y, Ohtori S, Ino H, Douya H, Ozawa T, Saito T, Moriya H, Takahashi K. Disc inflammation potentially promotes axonal regeneration of dorsal root ganglion neurons innervating lumbar intervertebral disc in rats. Spine 2004; 29:2621-2626.

221. Snider WD, McMahon SB. Tackling pain at the source: new ideas about nociceptors. Neuron 1998; 20:629-632.

222. Fortin JD, Kissling RO, O'Connor BL, Vilensky JA. Sacroiliac joint innervation and pain. Am J Orthop 1999; 28:687-690.

223. Grob KR, Neuhuber WL, Kissling RO. Innervation of the sacroiliac joint of the human. Z Rheumatol 1995; 54:117-122.

224. Ikeda R. Innervation of the sacroiliac joint. Macroscopical and histological studies. Nippon Ika Daigaku Zasshi 1991; 58:587596.

225. Vilensky JA, O’Connor BL, Fortin JD, Merkel GJ, Jimenez AM, Scofield BA, Kleiner JB. Histologic analysis of neural elements in the human sacroiliac joint. Spine 2002; 27:1202-1207.

226. Sakamoto N, Yamashita T, Takebayashi T, Sekine M, Ishii S. An electrophysiologic study of mechanoreceptors in the sacroiliac joint and adjacent tissues. Spine 2001; 26:E468-E471.

227. Murata Y, Takahashi K, Yamagata M, Takahashi Y, Shimada Y, Moriya H. Origin and pathway of sensory nerve fibers to the ventral and dorsal sides of the sacroiliac joint in rats. J Orthop Res 2001; 19:379383.

228. Sakamoto N, Yamashita T, Takebayashi T, Sekine M, Ishii S. Mechanoreceptors in the sacroiliac joint. Trans Orthop Res Soc 1999; 24:988.

229. Yin W, Willard F, Carreiro J, Dreyfuss P. Sensory stimulation-guided sacroiliac joint radiofrequency neurotomy: Technique based on neuroanatomy of the dorsal sacral plexus. Spine 2003; 28:24192425.

230. Solonon K. The sacroiliac joint in light of anatomical, roentgenological, and clinical studies. Act Orthop Scand Suppl 1957; 27: 1-127.

231. Fortin JD, Dwyer AP, West S, Pier J. Sacroiliac joint: Pain referral maps upon applying a new injection/arthrography technique. Part I: Asymptomatic volunteers. Spine 1994; 19:1475-1482.

232. Fortin JD, Aprill CN, Ponthieux B, Pier J. Sacroiliac joints: Pain referral maps upon applying a new injection/arthrography technique. Part II: Clinical evaluation. Spine 1994; 19:1483-1489.

233. Slipman CW, Jackson HB, Lipetz JS, Chan KT, Lenrow D, Vresilovic EJ. Sacroiliac joint pain referral zones. Arch Phys Med Rehabil 2000; 81:334-337.

234. Schwarzer AC, Aprill CN, Bogduk M. The sacroiliac joint in chronic low back pain. Spine 1995; 20:31-37.

235. Maigne JY, Aivakiklis A, Pfefer F. Results of sacroiliac joint double block and value of sacroiliac pain provocation test in $54 \mathrm{pa}$ tients with low back pain. Spine 1996; 21: 1889-1892.

236. Ebraheim NA, Elgafy H, Semaan HB. Computed tomographic findings in patients with persistent sacroiliac pain after posterior iliac graft harvesting. Spine 2000; 25 : 2047-2051.

237. Katz V, Schofferman J, Reynolds J. The sacroiliac joint: a potential cause of pain after lumbar fusion to the sacrum. J Spinal Disord Tech 2003;16:96-99.

238. Schofferman J, Reynolds J, Herzog R, Covington E, Dreyfuss P, O'Neill C. Failed back surgery: etiology and diagnostic evaluation. Spine J 2003; 3:400-403.

239. Manchikanti L, Singh V. Failed back surgery: etiology and diagnostic evaluation. Letter to the Editor. Spine J 2003; 4:486488.

240. Slipman CW, Shin CH, Patel RK, Isaac Z, Huston CW, Lipetz JS, Lenrow DA, Braverman DL, Vresilovic EJ Jr. Etiologies of failed back surgery syndrome. Pain Med 2002; 3:200-214.

241. Waguespack A, Schofferman J, Slosar $P$, Reynolds J. Etiology of long-term failures of lumbar spine surgery. Pain Med 2002; 3:18-22.

242. Boden S, Bohlman H. The Failed Spine. Lippincott, Williams \& Wilkins, Philadelphia, 2003.

243. Sampath P, Bendebba M, Davis JD, Ducker T. Outcome in patients with cervical radiculopathy. Prospective, multicenter study with independent clinical review. Spine 1999; 24:591-597.

244. Law JD, Lehman RAW, Kirsch WM. Reoperation after lumbar intervertebral disc surgery. J Neurosurg 1978; 48:259-263.

245. Waddell G, Kummel EG, Lotto WN, Graham JD, Hall H, McCulloch JA. Failed lumbar disc surgery and repeat surgery following industrial injury. J Bone Joint Surg (Am) 1979; 61:201-207.

246. Ross JS, Robertson JT, Frederickson RC, Petrie JL, Obuchowski N, Modic MT, deTribolet N. Association between peridural scar and recurrent radicular pain after lumbar discectomy: Magnetic resonance evaluation. Neurosurgery 1996; 38:855863.

247. Fritsch EW, Heisel J, Rupp S. The failed back surgery syndrome. Reasons, intraoperative findings, and long-term results: A report of 182 operative treatments. Spine 1996; 21:626-633.

248. North RB, Campbell JN, James CS, Conover-Walker MK, Wang $\mathrm{H}$, Piantadosi S, Rybock JD, Long DM. Failed back surgery syndrome: 5-year follow-up in 102 patients undergoing repeated operation. Neurosurgery 1991; 28:685-691.

249. Brox JI, Sørensen R, Friis A, Nygaard Ø, Indahl A, Keller A, Ingebrigtsen T, Eriksen HR, Holm I, Koller AK, Riise R, Reikerås 0 . Randomized clinical trial of lumbar instrumented fusion and cognitive intervention and exercises in patients with chronic low back pain and disc degeneration. Spine 2003; 28:1913-1921.

250. Cherkin DC, Deyo RA, Loeser JD, Bush T, Waddell G. An international comparison of back surgery rates. Spine 1994; 19: 1201-1206.

251. Hacker RJ, Miller CG. Failed anterior cervical foraminotomy. I Neurosurg Spine 2003; 98:126-130.

252. Katz JN. Lumbar spinal fusion. Surgical rates, costs, and complications. Spine 1995; 20:78S-83S.

253. Lieberman IH. Disc bulge bubble: Spine economics 101. Spine J 2004; 4:609-613.

254. Center for Medicare and Medicaid Services Web site. Available at: www.cms.hhs.gov.

255. Deyo RA, Nachemson A, Mirza SK. Spinal fusion surgery -- The case for restraint. $N$ Engl J Med 2004; 350:722-726.

256. Osterman H, Sund R, Seitsalo S, Keskimaki I. Risk of multiple reoperations after lumbar discectomy: a population-based study. Spine 2003; 28:621-627.

257. Logroscino C, Sgrambiglia R. Pointillart V. Intermediate follow-up after treatment of degenerative disc disease with Bryan Cervical Disc Prosthesis: single level and bilevel. Spine 2003; 28:2673-2678.

258. Bono CM, Lee CK. Critical analysis of trends in fusion for degenerative disc disease over the past 20 years: influence of technique of fusion rate and clinical outcome. Spine 2004; 29:455-463.

259. Edwards CC 2nd, Karpitskaya Y, Cha C, Heller JG, Lauryssen C, Yoon ST, Riew KD. Accurate identification of adverse outcomes after cervical spine surgery. I Bone Joint Surg Am 2004; 86A:251-256.

26o. Massie JB, Huang B, Malkmus S, Yaksh TL, Kim CW, Garfin SR, Akeson WH. A preclinical post laminectomy rat model mimics the human post laminectomy syndrome. J Neurosci Methods 2004; 137:283-289.

261. Manchikanti L, Bakhit CE, Pampati V. Role of epidurography in caudal neuroplasty. Pain Digest 1998; 8:277-281.

262. Manchikanti L, Pampati V, Baha A, Fellows B, Damron K, Barnhill R. Contribution of facet joints to chronic low back pain in postlumbar laminectomy syndrome: A controlled comparative prevalence evaluation. Pain Physician 2001; 4:175-180.

263. Viesca C, Racz G, Day M. Spinal techniques in pain management: lysis of adhesions. Anesthesiol Clin North America 2003; 21:745-766.

264. Manchikanti L, Bakhit CE. Percutaneous lysis of epidural adhesions. Pain Physician 2000; 3:46-64.

265. McCarron RF. Epidural fibrosis: Experimental model and therapeutic alternatives. In Racz GB (ed). Techniques of Neurolysis. Kluwer Academic Publishers, Boston, 1989, pp 87-94.

266. LaRocca H, Macnab I. The laminectomy membrane: Studies in its evolution, characteristics, effects and prophylaxis in 
dogs. J Bone Joint Surg BR 1974; 56:545550.

267. Cooper RG, Freemont AJ, Hoyland JA, Jenkins JP, West CG, Illingworth KJ, Jayson MI. Herniated intervertebral disc-associated periradicular fibrosis and vascular abnormalities occur without inflammatory cell infiltration. Spine 1995; 20:591-598.

268. Hoyland JA, Freemont AJ, Jayson MI. Intervertebral foramen venous obstruction. A cause of periradicular fibrosis? Spine 1989; 14:558-568.

269. Songer M, Ghosh L, Spencer D. Effects of sodium hyaluronate on peridural fibrosis after lumbar laminectomy and discectomy. Spine 1990; 15:550-554.

270. Pawl RP. Arachnoiditis and epidural fibrosis: The relationship to chronic pain. Curr Rev Pain 1998; 2:93-99.

271. Cervellini P, Curri D, Volpin L, Bernardi L, Pinna V, Benedetti A. Computed tomography of epidural fibrosis after discectomy. A comparison between symptomatic and asymptomatic patients. Neurosurgery 1988; 6:710-713.

272. Benoist M, Ficat C, Baraf P, Cauchoix J. Post operative lumbar epiduroarachnoiditis: Diagnostic and therapeutic aspects. Spine 1980; 5:432-436.

273. Key JA, Ford LT. Experimental intervertebral disc lesions. J Bone Joint Surg 1948; 30:621-630.

274. Maliszewski M, Tymowski M, Lelek P, Bierzynska-Macyszyn G, Majchrzak H. An attempt to use Gore-Tex surgical membrane in lumbar disc surgery. Neurol Neurochir Pol 2004; 38:271-277.

275. Kayaoglu CR, Calikoglu C, Binler S. Re-operation after lumbar disc surgery: results in 85 cases. J Int Med Res 2003; 31:318323.

276. Anderson SR. A rationale for the treatment algorithm of failed back surgery syndrome. Curr Rev Pain 2000; 4:395-406.

277. Zoidl G, Grifka J, Boluki D, Willburger RE, Zoidl C, Kramer J, Dermietzel R, Faustmann PM. Molecular evidence for local denervation of paraspinal muscles in failed-back surgery/post discotomy syndrome. Clin Neuropathol 2003; 22:71-77.

278. Amundsen T, Weber H, Nordal HJ, Magnaes B, Abdelnoor M, Lilleas F. Lumbar spinal stenosis: Conservative or surgical management? Spine 2000; 25:14241436.

279. Yuan P, Albert T. Nonsurgical and surgical management of lumbar spinal stenosis. I Bone Joint Surg 2004; 10:2320-2330.

280. Naderi S, Mertol T. Simultaneous cervical and lumbar surgery for combined symptomatic cervical and lumbar spinal stenoses. J Spin Disord Tech 2002; 15:229-232.

281. Fritz JM, Delitto A, Welch WC, Erhard RE. Lumbar spinal stenosis: A review of current concepts in evaluation, management, and outcome measurements. Arch Phys Med Rehabil 1998; 79:700-708.

282. Drew R, Bhandari M, Kulkarni AV, Louw D,
Reddy K, Dunlop B. Reliability in grading the severity of lumbar spinal stenosis. $J$ Spinal Disord 2000; 13:253-258.

283. Treatment of degenerative lumbar spinal stenosis. Evidence Report/Technology Assessment No. 32 University of North Carolina: Agency for Healthcare Research and Quality. AHRQ Publication No. 01-E048; March 2001.

284. Fox EJ, Melzack R. Transcutaneous electrical stimulation to acupuncture. Comparison of treatment of low back pain. Pain 1976; 2:141-148.

285. Flower RJ, Blackwell GJ. Anti-inflammatory steroid induced biosynthesis of a phospholipase $A_{2}$ inhibitor which prevents prostaglandin generation. Nature 1979; 278:456-459.

286. Devor M, Govrin-Lippmann R, Raber P. Corticosteroids suppress ectopic neural discharges originating in experimental neuromas. Pain 1985; 22:127-137.

287. Johansson A, Hao J, Sjolund B. Local corticosteroid application blocks transmission in normal nociceptor C-fibers. Acta Anaesthesiol Scand 1990; 34:335-338.

288. Olmarker K, Byrod G, Cornefjord M, Nordborg C, Rydevik B. Effects of methylprednisolone on nucleus pulposus-induced nerve root injury. Spine 1994; 19:18031808.

289. Nicol GD, Klingberg DK, Vasko MR. Prostaglandin $E_{2}$ enhances calcium conductance and stimulates release of substance $P$ in avian sensory neurons. J Neurosci 1992; 12:1917-1927.

290. Hua SY, Chen YZ. Membrane receptor-mediated electrophysiological effects of glucocorticoid on mammalian neurons. Endocrinology 1989; 124:687-691.

291. Hayashi N, Weinstein JN, Meller ST, Lee HM, Spratt KF, Gebhart GF. The effect of epidural injection of betamethasone or bupivacaine in a rat model of lumbar radiculopathy. Spine 1998; 23:877-885.

292. Lee HM, Weinstein JN, Meller ST, Hayashi N, Spratt KF, Gebhart GF. The role of steroids and their effects on phospholipase $A_{2}$. An animal model of radiculopathy. Spine 1998; 23:1191-1196.

293. Minamide A, Tamaki T, Hashizume H, Yoshida M, Kawakami M, Hayashi N. Effects of steroids and lipopolysaccharide on spontaneous resorption of herniated intervertebral discs. An experience study in the rabbit. Spine 1998; 23:870-876.

294. Kingery WS, Castellote JM, Maze M. Methylprednisolone prevents the development of autotomy and neuropathic edema in rats, but has no effect on nociceptive thresholds. Pain 1999; 80:555-566.

295. Johansson A, Bennett GJ. Effect of local methylprednisolone on pain in a nerve injury model. A pilot study. Reg Anesth 1997; 22:59-65.

296. Kantowitz F, Robinson D, McGuire M. Corticosteroids inhibit prostaglandin production by rheumatoid synovia. Nature 1975; 258:737-739.
297. Merskey H, Thompson EN. Nerve blocks and cognitive therapy: A beneficial failure. Pain Res Manage 2002; 7:175-176.

298. McCormack K. Signal transduction in neuropathic pain, with special emphasis on the analgesic role of opioids - Part I: The basic science of phenotype expression in normal and regenerating nerves. Pain Rev 1999; 6:3-33.

299. McCormack K. Signal transduction in neuropathic pain, with special emphasis on the analgesic role of opioids - Part II: Moving basic science towards a new pharmacotherapy. Pain Rev 1999; 6:99-131.

300. Watkins L, Milligan ED, Maier SF. Spinal glia: New players in pain. Pain 2001; 93: 201-205

301. Kim SH, Na HS, Sheen K, Chung JM. Effects of sympathetectomy on a rat model of peripheral neuropathy. Pain 1993; 55: 85-92.

302. Deyo RA, Weinstein JN. Low back pain. $N$ Engl J Med 2001; 344:363-370.

303. Deyo RA, Rainville J, Kent DL. What can the history and physical examination tell us about low back pain? JAMA 1992; 268: 760-765.

304. Bogduk N, Lord S. Cervical zygapophysial joint pain. Neurosurg Q 1998; 8:107-117.

305. Schwarzer AC, Derby R, Aprill CN, Fortin J, Kine G, Bogduk N. The value of the provocation response in lumbar zygapophysial joint injections. Clin J Pain 1994; 10:309313.

306. Bogduk N. Diskography. APS / 1994; 3: 149-154.

307. Barnsley L, Lord S, Bogduk N. Comparative local anesthetic blocks in the diagnosis of cervical zygapophysial joints pain. Pain 1993; 55:99-106.

308. Lord SM, Barnsley L, Bogduk N. The utility of comparative local anesthetic blocks versus placebo-controlled blocks for the diagnosis of cervical zygapophysial joint pain. Clin J Pain 1995; 11:208-213.

309. Revel M, Poiraudeau S, Auleley GR, Payan C, Denke A, Nguyen M, Chevrot A, Fermanian J. Capacity of the clinical picture to characterize low back pain relieved by facet joint anesthesia. Proposed criteria to identify patients with painful facet joints. Spine 1998; 23:1972-1977

310. Schwarzer AC, Derby R, Aprill CN, Fortin J, Kine G, Bogduk N. Pain from the lumbar zygapophysial joints: A test of two models. J Spinal Disord 1994; 7:331-336

311. Laslett M, Oberg B, Aprill CN, McDonald B. Zygoapophysial joint blocks in chronic low back pain; a test of Revel's model as a screening test. BMC musculoskelet Disord 2004;5:43.

312. Young S, Aprill C, Laslett M. Correlation of clinical examination characteristics with three sources of chronic low back pain. Spine J 2003; 460-465.

313. Laslett M, Young SB, Aprill CN, McDonald B. Diagnosing painful sacroiliac joints: A validity study of a McKenzie evaluation 
and sacroiliac provocation tests. Aust J Physiother 2003; 49:89-97.

314. Bogduk N, McGuirk B. Precision diagnosis. In: Bogduk N, McGuirk B, eds. Medical Management of Acute and Chronic Low Back pain. An Evidence-Based Approach: Pain Research and Clinical Management, Vol. 13. Elsevier Science BV, Amsterdam, 2002, pp 169-176.

315. Bogduk N, McGuirk B. Assessment. In: Bogduk N, McGuirk B (eds). Management of Acute and Chronic Low Back pain. An Evidence-Based Approach: Pain Research and Clinical Management, Vol. 13. Elsevier Science BV, Amsterdam, 2002, pp 127138.

316. Schwarzer AC, Scott AM, Wang SC, Hoschl R, Wiseman JC, Copper RA. The role of bone scintigraphy in chronic low back pain: A comparison of SPECT and planar images and zygapophysial joint injection. Aust NZJ Med 1992; 22:185.

317. Schwarzer AC, Wang SC, O'Driscoll D, Harrington T, Bogduk N, Laurent R. The ability of computed tomography to identify a painful zygapophysial joint in patients with chronic low back pain. Spine 1995; 20:907-912.

318. Binet EF, Moro JJ, Marangola JP, Hodge C). Cervical spine tomography in trauma. Spine 1977; 2:163-172.

319. Abel MS. Occult traumatic lesions of the cervical vertebrae. Critical Rev Clin Radiol Nuclear Med 1975; 6:469-553.

320. Woodring JH, Goldstein SJ. Fractures of the articular processes of the cervical spine. Am / Roentgenol 1982; 139:341344.

321. Magora A, Bigos SJ, Stolov WC, Tomsli MA, Magora F, Vatine JJ. The significance of medical imaging findings in low back pain. Pain Clinic 1994; 7:99-105.

322. Manchikanti L, Pampati V, Rivera J, Fellows B, Beyer C, Damron K. Role of facet joints in chronic low back pain in the elderly: A controlled comparative prevalence study. Pain Practice 2001; 1:332-337.

323. Schwarzer AC, Aprill CN, Derby R, Fortin J, Kine G, Bogduk N. The false-positive rate of uncontrolled diagnostic blocks of the lumbar zygapophysial joints. Pain 1994; 58:195-200.

324. Barnsley L, Lord S, Wallis B, Bogduk N. False-positive rates of cervical zygapophysial joint blocks. Clin J Pain 1993; 9:124130.

325. Manchikanti L, Pampati V, Singh V, Beyer C, Damron K, Fellows B. Evaluation of role of facet joints in persistent low back pain in obesity: A controlled, perspective, comparative evaluation. Pain Physician 2001; 4:266-272.

326. Manchikanti L, Damron KS, Rivera J, McManus C, Jackson S, Barnhill R, Martin J. Evaluation of effect of sedation as a confounding factor in the diagnostic validity of lumbar facet joint pain: A prospective, randomized, double-blind, placebo-controlled evaluation. Pain Physician 2004;
7:411-417.

327. Manchikanti L, Pampati V, Damron KS, McManus C, Jackson S, Barnhill R, Martin J. A randomized, prospective, double-blind, placebo-controlled evaluation of the effect of sedation on diagnostic validity of cervical facet joint pain. Pain Physician 2004; 7:301-310.

328. Manchikanti L, Singh V, Pampati V. Are diagnostic lumbar medial branch blocks valid? Results of 2-year follow up. Pain Physician 2003; 6:147-153.

329. Manchikanti L, Pampati V, Fellows B, Rivera J, Damron K, Beyer C, Cash K. Influence of psychological factors on the ability of diagnose chronic low back pain of facet joint origin. Pain Physician 2001; 4:349357.

330. Bogduk N, Holmes S. Controlled zygapophysial joint blocks: The travesty of cost-effectiveness. Pain Medicine 2000; 1:24-34.

331. Manchikanti L, Singh V. An algorithmic approach to diagnosis and management of low back pain. In Manchikanti L, Slipman CW, Fellows B (eds), Interventional Pain Management: Low Back Pain - Diagnosis and Treatment. ASIPP Publishing, Paducah, KY 2002, 597-604.

332. Manchikanti L, Rivera JJ, Pampati V, Beyer C, Damron K, Barnhill R. Effectiveness of clinical guidelines in interventional pain management. Pain Physician 2002; 5:127132.

333. Manchikanti L, Singh V, Fellows B, Pampati V. Evaluation of influence of gender, occupational injury, and smoking on chronic low back pain of facet joint origin: A subgroup analysis. Pain Physician 2002; 5 : 30-35.

334. Speldewinde GC, Bashford GM, Davidson IR. Diagnostic cervical zygapophyseal joint blocks for chronic cervical pain. Med J Aust 2001; 174:174-176.

335. Aprill C, Bogduk N. The prevalence of cervical zygapophyseal joint pain. Spine 1992; 17:744-747.

336. Windsor RE, Storm S, Sugar R. Prevention and management of complications resulting from common spinal injections. Pain Physician 2003; 6:473-484.

337. Orpen NM, Birch NC. Delayed presentation of septic arthritis of a lumbar facet joint after diagnostic facet joint injection. J Spinal Disord Tech 2003; 16:285-287.

338. Alcock E, Regaard A, Browne J. Facet joint injection: A rare form cause of epidural abscess formation. Pain 2003; 103:209210.

339. Dreyfuss P, Kaplan M, Dreyer SJ. Zygapophyseal joint injection techniques in the spinal axis. In Lennard T (ed.) Pain Procedures in Clinical Practice, $2^{\text {nd }}$ ed. Hanley \& Belfus, Inc., Philadelphia, 2000, pp 276-308.

340. Windsor RE, Pinzon EG, Gore HC. Complications of common selective spinal injections: Prevention and management. $\mathrm{Am}$ J Orthop 2000; 29:759-770.
341. Schellhas KP, Smith MD, Gundry CR, Pollei SR.. Cervical discogenic pain. Prospective correlation of magnetic resonance imaging and discography in asymptomatic subjects and pain sufferers. Spine 1996; 21: 300-312.

342. Wood KB, Schellhas KP, Garvey TA, Aeppli $D$.. Thoracic discography in healthy individuals. A controlled prospective study of magnetic resonance imaging and discography in asymptomatic and symptomatic individuals. Spine 1999; 24:1548-1555.

343. Walsh TR, Weinstein JN, Spratt KF, Lehmann TR, Aprill C, Sayre H.. Lumbar discography in normal subjects. J Bone Joint Surg AM 1990; 72:1081-1088.

344. Maigne JY, Lapeyre E, Morvan G, Chatellier G. Pain immediately upon sitting down and relieved by standing up is often associated with radiologic lumbar instability or marked anterior loss of disc space. Spine 2003; 28:1327-1334.

345. Ohnmeiss DD, Guyer RD, Mason SL. The relation between cervical discographic pain responses and radiographic images. Clin J Pain 2000; 16:1-5.

346. Adams MA, Dolan P, Hutton WC. The stages of disc degeneration as revealed by discograms. J Bone Joint Surg BR 1986; 68: 36-41.

347. Yasuma T, Ohno R, Yamauchi Y. False-negative lumbar discograms: Correlation of discographic and histologic findings in postmortem and surgical specimens. J Bone Joint Surg AM 1988; 70:1279-1290.

348. Yu SW, Haughton VM, Sether LA, Wagner $M$. Comparison of MR and discography in detecting radial tears of the annulus: $\mathrm{A}$ post-mortem study. AJNR 1989; 10:10771081.

349. Saternus KS, Bornscheuer HH. Comparative radiologic and pathologic-anatomic studies on the value of discography in the diagnosis of acute intravertebral disk injuries in the cervical spine. Fortschr Geb Rontgenstr Nuklearmed 1983; 139:651657.

350. Viikari-Juntura E, Raininko R, Videman T, Porkka L. Evaluation of cervical disc degeneration with ultralow field MRI and discography. An experimental study on cadavers. Spine 1989; 14:616-619.

351. Agorastides ID, Lam KS, Freeman BJ, Mulholland RC. The Adams classification for cadaveric discograms: Inter- and intraobserver error in the clinical setting. Eur Spine J 2002; 11:76-79.

352. Jackson RP, Becker GJ, Jacobs RR, Montesano PX, Cooper BR, McManus GE.. The neuroradiographic diagnosis of lumbar herniated nucleus pulposus: I. A comparison of computed tomography (CT), myelography, CT-myelography, discography, and CT-discography. Spine 1989; 14:13561361.

353. Gresham JL, Miller R. Evaluation of the lumbar spine by diskography and its use in selection of proper treatment of the herniated disk syndrome. Clin Orthop 1969; 
67:29-41.

354. Brodsky AE, Binder WF. Lumbar discography: Its value in diagnosis and treatment of lumbar disc lesions. Spine 1979; 4:110120.

355. Birney TJ, White JJ Jr, Berens D, Kuhn G. Comparison of MRI and discography in the diagnosis of lumbar degenerative disease. J Spin Disord 1992; 5:417-423.

356. Bernard TN Jr. Repeat lumbar spine surgery: Factors influencing outcome. Spine 1993; 18:2196-2200.

357. Southern EP, Fye MA, Panjabi MM, Patel TC, Cholewicki J. Disc degeneration: A human cadaveric study correlation magnetic resonance imaging and quantitative discomanometry. Spine 2000; 25:2171-2175.

358. Simmons JW, Emery SF, McMillin JN, Landa D, Kimmich SJ. Awake discography. A comparison study with magnetic resonance imaging. Spine 1991; 16:S216 S221.

359. Simmons EH, Segil CM. An evaluation of discography in the localization of symptomatic levels in discogenic disease of the spine. Clin Orthop 1975;108:57-69.

360. Lehmer SM, Dawson MH, O’Brien JP. Delayed pain response after lumbar discog. raphy. Eur Spine J 1994; 3:28-31.

361. Jackson RP, Glah JJ. Foraminal and extraforaminal lumbar disc herniation: Diagnosis and treatment. Spine 1987; 12:577-585.

362. Grubb SA, Lipscomb HJ, Guilford WB. The relative value of lumbar roentgenograms, metrizamide myelography, and discography in the assessment of patients with chronic low back syndrome. Spine 1987; 12:282-286

363. Winter RB, Schellhas KP. Painful adult thoracic Scheuermann's disease. Diagnosis by discography and treatment by combined arthrodesis. Am J Orthop 1996; 25 : 783-786.

364. Wiley JJ, Macnab I, Wortzman G. Lumbar discography and its clinical applications. Can J Surgy 1968; 11:280-289.

365. Sachs BL, Vanharanta H, Spivey MA, Guyer RD, Videman T, Rashbaum RF, Johnson RG, Hochschuler SH, Mooney V. Dallas discogram description: A new classification of $\mathrm{CT} /$ discography in low-back disorders. Spine 1987; 12:287-294.

366. Milette PC, Raymond J, Fontaine S. Comparison of high-resolution computed tomography with discography in the evaluation of lumbar disc herniations. Spine 1990; 15:525-533.

367. Gibson MJ, Buckley J, Mawhinney R, Mulholland RC, Worthington BS. Magnetic resonance imaging and discography in the diagnosis of disc degeneration: A comparative study of 50 discs. I Bone Joint Surg BR 1986; 68:369-373.

368. Schneiderman G, Flannigan B, Kingston S, Thomas J, Dillin WH, Watkins RG. Magnetic resonance imaging in the diagnosis of disc degeneration: Correlation with discography. Spine 1987; 12:276-282.
369. Whitecloud TS, Seago RA. Cervical discogenic syndrome: results of operative intervention in patients with positive discography. Spine 1987;12:313-316.

370. Horton WC, Daftari TK. Which disc as visualized by magnetic resonance imaging is actually a source of pain? A correlation between magnetic resonance imaging and discography. Spine 1992; 17:S164-S171.

371. Kornberg M. Discography and magnetic resonance imaging in the diagnosis of lumbar disc disruption. Spine 1989; 14: 1368-1372.

372. Zucherman J, Derby R, Hsu K, Picetti G, Kaiser J, Schofferman J, Goldthwaite N, White A. Normal magnetic resonance imaging with abnormal discography. Spine 1988; 13:1355-1359.

373. Parfenchuck TA, Janssen ME. A correlation of cervical magnetic resonance imaging and discography/computed tomographic discograms. Spine 1994; 19:2819-2825.

374. Huang TS, Zucherman JF, Hsu KY, Shapiro M, Lentz D, Gartland J. Gadopentetate dimeglumine as an intradiscal contrast agent. Spine 2002; 27:839-843.

375. Zheng Y, Liew SM, Simmons ED. Value of magnetic resonance imaging and discography in determining the level of cervical discectomy and fusion. Spine 2004; 29 : 2140-2146.

376. Ito M, Incorvaia KM, Yu SF, Fredrickson BE, Yuan HA, Rosenbaum AE. Predictive signs of discogenic lumbar pain on magnetic resonance imaging with discography correlation. Spine 1998; 23:1252-1260.

377. Osti OL, Fraser RD. MRI and discography of anular tears and intervertebral disc degeneration. A prospective clinical comparison. J Bone Joint Surg BR 1992; 74:431435.

378. Greenspan A, Amparo EG, Gorczyca DP, Montesano PX. Is there a role of discography in the era of magnetic resonance imaging? Prospective correlation and quantitative analysis of computed tomographydiskography, magnetic resonance imaging, and surgical findings. J Spinal Disord 1992; 5:26-31.

379. Buirski G, Silberstein M. The symptomatic lumbar disc in patients with lowback pain: Magnetic resonance imaging appearances in both a symptomatic and control population. Spine 1993; 18:18081811.

380. Gill K, Blumenthal SL. Functional results after anterior lumbar fusion at $L_{5} / \mathrm{S}_{1}$ in patients with normal fusion at $L 5 / S_{1}$ in patients with normal and abnormal MRI scans. Spine 1992; 17:940-942.

381. Milette PC, Fontaine S, Lepanto L, Cardinal E, Breton G. Differentiating lumbar disc protrusions, disc bulges, and discs with normal contour but abnormal signal intensity: Magnetic resonance imaging with discographic correlations. Spine 1999; 24: 44-53.

382. Aprill C, Bogduk N. High-intensity zone: A diagnostic sign of painful lumbar disc on magnetic resonance imaging. $\mathrm{Br} /$ Radiol 1992; 65:361-369.

383. Schellhas KP, Pollei SR, Gundry CR, Heithoff KB. Lumbar disc high-intensity zone. Correlation of magnetic resonance imaging and discography. Spine 1996; 21: 79-86.

384. Saifuddin A, Braithwaite I, White J, Taylor $B A$, Renton P. The value of lumbar spine magnetic resonance imaging in the demonstration of anular tears. Spine 1998; 23: 453-457.

385 Smith BM, Hurwitz EL, Solsberg D, Rubinstein D, Corenman DS, Dwyer AP, Kleiner J. Interobserver reliability of detecting lumbar intervertebral disc high-intensity zone on magnetic resonance imaging and association of high-intensity zone with pain and anular disruption. Spine 1998; 23: 2074-2080.

386. Lappalainen AK, Kääpä E, Lamminen A Laitinen OM, Gronblad M. The diagnostic value of contrast-enhanced magnetic resonance imaging in the detection of experimentally induced anular teras in sheep. Spine 2002; 27:2806-2810.

387. Ricketson R, Simmons JW, Hauser BO. The prolapsed intervertebral disc. The high-intensity zone with discography correlation. Spine 1996; 21:2758-2762.

388. Carragee EJ, Paragiodakis SJ, Khurana S Lumbar high-intensity zone and discog raphy in subjects without low back problems. Spine 2000; 25:2987-2992.

389. Lam KS, Carlin D, Mulholland RC. Lumbar disc high-intensity zone: The value and significance of provocative discography in the determination of the discogenic pain source. Eur Spine J 2000; 9:36-41.

390. O'Neill C, Kurgansky M. Subgroups of positive discs on discography. Spine 2004; 29:2134-2139.

391. Carragee EJ, Tanner CM, Yang B, Brito JL, Truong T. False-positive findings on lumbar discography: Reliability of subjective findings on lumbar discography: Reliability of subjective concordance assessment during provocative disc injection. Spine 1999; 24:2542-2547.

392. Holt EP Jr. The question of lumbar discography. J Bone Joint Surg (Am) 1968; 50: 720-726.

393. Holt EP Jr. Fallacy of cervical discography. Report of 50 cases in normal subjects. JAMA 1964; 188:799-801.

394. Simmons JW, Aprill CN, Dwyer AP, Brod sky AE. A reassessment of Holt's data on: "The question of lumbar discography." Clin Orthop 1988; 237:120-124.

395. Carragee EJ, Tanner CM, Khurana S, Hayward C, Welsh J, Date E, Truong T, Rossi M, Hagle C. The rates of false-positive lumbar discography in select patients without low back symptoms. Spine 2000; 25:13731381.

396. Carragee EJ, Chen Y, Tanner CM, Truong T, Lau E, Brito JL. Provocative discography in patients after limited lumbar discectomy. Spine 2000; 25:3065-3071. 
397. Carragee EJ, Alamin TF, Miller J, Grafe M. Provocative discography in volunteer subjects with mild persistent low back pain. Spine 2002; 2:25-34.

398. Carragee EJ. Low pressure positive discography in subject without significant LBP illness. Spine J 2003; 3:68-69.

399. Carragee EJ, Paragioudakis SJ, Khurana S. 2000 Volvo Award winner in clinical studies: Lumbar high-intensity zone and discography in subjects without low back problems. Spine. 2000; 25:2987-2992.

400. Manchikanti L, Singh V, Pampati V, Fellows B, Beyer C, Damron K, Cash K. Provocative discography in low back pain patients with or without somatization disorder: A randomized prospective evaluation. Pain Physician 2001; 4:227-239.

401. Zeidman SM, Thompson K, Ducker TB. Complications of cervical discography: Analysis of 4400 diagnostic disc injections. Neurosurgery 1995; 37:414-417.

402. Grubb SA, Kelly CK. Cervical discography: Clinical implications from 12 years of experience. Spine 2000; 25:1382-1389.

403. Connor PM, Darden BV II. Cervical discography complications and clinical efficacy. Spine 1993; 18:2035-2038.

404. Fraser RD, Osti OL, Vernon-Roberts B. Discitis after discography. I Bone Joint Surg 1987; 69-B:26-35.

405. Lownie SP, Ferguson GG. Spinal subdural empyema complicating cervical discography. Spine 1989; 14:1415-1417.

406. Schreck RI, Manion WL, Kambin P, Sohn M. Nucleus pulposus pulmonary embolism. A case report. Spine 1997; 22:927-928.

407. Laun A, Lorenz R, Agnoli NL. Complications of cervical discography. J Neurosurg Sci 1981; 25:17-20.

408. Tsuji N, Igarashi S, Koyama T. Spinal epidural abscess. No Shinkei Geka 1987; 15: 1079-1085.

409. Junila J, Niinimäki T, Tervonen O. Epidural abscess after lumbar discography. Spine 1997; 22:2191-2193.

410. Carragee EJ, Chen Y, Tanner CM, Hayward C, Rossi M, Hagle C. Can discography cause long-term back symptoms in previously asymptomatic subjects? Spine 2000; 25:1803-1808.

411. Johnson RG. Does discography injure normal discs? An analysis of repeat discograms. Spine 1989; 14:424-426.

412. Heggeness MH, Doherty BJ. Discography causes end plate deflection. Spine 1993; 18:1050-1053.

413. Reitman CA, Hipp JA, Kirking BC, Haas S, Esses SI. Posterior annular strains during discography. J Spinal Disord 2001; 14:347352.

414. Willems PC, Jacobs W, Duinkerke ES, De Kleuver M. Lumbar discography: should we use prophylactic antibiotics? A study of 435 consecutive discograms and a systematic review of the literature. I Spinal Disord Tech 2004; 17:243-247.

415. Guiboux JP, Cantor JB, Small SD, Zervos
M, Herkowitz HN. The effect of prophylactic antibiotics on iatrogenic intervertebral disc infections. a rabbit model. Spine 1995; 20:685-688.

416. Koroglu A, Acar O, Ustun ME, Tiras B, Eser $O$. The penetration of cefoperazone and sulbactam into the lumbar intervertebral discs. J Spinal Disord 2001; 14:453-454.

417. Boswell M, Wolfe J. Intrathecal cefazolin-induced seizures following attempted discography. Pain Physician 2004; 7:103106.

418. Slipman CW, Plastaras CT, Palmitier RA, Huston CW, Sterenfeld EB. Symptom provocation of fluoroscopically guided cervical nerve root stimulation. Are dynatomal maps identical to dermatomal maps? Spine 1998; 23:2235-2242.

419. Wolff AP, Groen GJ, Crul BJ. Diagnostic lumbosacral segmental nerve blocks with local anesthetics: A prospective doubleblind study on the variability and interpretation of segmental effects. Reg Anesth Pain Med 2001; 26:147-155.

420. Pfirrmann CW, Oberholzer PA, Zanetti M, Boos N, Trudell DJ, Resnick D, Hodler J. Selective nerve root blocks for the treatment of sciatica: Evaluation of injection site and effectiveness - a study with patients and cadavers. Radiology 2001; 221: 704-711.

421. Schutz H, Lougheed WM, Wortzman G, Awerbuck BG. Intervertebral nerve-root in the investigation of chronic lumbar disc disease. Can / Surg 1973; 16:217-221.

422. Steindler A. Luck JV. Differential diagnosis of pain in the low back: Allocation of the source of the pain by the procaine hydrochloride method. JAMA 1938; 110:106-113.

423. MacNab I. Negative disc exploration: An analysis of the causes of nerve root involvement in sixty-eight patient. J Bone Joint Surg AM 1971; 53:5891-5903.

424. Krempen JF, Smith BS. Nerve root injection: A method for evaluating the etiology of sciatica. J Bone Joint Surg AM 1974; 56: 1435-1444.

425. Tajima T, Furukawa K, Kuramochi E. Selective lumbosacral radiculography and block. Spine 1980; 1:68-77.

426. Haueisen DC, Smith BS, Myers SR, Pryce $M L$. The diagnostic accuracy of spinal nerve injection studies. Clin Orthop 1985; 198:179-183.

427. Dooley JF, McBroom RJ, Taguchi T, Macnab I. Nerve root infiltration in the diagnosis of radicular pain. Spine 1988; 13:79-83.

428. Stanley D, McLaren MI, Euinton HA, Getty CJ. A prospective study of nerve root infiltration in the diagnosis of sciatica: A comparison with radiculography, computed tomography, and operative findings. Spine 1990; 6:540-543.

429. Derby R, Kine G, Saal JA, Reynolds J, Goldthwaite N, White AH, Hsu K, Zucherman J. Response to steroid and duration of radicular pain as predictors of surgical outcome. Spine 1992; 17 (Suppl):176-183.

430. Castro WH, van Akkerveeken PF. Der di- agn ostische Wert der selektiven lumbalen Nervenwurzelblockde. Z orthop Ihre Grenzgeb 1991; 129:374-379.

431. Kikuchi S, Hasue M, Nishiyama K. Anatomic and clinical studies of radicular symptoms. Spine 1984; 9:23-30.

432. Van Akkerveeken PF. The diagnostic value of nerve root sheath infiltration. Acta Orthop Scand 1993; 251:61-63.

433. Herron LD. Selective nerve root block in patient selection for lumbar surgery: Surgical results. I Spinal Disord 1989; 2:7579.

434. Strobel K, Pfirrmann CW, Schmid M, Hodler J, Boos N, Zanetti M. Cervical nerve root blocks: indications and role of MR imaging. Radiology. 2004; 233:87-92.

435. Koning HM, Koning AJ. Prolonged pain relief following selective nerve root infiltration. Pain Clinic 2003;14:225-233.

436. Anderberg L, Annertz M, Brandt L, Saveland $H$. Selective diagnostic cervical nerve root block - correlation with clinical symptoms and MRI pathology. Acta Neurochir 2004;146:559-565.

437. Nachemson A. Newest knowledge of low back pain: A critical look. Clin Orthop Rel Res 1992; 279:8-20.

438. North RB, Kidd DH, Zahurak M, Piantadosi S. Specificity of diagnostic nerve blocks: a prospective, randomized study of sciatica due to lumbosacral spine disease. Pain 1996; 65:77-85.

439. White A. Injection techniques for the diagnosis and treatment of low back pain. Orthop Clin N Am 1983; 14:553-567.

440. Houten JK, Errico TJ. Paraplegia after lumbosacral nerve root block: Report of three cases. The Spine Journal 2002; 2:70-75.

441. Elias M. A rare cause of radiculopathy following transforaminal epidural steroid injection. Pain Clinic 1998; 11:159-160.

442. Brouwers PJ, Kottink EJ, Simon MA, Prevo RL. A cervical anterior spinal artery syndrome after diagnostic blockade of the right C6-nerve root. Pain 2001; 91:397399.

443. Nash TP. Comment on A cervical anterior spinal artery syndrome after diagnostic blockade of the right C6-nerve root. Pain 2002; 91:217-218.

444. Stohr M, Mayer K. Nerve-root damage from local injections. Dtsch Med Wochenschr 1976; 101:1218-1220.

445. Milhaud D, Heroum C, Charif M, Saulnier P, Pages M, Blard JM. Dural puncture and corticotherapy as risks factors for cerebral venous sinus thrombosis. Eur / Neruol 2000; 7:123-124.

446. Schultz D. Risk of transforaminal epidural injections. Pain Physician 2004; 7:289290.

447. Helm S, Jasper J, Racz G. Complications of transforaminal epidural injections. Pain Physician 2003; 6:389-390.

448. Young WF. Transient blindness after lumbar epidural steroid injection. Spine 2002; 27:E476-E477. 
449. Baker R, Dreyfuss P, Mercer S, Bogduk N. Cervical transforaminal injection or corticosteroids into a radicular artery: A possible mechanism for spinal cord injury. Pain 2003; 109:211-215.

450. Rozin L, Rozin R, Koehler SA, Shakir A, Ladham S, Barmada M, Dominick J, Wecht CH. Death during transforaminal epidural steroid nerve root block ( $\left.\mathrm{C}_{7}\right)$ due to perforation of the left vertebral artery. Am J Foren sic Med Pathol 2003; 24:351-355.

451. Dreyfuss P, Michaelsen M, Pauza K, McLarty J, Bogduk N. The value of medical history and physical examination in diagnosing sacroiliac joint pain. Spine 1996; 21:25942602

452. Dreyfuss P, Dryer S, Griffin J, Hoffman J, Walsh N. Positive sacroiliac screening tests in asymptomatic adults. Spine $1994^{\circ}$ 19:1138-1143.

453. Hansen $H$, Helm S. Sacroiliac joint pain and dysfunction. Pain Physician 2003; 6 : 179-190.

454. Slipman CW, Sterenfeld EB, Chou LH, Herzog R, Vresilovic E. The predictive value of provocative sacroiliac joint stress maneuvers in the diagnosis of sacroiliac joint syndrome. Arch Phys Med Rehab 1998; 79:288-292.

455. Broadhurst NA, Bond MJ. Pain provocation tests for the assessment of sacroiliac joint dysfunction. J Spin Disord 1998; 11: 341-345.

456. Meijne W, van Neerbos K, Aufdemkampe $G$, van der Wurff P. Intraexaminer and interexaminer reliability of the Gillet test. J Man Phys Ther 1999; 22:4-9.

457. Ebraheim NA, Mekhail AO, Wiley WF, Jackson WT, Yeasting RA. Radiology of the sac roiliac joint. Spine 1997; 22: 869-876.

458. Vogler JB 3rd, Brown WH, Helms CA Genant HK. The normal sacroiliac joint: a CT study of asymptomatic patients. Radiology. 1984; 151:433-437.

459. Resnik CS, Resnick D. Radiology of disorders of the sacroiliac joints. JAMA 1985; 253:2863-2866.

46o. Slipman CW, Sterenfeld EB, Chou LH, Her$\operatorname{zog} R$, Vresilovic $E$. The value of radionuclide imaging in the diagnosis of sacroiliac joint syndrome. Spine 1996; 21:22512254.

461. Maigne JY, Boulahdour H, Charellier G. Value of quantitative radionuclide bone scanning in the diagnosis of sacroiliac joint syndrome in 32 patients with low back pain. Eur Spine Jour 1998; 7:328-331.

462. Goldberg RP, Genant HK, Shimshak R, Shames D. Applications and limitations of quantitative sacroiliac joint scintigraphy. Radiology 1978; 128:683-686.

463. Lantto T. The scintigraphy of sacroiliac joints: A comparison of 99-mTc-VPB and 99mTc-MDP. Eur J Nucl Med 1990; 16:677 681.

464. Lentle BC, Russell AS, Percy JS, Jackson FI. The scintigraphic investigation of sacroiliac disease. J Nucl Med 1977; 6:529-533.
465. Verlooy H, Mortelmans L, Vleugels S, De Roo M. Quantitative scintigraphy of the sacroiliac joints. Clin Imaging 1992; 16: 230-233.

466. Hanly JG, Mitchell MJ, Barnes DC, MacMilIan L. Early recognition of sacroiliitis by magnetic resonance imaging and single photon emission computed tomography. J Rheum 1994; 21:2088-2095.

467. Rosenberg JM, Quint TJ, de Rosayro AM. Computerized tomographic localization of clinically-guided sacroiliac joint injections. Clin I Pain 2000; 16:18-21.

468. Hansen $\mathrm{H}$. Is fluoroscopy necessary for sacroiliac joint injections? Pain Physician. 2003; 6:155-158.

469. Fortin J, Tolchin R. Sacroiliac arthrograms and post-arthrography computerized tomography. Pain Physician. 2003; 6:287290.

470. Jackson RP. The facet syndrome: Myth or reality? Clin Orthop 1992; 279:110-121.

471. Jackson RP, Jacobs RR, Montesano PX. Facet joint injection in low back pain. A prospective statistical study. Spine 1988; 13:966-971.

472. Deyo RA. Fads in the treatment of low back pain. N Engl J Med 1991; 325:1039-1040.

473. Carette S, Marcoux S, Truchon R, Grondin C, Gagnon J, Allard Y, Latulippe M. A controlled trial of corticosteroid injections into facet joints for chronic low back pain. N Engl J Med 1991; 325:1002-1007.

474. Barnsley L, Lord SM, Wallis BJ, Bogduk N. Lack of effect of intra-articular corticosteroids for chronic pain in the cervical zygapophyseal joints. N Engl J Med 1994; 330:1047-1050

475. Marks RC, Houston T, Thulbourne T. Facet joint injection and facet nerve block. A randomized comparison in 86 patients with chronic low back pain. Pain 1992; 49: 325-328.

476. Nash TP. Facet joints. Intra-articular steroids or nerve blocks? Pain Clinic 1990; 3 : 77-82.

477. Lilius G, Laasonen EM, Myllynen P, Harilainen A, Gronlund G. Lumbar facet joint syndrome. A randomized clinical trial. J Bone Joint Surg Br 1989; 71:681-684.

478. Murtagh FR. Computed tomography and fluoroscopy guided anesthesia and steroid injection in facet syndrome. Spine 1988; 13:686-689.

479. Destouet JM, Gilula LA, Murphy WA, Monsees B. Lumbar facet joint injection: Indication, technique, clinical correlation, and preliminary results. Radiology 1982; 145: 321-325.

480. Lynch MC, Taylor JF. Facet joint injection for low back pain. A clinical study. J Bone Joint Surg Br 1986; 68:138-141.

481. Lippitt $A B$. The facet joint and its role in spine pain. Management with facet joint injections. Spine 1984; 9:746-750.

482. Lau LS, Littlejohn GO, Miller MH. Clinical evaluation of intra-articular injections for lumbar facet joint pain. Med J Aust 1985;
143:563-565.

483. Manchikanti L, Pampati V, Bakhit C, Rivera J, Beyer C, Damron K, Barnhill R. Effectiveness of lumbar facet joint nerve blocks in chronic low back pain: A randomized clinical trial. Pain Physician 2001; 4: 101-117.

484. Manchikanti KN, Pampati V, Damron KS McManus C. A double-blind, controlled evaluation of the value of Sarapin in neural blockade. Pain Physician 2004; 7:5962.

485. Manchikanti L, Manchikanti KN, Damron KS, Pampati V. Effectiveness of cervica medial branch blocks in chronic neck pain: A prospective outcome study. Pain Physician 2004; 7:195-202.

486. Lord SM, Barnsley L, Wallis BJ, McDonald GJ, Bogduk N. Percutaneous radiofrequency neurotomy for chronic cervical zygapophyseal joint pain. $N$ Engl J Med 1996; 335:1721-1726.

487. van Kleef $M$, Barendse $G A$, Kessels $A$ Voets HM, Weber WE, de Lange S. Randomized trial of radiofrequency lumbar facet denervation for chronic low back pain. Spine 1999; 24:1937-1942

488. Gallagher J, Vadi PLP, Wesley JR. Radiofrequency facet joint denervation in the treatment of low back pain - A prospective controlled double-blind study to assess efficacy. Pain Clinic 1994; 7:193-198.

489. Sanders M, Zuurmond WWA. Percutaneous intraarticular lumbar facet joint denervation in the treatment of low back pain: A comparison with percutaneous extra-articular lumbar facet denervation. Pain Clin 1999; 11:329-335.

490. Leclaire R, Fortin L, Lambert R, Bergeron YM, Rossignol M. Radiofrequency facet joint denervation in the treatment of low back pain: a placebo-controlled clinical trial to assess efficacy. Spine 2001; 26:14111416.

491. Buijs EJ, van Wijk RM, Geurts JW, Weese man RR, Stolker RJ, Groen GG. Radiofrequency lumbar facet denervation: a comparative study of the reproducibility of lesion size after 2 current radiofrequency techniques. Reg Anesth Pain Med 2004; 9:400-407.

492. McDonald GJ, Lord SM, Bogduk N. Long term follow-up of patients treated with cervical radiofrequency neurotomy for chronic neck pain. Neurosurgery 1999; 45:61-68.

493. Dreyfuss P, Halbrook B, Pauza K, Joshi A, McLarty J, Bogduk N. Efficacy and validity of radiofrequency neurotomy for chronic lumbar zygapophysial joint pain. Spine 2000; 25:1270-1277.

494. Sapir D, Gorup JM. Radiofrequency medi al branch neurotomy in litigant and nonlitigant patients with cervical whiplash. Spine 2001; 26:E268-E273.

495. Vad V, Cano W, Basrai D, Lutz G, Bhat A. Role of radiofrequency denervation in lumbar zygapophyseal joint synovitis in baseball pitchers: A clinical experience. Pain Physician 2003; 6:307-312. 
496. Schofferman J, Kine G. Effectiveness of repeated radiofrequency neurotomy for lumbar facet pain. Spine 2004; 29:24712473.

497. Stolker RJ, Vervest AC, Groen GJ. Percutaneous facet denervation in chronic thoracic spinal pain. Acta Neurochir 1993; 122: 82-90.

498. Mikeladze G, Espinal R, Finnegan R, Routon J, Martin D. Pulsed radiofrequency application in treatment of chronic zygapophyseal joint pain. Spine / 2003; 3: 360-362.

499. Schaerer JP. Radiofrequency facet rhizotomy in the treatment of chronic neck and low back pain. Int Surg 1978; 63:53-59.

500. Tzaan WC, Tasker RR. Percutaneous radiofrequency facet rhizotomy - experience with 118 procedures and reappraisal of its value. Can J Neurol Sci 2000; 27:125-130.

501. North RB, Han M, Zahurak M, Kidd DH. Radiofrequency lumbar facet denervation: Analysis of prognostic factors. Pain 1994; 57:77-83.

502. Nelson DA, Landau WM. Intraspinal steroids: History, efficacy, accidentality, and controversy with review of United States Food and Drug Administration reports. J Neurol Neurosurg Psychiatry 2001; 70: 433-443.

503. Muffolerro AJ, Nader R, Westmark RM, Nauta HJ, Garges KJ, Hadjipavlou AG. Hematogenous pyogenic facet joint infection of the subaxial cervical spine. A report of two cases and review of the literature. I Neurosurg Spine 2001; 95:135-138.

504. Doita M, Nishida K, Miyamoto H, Yoshiya S, Kurosaka M, Nabeshima Y. Septic arthritis of bilateral lumbar facet joints: report of a case with MRI findings in the early stage. Spine 2003; 28:E198-E202.

505. Uribe J, Moza K, Jimenez O, Green B, Levi AD. Delayed postoperative spinal epidural hematomas. Spine / 2003; 3:125-129.

506. Manchikanti L, Cash KA, Moss TL, Pampati V. Effectiveness of protective measures in reducing risk of radiation exposure in interventional pain management: A prospective evaluation. Pain Physician 2003; 6:301-305.

507. Magee M, Kannangara S, Dennien B, Lonergan R, Emmett L, van der Wall H. Paraspinal abscess complicating facet joint injection. Clin Nucl Med 2000; 25:71-73.

508. Manchikanti L, Cash KA, Moss TL, Pampati V. Radiation exposure to the physician in interventional pain management. Pain Physician 2002; 5:385-393.

509. Marks R, Semple AJ: Spinal anaesthesia after facet joint injection. Anaesthesia 1988; 43:65-66.

510. Cook NJ, Hanrahan P, Song S. Paraspinal abscess following facet joint injection. Clin Rheumatol 1999; 18:52-53.

511. Manchikanti L, Cash K, Moss T, Rivera JJ, Pampati V. Risk of whole body radiation exposure and protective measures in fluoroscopically guided interventional techniques: A prospective evaluation. $B M C$
Anesthesiol 2003; 3:2.

512. Berrigan T. Chemical meningism after lumbar facet joint block. Anesthesia 1992; 7:905-906.

513. Thomson SJ, Lomax DM, Collett BJ. Chemical meningism after lumbar facet joint nerve block with local anesthetic and steroids. Anesthesia 1993; 46:563-564.

514. Raj PP, Shah RV, Kay AD, Denaro S, Hoover $J M$. Bleeding risk in interventional pain practice: Assessment, management, and review of the literature. Pain Physician 2004; 7:3-52.

515. Zhou Y, Singh N, Abdi S, Wu J, Crawford J, Furgang F. Fluoroscopy radiation safety for spine interventional pain procedures in university teaching hospitals. Pain Physician 2005.

516. Svendsen RN. [Purulent arthritis after blockade treatment]. Ugeskr Laeger 1993; 155:2414-2415.

517. Manchikanti L. Role of neuraxial steroids in interventional pain management. Pain Physician 2002; 5:182-199.

518. Manchikanti L, Pampati V, Beyer C, Damron KS, Cash KA, Moss TL. The effect of neuraxial steroids on weight and bone mass density: A prospective evaluation. Pain Physician 2000; 3:357-366.

519. Coscia MF, Trammell TR. Pyogenic lumbar facet joint arthritis with intradural extension: a case report. I Spinal Disord Tech 2002; 15:526-528.

520. Kornick CA, Kramarich SS, Sitzman BT, Marshall KA, Santiago-Palma J, Lamer TJ. Complication rate associated with facet joint radiofrequency denervation procedures. Pain Med 2002; 3:175-176.

521. Kornick CA, Kramarich SS, Lamer TJ, Sitzman BT. Complications of lumbar facet radiofrequency denervation. Spine 2004; 29:1352-1354.

522. Breivik H, Hesla PE, Molnar I, Lind B. Treatment of chronic low back pain and sciatica. Comparison of caudal epidural injections of bupivacaine and methylprednisolone with bupivacaine followed by saline. In Bonica JJ, Albe-Fesard D (eds). Advances in pain research and therapy. $R a-$ ven Press, New York, 1976, pp 927-932.

523. Bush K, Hillier S. A controlled study of caudal epidural injections of triamcinolone plus procaine for the management of intractable sciatica. Spine 1991; 16:572575.

524. Mathews JA, Mills SB, Jenkins VM, Grimes SM, Morkel MJ, Mathews W, Scott CM, Sittampalam Y. Back pain and sciatica: Controlled trials of manipulation, traction, sclerosant and epidural injections. Brit J Rheumatol 1987; 26:416-423.

525. Beliveau P. A comparison between epidural anesthesia with and without corticosteroids in the treatment of sciatica. Rheum Phys Med 1971; 11:40-43.

526. Czarski Z. Leczenie rwy kulszowej wstrzykiwaniem hydrokortyzonu inowokainy do rozworu kryzowego. Przeglad Kekarski 1965; 21:511-513.
527. Hesla PE, Breivik H. Epidural analgesia and epidural steroid injection for treatment of chronic low back pain and sciatica. Tidsskr Nor Laegeforen 1979; 99:936939.

528. Revel M, Auleley GR, Alaoui S, Nguyen M, Duruoz T, Eck-Michaud S, Roux C, Amor B. Forceful epidural injections for the treatment of lumbosciatic pain with post-operative lumbar spinal fibrosis. Rev Rhum Engl Ed 1996; 63:270-277.

529. Meadeb J, Rozenberg S, Duquesnoy B, Kuntz JL, Le Loet X, Sebert JL, Le Goff P, Fallut $M$, Marty M, Blevin S, Guggenbuhl P, Chales G, Duvauferrier R. Forceful sacrococcygeal injections in the treatment of postdiscectomy sciatica. A controlled study versus glucocorticoid injections. Joint Bone Spine 2001; 68:43-49.

530. Manchikanti L, Pampati V, Rivera JJ, Beyer C, Damron K, Barnhill R. Caudal epidural injections with sarapin or steroids in chronic low back pain. Pain Physician 2001; 4:322-335.

531. Manchikanti L, Singh V, Rivera J, Pampati V, Beyer C, Damron K, Barnhill R. Effectiveness of caudal epidural injections in discogram positive and negative chronic low back pain. Pain Physician 2002; 5:18-29.

532. Yates DW. A comparison of the types of epidural injection commonly used in the treatment of low back pain and sciatica. Rheum Rehab 1978; 17:181-186.

533. McGregor AH, Anjarwalla NK, Stambach T. Does the method of injection alter the outcome of epidural injections? J Spinal Disord 2001; 14:507-510.

534. Waldman SD. The caudal epidural administration of steroids in combination with local anesthetics in the palliation of pain secondary to radiographically documented lumbar herniated disc: A prospective outcome study with 6-months follow-up. Pain Clinic 1998; 11:43-49.

535. Ciocon JO, Galindo-Ciocon D, Amaranath L, Galindo D. Caudal epidural blocks for elderly patients with lumbar canal stenosis. J Am Geriatr Soc 1994; 42:593-596.

536. Manchikanti L, Pakanati RR, Pampati V. Comparison of three routes of epidural steroid injections in low back pain. Pain Digest 1999; 9:277-285.

537. Carette S, Leclaire R, Marcoux S, Morin F, Blaise GA, St-Pierre A, Truchon R, Parent $\mathrm{F}$, Levesque J, Bergeron V, Montminy P, Blanchette C. Epidural corticosteroid injections for sciatica due to herniated nucleus pulposus. N Engl / Med 1997; 336: 1634-1640.

538. Snoek W, Weber H, Jorgensen B. Doubleblind evaluation of extradural methylprednisolone for herniated lumbar disc. Acta Orthop Scand 1977; 48:635-641.

539. Cuckler JM, Bernini PA, Wiesel SW, Booth RE Jr, Rothman RH, Pickens GT. The use of epidural steroid in the treatment of radicular pain. J Bone Joint Surg AM 1985; 67: 63-66.

540. Dilke TFW, Burry HC, Grahame R. Extradu- 
ral corticosteroid injection in the management of lumbar nerve root compression. Br Med J 1973; 2:635-637.

541. Serrao JM, Marks RL, Morley SJ, Goodchild CS. Intrathecal midazolam for the treatment of chronic mechanical low back pain: A controlled comparison with epidural ste roid in a pilot study. Pain 1992; 48:5-12.

542. Klenerman L, Greenwood R, Davenport HT, White DC, Peskett S. Lumbar epidural injections in the treatment of sciatica. $\mathrm{Br}$ Rheumatol 1984; 23:35-38.

543. Rocco AG, Frank E, Kaul AF, Lipson SJ, Gallo JP. Epidural steroids, epidural morphine and epidural steroids combined with morphine in the treatment of postlaminectomy syndrome. Pain 1989; 36:297-303.

544. Ridley MG, Kingsley GH, Gibson T, Grahame R. Outpatient lumbar epidural corticosteroid injection in the management of sciatica. Br/Rheumatol 1988; 27:295299.

545. Rogers P, Nash T, Schiller D, Norman J. Epidural steroids for sciatica. Pain Clinic 1992; 5:67-72.

546. Castagnera L, Maurette P, Pointillart V, Vital JM, Erny P, Senegas J. Long-term results of cervical epidural steroid injection with and without morphine in chronic cervical radicular pain. Pain 1994; 58:239243.

547. Hernandez R, Lopez F. Assessment of pain intensity in patients with diabetic polyneuropathy treated with peridural $2 \%$ lidocaine methylprednisolone acetate vs peridural $2 \%$ lidocaine. Anestesia en Mexico 1999; 11:65-69.

548. Kikuchi A, Kotani N, Sato T, Takamura K, Sakai I, Matsuki A. Comparative therapeutic evaluation of intrathecal versus epidural methylprednisolone for long-term analgesia in patients with intractable posther petic neuralgia. Reg Anesth Pain Med 1999; 24:287-293.

549. Helliwell M, Robertson JC, Ellia RM. Outpatient treatment of low back pain and sciatica by a single extradural corticosteroid injection. Br J Clin Pract 1985; 39:228231.

550. Stav A, Ovadia L, Sternberg A, Kaadan M Weksler N. Cervical epidural steroid injec tion for cervicobrachialgia. Acta Anaes thesiol Scand 1993; 37:562-566.

551. Buchner M, Zeifang F, Brocai DR, Schiltenwolf $M$. Epidural corticosteroid injection in the conservative management of sciatica. Clin Orth Rel Res 2000; 375:149-156.

552. Valat JP, Giraudeau B, Rozenberg S, Goupille P, Bourgeois P, Micheau-Beaugendre V, Soubrier M, Richard S, Thomas E. Epidural corticosteroid injections for sciatica: a randomised, double blind, controlled clinical trial. Ann Rheum Dis 2003; 62:639-643.

553. Kraemer J, Ludwig J, Bickert U, Owczarek V, Traupe M. Lumbar epidural perineural injection: A new technique. Eur Spine J 1997; 6:357-361.

554. Pirbudak L, Karakurum G, Oner U, Gulec
A, Karadasli H. Epidural corticosteroid injection and amitriptyline for the treatment of chronic low back pain associated with radiculopathy. Pain Clinic 2003; 15:247253.

555. Bush K, Hillier S. Outcome of cervical radiculopathy treated with periradicular/ epidural corticosteroid injections: A prospective study with independent clinical review. Eur Spine J 1996; 5:319-325.

556. Rull BM, Miralles M, Aure S. Therapeutic epidural infiltrations in the lumbar nerve roots. Rev Ortop Traumatol 1996; 40:209217.

557. Caglar S, Erdine S, Aldemir T. The results of the epidural steroid injections in patients with radiculopathies due to lumbar disc herniations. Fiz Tedavi Rehabil Derg 1995; 19:186-190.

558. Dallas TL, Lin RL, Wu WH, Wolskee P. Epidural morphine and methylprednisolone for low-back pain. Anesthesiology 1987; 67:408-411.

559. Rivest C, Katz JN, Ferrante FM, Jamison RN. Effects of epidural steroid injection on pain due to lumbar spinal stenosis or herniated discs: A prospective study. Arthritis Care Res 1998; 11:291-297.

560. Koning HM, Koning AJ, Bruinen TCM; Koster HG; Heybroek E. The period of pain relief following a successful epidural steroid injection for low back pain. Pain Clinic 2002; 13:331-338.

561. Andersen KH, Mosdal C. Epidural application of corticosteroids in low-back pain and sciatica. Acta Neurochir 1987; 87:5253

562. Warfield CA, Crews DA. Epidural steroid injection as a predictor of surgical outcome. Surg Gyn Obstet 1987; 164:457458.

563. Fukusaki M, Kobayashi I, Hara T, Sumikawa K. Symptoms of spinal stenosis do not improve after epidural steroid injection. Clin J Pain 1998; 14:148-151.

564. Ferrante FM, Wilson SP, lacobo C, Orav EJ, Rocco AG, Lipson S. Clinical classification as a predictor of therapeutic outcome after cervical epidural steroid injection. Spine 1993; 18:730-736.

565. Stav A, Ovadia L, Landau M, Weksler N, Berman M. Epidural steroid injection in the treatment of lumbar and cervical pain syndromes. A preliminary retrospective comparison. Pain Clinic 1991; 4:95-112.

566. Shulman M. Treatment of neck pain with cervical epidural steroid injection. Reg Anesth 1986; 11:92-94.

567. Catchlove RFH, Braha R. The use of cervical epidural nerve blocks in the management of chronic head and neck pain. Can Anaesth Soc J 1984; 31:188-191.

568. Purkis IE. Cervical epidural steroids. Pain Clinic 1986; 1:3-7.

569. Rowlingson JC, Kirschenbaum LP. Epidural analgesic techniques in the management of cervical pain. Anesth Analg 1986; 65: 938-942.
570. Warfield CA, Biber MP, Crews DA, Dwarakanath,GK. Epidural steroid injection as a treatment for cervical radiculitis. Clin J Pain 1988; 4:201-204.

571. Cicala RS, Thoni K, Angel JJ. Long-term results of cervical epidural steroid injections. Clin J Pain 1989; 5:143-145.

572. Pawl RP, Anderson W, Shulman M. Effect of epidural steroids in the cervical and lumbar region on surgical intervention for discogenic spondylosis. Clin J Pain 1985: 1:181-185.

573. Ozyalcin S, Yucel A, Erdine S. Epidural steroid injection in the treatment of cervical pain syndromes: A retrospective follow up study. Angri Dergisi 1996; 8:9-14

574. Riew KD, Yin Y, Gilula L, Bridwell KH, Lenke LG, Lauryssen C, Goette K. The effect of nerve-root injections on the need for operative treatment of lumbar radicular pain. $J$ Bone Joint Surg AM 2000; 82: 1589-1593.

575. Karppinen J, Malmivaara A, Kurunlahti M, Kyllonen E, Pienimaki T, Nieminen P, Ohinmaa A, Tervonen O, Vanharanta H. Periradicular infiltration for sciatica. Spine 2001; 26:1059-1067.

576. Karppinen J, Ohinmaa A, Malmivaara A Kurunlahti M, Kyllonen E, Pienimaki T, Nieminen P, Tervonen O, Vanharanta H. Cost effectiveness of periradicular infiltration for sciatica. Spine 2001; 26:2587-2595.

577. Devulder J, Deene P, De Laat M, Van Bastelaere M, Brusselmans G, Rolly G. Nerve root sleeve injections in patients with failed back surgery syndrome: A comparison of three solutions. Clin J Pain 1999; 15: 132-135.

578. Kolsi I, Delecrin J, Berthelot JM, Thomas L, Prost A, Maugars Y. Efficacy of nerve root versus interspinous injections of glucocorticoids in the treatment of disc-related sciatica. A pilot, prospective, randomized, double-blind study. Joint Bone Spine 2000; 67:113-118.

579. Vad VB, Bhat AL, Lutz GE, Cammisa F. Transforaminal epidural steroid injections in lumbosacral radiculopathy; A prospective randomized study. Spine 2002; 27:1116

580. Thomas E, Cyteval C, Abiad L, Picot MC, Taourel P, Blotman F. Efficacy of transforaminal versus interspinous corticosteroid injection in discal radiculalgia - a prospective, randomised, double-blind study. Clin Rheumatol 2003; 22:299-304.

581. Lutz GE, Vad VB, Wisneski RJ. Fluoroscopic transforaminal lumbar epidural steroids: An outcome study. Arch Phys Med Rehabil 1998; 79:1362-1366.

582. Berger O, Dousset V, Delmer O, Pointillart V, Vital JM, Caille JM. Evaluation of the efficacy of foraminal infusions of corticosteroids guided by computed tomography in the treatment of radicular pain by foraminal injection. J Radiol 1999; 80:917-925.

583. Melzer A, Seibel RM. Magnetic resonance (MR)-guided percutaneous pain therapy of degenerative spinal diseases. Semin Interv Radiol 1999; 16:143-150. 
584. Sequeiros RB, Ojala RO, Klemola R, Vaara TJ, Jyrkinen L, Tervonen OA. MRI-guided periradicular nerve root infiltration therapy in low-field (0.23-T) MRI system using optical instrument tracking. Eur Radiol 2002; 12:1331-1337.

585. Zennaro H, Dousset V, Viaud B, Allard M, Dehais J, Senegas J, Caille JM. Periganglionic foraminal steroid injections performed under CT control. Am I Neuroradiol 1998; 19:349-352.

586. Groenemeyer DH, Gevargez A, Schindler O, Schirp S, Braun M. CT-guided periradicular injections of corticosteroids in the management of lumbar radiculopathy associated with disk herniation. / Radiol 2002; 1-12.

587. Buttermann GR. Lumbar disc herniation regression after successful epidural steroid injection. J Spin Dis Tech 2002; 15: 469-476

588. Buttermann GR. The effect of spinal steroid injections for degenerative disc disease. Spine J 2004; 4:495-505.

589. Buttermann GR. Treatment of lumbar disc herniation: epidural steroid injection compared with discectomy. A prospective, randomized study. J Bone Joint Surg Am 2004; 86-A:670-679.

590. Cyteval C, Thomas E, Decoux E, Sarrabere MP, Cottin A, Blotman F, Taourel P. Cervical radiculopathy: Open study on percutaneous periradicular foraminal steroid infiltration performed under $\mathrm{CT}$ control in 30 patients. AJNR Am J Neuroradiol 2004; 25: 441-445.

591. Tong HC, Williams JC, Haig AJ, Geisser ME, Chiodo A. Predicting outcomes of transforaminal epidural injections for sciatica. Spine J 2003; 3:430-434.

592. Ng LC, Sell P. Outcomes of a prospective cohort study on peri-radicular infiltration for radicular pain in patients with lumbar disc herniation and spinal stenosis. Eur Spine J 2004; 13:325-329.

593. Botwin KP, Gruber RD, Bouchlas CG, Torres-Ramos FM, Sanelli JT, Freeman ED, Slaten WK, Rao S. Fluoroscopically guided lumbar transformational epidural steroid injections in degenerative lumbar stenosis: an outcome study. Am J Phys Med Rehabil 2002; 81:898-905.

594. Slipman CW, Lipetz JS, Jackson HB, Rogers DP, Vresilovic EJ. Therapeutic selective nerve root block in the nonsurgical treatment of atraumatic cervical spondylotic radicular pain: A retrospective analysis with independent clinical review. Arch Phys Med Rehabil 2000; 81:741-746.

595. Slipman CW, Lipetz JS, DePalma MJ, Jackson HB. Therapeutic selective nerve root block in the nonsurgical treatment of traumatically induced cervical spondylotic radicular pain. Am J Phys Med Rehabil 2004; 83:446-454.

596. Slipman CW, Lipetz JS, Jackson HB, Plastaras CT, Vresilovic EJ. Outcomes of therapeutic selective nerve root blocks for whiplash induced cervical radicular pain.
Pain Physician 2001; 4:167-174.

597. Lutze M, Stendel R, Vesper J, Brock M. Periradicular therapy in lumbar radicular syndromes: Methodology and results. Acta Neurochir 1997; 139:719-724.

598. Uhlenbrock D, Arlinghaus J. Results of CT guided periradicular pain therapy. Rofo Fortschr Geb Rontgenstr Neuen Bildgeb Verfahr 1997; 166:528-534.

599. Le Chevallier PL, Videgrain M, Roulleau P, Delvert JC, Valat JP, Castaing J. Injection of the sacrolumbar roots: A complementary method of staging sciatica. 18 cases. Rev Rhum Mal Osteoartic 1978; 45:473-477.

600. Devulder J. Transforaminal nerve root sleeve injection with corticosteroids, hyaluronidase, and local anesthetic in the failed back surgery syndrome. I Spinal Disord 1998; 11:151-154.

601. Weiner BK, Fraser RD. Foraminal injection for lateral lumbar disc herniation. J Bone Joint Surg 1997; 79-B:804-807.

602. Narozny M, Zanetti M, Boos N. Therapeutic efficacy of selective nerve root blocks in the treatment of lumbar radicular leg pain. Swiss Med Wkly 2001; 131:75-80.

603. Friedman R, Li V, Mehrotra D, Mosuro Y, Atkinson $\mathrm{G}$. Foraminal injection of a painful sacral nerve root using an epidural catheter: Case report. Reg Anesth Pain Med 2002; 27:214-216.

604. Rosenberg SK, Grabinsky A, Kooser C, Boswell $M$. Effectiveness of transforaminal epidural steroid injections in low back pain: A one year experience. Pain Physician 2002; 5:266-270.

605. Wang JC, Lin E, Brodke DS, Youssef JA. Epidural injections for the treatment of symptomatic lumbar herniated discs. I Spinal Disord Tech 2002; 15:269-272.

606. Botwin KP, Sakalkale DP. Epidural steroid injections in the treatment of symptomatic lumbar spinal stenosis associated with epidural lipomatosis. Am J Phys Med Rehabil 2004; 83:926-930.

607. Schmid G, Vetter S, Gottmann D, Strecker EP. CT-guided epidural/perineural injections in painful disorders of the lumbar spine: Short- and extended-term results. Cardiovasc Intervent Radiol 1999; 22:493498.

608. Gronemeyer D, Seibel R, Schindler O, Schattauer K, Lange S, Schmidt A. Microinvasive $\mathrm{CT}$ guided periradicular therapy for treatment of chronical functional disorders of the spine. Weiner Medizinische Wochenschrift 1995; 145:129-139.

609. Waldman SD. Complications of cervical epidural nerve blocks with steroids: A prospective study of 790 consecutive blocks. Reg Anesth 1989; 14:149-151.

610. Furman MB, Giovanniello MT, O’Brien EM. Incidence of intravascular penetration in transforaminal cervical epidural steroid injections. Spine 2003; 28:21-25.

611. Furman MB, O’Brien EM, Zgleszewski TM. Incidence of intravascular penetration in transforaminal lumbosacral epidural steroid injections. Spine 2000; 25:2628
2632.

612. Botwin KP, Gruber RD, Bouchlas CG, Torres-Ramos FM, Freeman TL, Slaten WK. Complications of fluoroscopically guided transforaminal lumbar epidural injections. Arch Phys Med Rehabil 2000; 81: 1045-1050.

613. Botwin KP, Castellanos R, Rao S, Hanna AF, Torres-Ramos FM, Gruber RD, Bouchlas CG, Fuoco GS. Complications of fluoroscopically guided interlaminar cervical epidural injections. Arch Phys Med Rehabil 2003; 84:627-633.

614. Huang RC, Shapiro GS, Lim M, Sandhu HS, Lutz GE, Herzog RJ. Cervical epidural abscess after epidural steroid injection. Spine 2004; 29:E7-E9.

615. Hooten WM, Kinney MO, Huntoon MA. Epidural abscess and meningitis after epidural corticosteroid injection. Mayo Clin Proc 2004; 79:682-686.

616. Stitz MY, Sommer HM. Accuracy of blind versus fluoroscopically guided caudal epidural injection. Spine 1999; 24:13711376.

617. Williams KN, Jackowski A, Evans PJ. Epidural hematoma requiring surgical decom pression following repeated cervical epidural steroid injections for chronic pain. Pain 1990; 42:197-199.

618. Reitman CA, Watters W. Subdural hematoma after cervical epidural steroid injec tion. Spine 2002; 27:E174-E176.

619. Bromage RP, Benumof JL. Paraplegia following intracord injection during attempted epidural anesthesia under general anesthesia. Reg Anesth Pain Med 1998; 23: 104-107.

620. MacLean CA, Bachman DT. Documented arterial gas embolism after spinal epidural injection. Ann Emerg Med 2001; 38:592595.

621. Yue WM, Tan SB. Distant skip level discitis and vertebral osteomyelitis after caudal epidural injection: A case report of a rare complication of epidural injections. Spine 2003; 28:E209-E211.

622. McMillan MR, Crumpton C. Cortical blindness and neurologic injury complicating cervical transforaminal injection for cervical radiculopathy. Anesthesiology 2003; 99:509-511.

623. Hodges SD, Castleberg RL, Miller T, Ward $R$, Thornburg C. Cervical epidural steroid injection with intrinsic spinal cord damage. Two case reports. Spine 1998; 23: 2137-2142.

624. Mateo E, Lopez-Alarcon MD, Moliner S, Calabuig E, Vivo M, De Andres J, Grau F. Epidural and subarachnoid pneumocephalus after epidural technique. Eur J Anesthesiol 1999; 16:413-417.

625. Katz JA, Lukin R, Bridenbaugh PO, Gunzenhauser L. Subdural intracranial air: An unusual cause of headache after epidural steroid injection. Anesthesiology 1991; 74 615-618.

626. Benzon HT, Wong HY, Siddiqui T, Ondra S. Caution in performing epidural injections 
in patients on several antiplatelet drugs. Anesthesiology 1999; 91:1558-1559.

627. Waldman SD. Cervical epidural abscess after cervical epidural nerve block with steroids (Letter). Anesth Anal 1991; 72:717.

628. Mamourian AC, Dickman CA, Drayer BP, Sonntag VK. Spinal epidural abscess: Three cases following spinal epidural injection demonstrated with magnetic resonance imaging. Anesthesiology 1993; 78: 204-207.

629. Knight JW, Cordingley JJ, Palazzo MG. Epidural abscess following epidural steroid and local anesthetic injection. Anaesthesia 1997; 52:576-578.

630. Kaul S, Meena AK, Sundaram C, Reddy JM, Naik RT, Murthy JM. Spinal extradural abscess following local steroid injection. Neurol India 2000; 48:181-183.

631. Tekkok IH, Carter DA, Brinker R. Spinal subdural hematoma as a complication of immediate epidural blood patch. Can J Anaesth 1996; 43:306-309.

632. Sabel M, Felsberg J, Neuen-Jacob E, Lichota A, Schnitzler A, Herdmann J. Enlargement of a chronic aseptic lumbar epidural abscess by intraspinal injections - a rare cause of progressive paraparesis. Zentralbl Neurochir 2000; 61:111-114.

633. Gutknecht DR. Chemical meningitis following epidural injections of corticosteroids (Letter). Am J Med 1987; 82:570.

634. Kusher FH, Olson JC. Retinal hemorrhage as a consequence of epidural steroid injection. Arch Opthalmol 1995; 113:309313.

635. Tiso RL, Cutler T, Catania JA, Whalen K. Adverse central nervous system sequelae af ter selective transforaminal block: the role of corticosteroids. Spine J 2004; 4:468474 .

636. Huntoon MA, Martin DP. Paralysis after transforaminal epidural injection and previous spinal surgery. Reg Anesth Pain Med 2004; 29:494-495.

637. Huntoon MA. The ascending and deep cervical arteries are vulnerable to injury during cervical transforaminal epidural injections: An anatomic study. Presented at the ASA Annual Meeting, October 23-27, 2004, Las Vegas, Nevada.

638. Nishimura H, Uemura Y, Fukuda S, Kamada Y, Moriwaki T. Two cases of pyogenic cervical discitis presenting tetraparesis. No Shinkei Geka 2000; 28:631-637.

639. McHaourab AS. Cervical epidural steroid injection: impact of cervical epidural anatomy. Anesthesiology 2004; 101:12381239.

640. Manchikanti L, Singh V. Epidural lysis of adhesions and myeloscopy. Curr Pain Headache Rep 2002; 6:427-435.

641. Heavner JE, Racz GB, Raj P. Percutaneous epidural neuroplasty. Prospective evaluation of $0.9 \% \mathrm{NaCl}$ versus $10 \% \mathrm{NaCl}$ with or without hyaluronidase. Reg Anesth Pain Med 1999; 24:202-207.

642. Racz GB, Heavner JE, Raj PP. Percutane- ous epidural neuroplasty. Prospective one-year follow up. Pain Digest 1999; 9: 97-102.

643. Manchikanti L, Rivera J, Pampati V, Damron KS, MCManus CD, Brandon DE, Wilson SR. One day lumbar epidural adhesiolysis and hypertonic saline neurolysis in treatment of chronic low back pain: A randomized double blind trial. Pain Physician. 2004; 7:177-186.

644. Manchikanti L, Pampati V, Fellows B, Rivera JJ, Beyer CD, Damron KS. Role of one day epidural adhesiolysis in management of chronic low back pain: A randomized clinical trial. Pain Physician 2001; 4:153166.

645. Manchikanti L, Pakanati R, Bakhit CE, Pampati V. Role of adhesiolysis and hypertonic saline neurolysis in management of low back pain. Evaluation of modification of Racz protocol. Pain Digest 1999; 9:9196.

646. Manchikanti L, Pampati V, Bakhit CE, Pakanati RR. Non-endoscopic and endoscopic adhesiolysis in post lumbar laminectomy syndrome. A one-year outcome study and cost effective analysis. Pain Physician 1999; 2:52-58.

647. Manchikanti L, Pampati V, Rivera J, Fellows B, Beyer CD, Damron KS, Cash KA. Effectiveness of percutaneous adhesiolysis and hypertonic saline neurolysis in refractory spinal stenosis. Pain Physician 2001; 4:366-373

648. Racz GB, Holubec JT. Lysis of adhesions in the epidural space. In Racz GB (ed). Techniques of Neurolysis. Kluwer Academic press, Boston, 1989, pp 57-72.

649. Hammer M, Doleys D, Chung O. Transforaminal ventral epidural adhesiolysis. Pain Physician 2001; 4: 273-279.

650. Devulder J, Bogaert L, Castille F, Moerman A, Rolly G. Relevance of epidurography and epidural adhesiolysis in chronic failed back surgery patients. Clin J Pain 1995; 11: 147-150.

651. Arthur J, Racz GB, Heinrich R, Diede JH, McCann M, Wilson E, Heavner J C., Noe C. Epidural space. Identification of filling defects in lysis of adhesions in the treatment of chronic painful conditions. In: $A b$ stracts, 7 th World Congress of Pain. Paris, IASP Publications, 1993, pp 557.

652. Manchikanti L, Rivera JJ, Pampati V, Damron KS, Beyer CD, Brandon DE, Wilson SR. Spinal endoscopic adhesiolysis in the management of chronic low back pain: A preliminary report of a randomized, double-blind trial. Pain Physician 2003; 6: 259-268.

653. Manchikanti L, Boswell MV, Rivera JJ, Pampati V, Damron KS, McManus CD, Brandon DE, Wilson SR. Evaluation of spinal endoscopic adhesiolysis in chronic refractory low back pain with a randomized, doubleblind trial with one year follow-up. 2004; in press.

654. Geurts JW, Kallewaard JW, Richardson J, Groen. Targeted methylprednisolone acetate/hyaluronidase/clonidine injection after diagnostic epiduroscopy for chronic sciatica: a prospective, 1-year follow-up study. Reg Anesth Pain Med 2002; 27:343-352.

655. Igarashi T, Hirabayashi Y, Seo N, Saitoh K, Fukuda H, Suzuki H. Lysis of adhesions and epidural injection of steroid/local anesthetic during epiduroscopy potentially alleviate low back and leg pain in elderly patients with lumbar spine stenosis. $\mathrm{Br}$ Anaesth 2004; 93:181-187.

656. Richardson J, McGurgan P, Cheema S, Prasad R, Gupta S. Spinal endoscopy in chronic low back pain with radiculopathy: A prospective case series. Anaesthesia 2001; 56:454-460.

657. Manchikanti L, Pakanati RR, Pampati V. The value and safety of epidural endoscopic adhesiolysis. Am / Anesthesiol 2000; 27:275-279.

658. Saberski L. A retrospective analysis of spinal canal endoscopy and laminectomy outcomes data. Pain Physician 2000; 3 : 193-196.

659. Lewandowski EM. The efficacy of solutions used in caudal neuroplasty. Pain Digest 1997; 7:323-330.

660. Aldrete JA, Zapata JC, Ghaly R. Arachnoiditis following epidural adhesiolysis with hypertonic saline report of two cases. Pain Digest 1996; 6:368-370.

661. Hitchcock ER, Prandini MN. Hypertonic saline in management of intractable pain. Lancet 1973; 1:310-312.

662. Lucas JT, Ducker TB, Perot PL. Adverse re actions to intrathecal saline injections for control of pain. J Neurosurg 1975; 42:57561

663. Dagi TF. Comments on myelopathy after the intrathecal administration of hypertonic saline. Neurosurgery 1988; 22:944945.

664. Lundy JS, Essex HE, Kernohan JW. Ex periments with anesthetics. IV. Lesions produced in the spinal cord of dogs by a dose of procaine hydrochloride sufficient to cause permanent and fatal paralysis. JAMA 1936; 101: 1546-1550.

665. Gentili ME, Samii K. Accidental epidural injection of hypertonic sodium chloride solution. Ann Fr Anesth Reanim 1991; 10: 401-403.

666. Manchikanti L, Bakhit CE. Removal of torn Racz catheter from lumbar epidural space. Reg Anesth 1997; 22:579-581.

667. Tabandeh H. Intraocular hemorrhages associated with endoscopic spinal surgery. Am J Ophthalmol 2000; 129:688-690.

668. Hammer M. Safety of spinal endoscopy is contingent on basic image interpretation. Letter to the editor. Reg Anesth Pain Med 2002; 27:621.

669. Luukkainen RK, Wennerstrand PV, Kautiainen HH, Sanila MT, Asikainen EL.. Efficacy of periarticular corticosteroid treatment of the sacroiliac joint in non-spondylarthropathic patients with chronic low back pain in the region of the sacroiliac joint. 
Clin Exp Rheumatol 2002; 20:52-54.

670. Maugars Y, Mathis C, Berthelot JM, Charlier C, Prost A. Assessment of the efficacy of sacroiliac corticosteroid injections spondyloarthropathies: a double blind study. BrJ Rheumatol 1996; 35:767-770.

671. Karabacakoglu A, Karakose S, Ozerbil OM, Odev K.. Fluoroscopy-guided intraarticular corticosteroid injection into the sacroiliac joints in patients with ankylosing spondylitis. Acta Radiol 2002; 43: 425-427.

672. Fischer T, Biedermann T, Hermann KG, Diekmann F, Braun J, Hamm B, Bollow M. Sacroiliitis in children with spondyloarthropathy: therapeutic effect of CT-guided intra-articular corticosteroid injection. Rofo 2003; 175:814-821.

673. Hanly JG, Mitchell M, MacMillan L, Mosher D, Sutton E. Efficacy of sacroiliac corticosteroid injections in patients with inflammatory spondyloarthropathy: Results of a 5 month controlled study. J Rheum 2000; 27:719-722.

674. Slipman CW, Lipetz JS, Plastaras CT, Jackson HB, Vresilovic EJ, Lenrow DA, Braverman DL. Fluoroscopically guided therapeutic sacroiliac joint injections for sacroiliac joint syndrome. Am J Phys Med Rehabil 2001; 80:425-432.

675. Gevargez A, Groenemeyer D, Schirp S, Braun M. CT-guided percutaneous radiofrequency denervation of the sacroiliac joint. Eur Radiol 2002; 12:1260-1365.

676. Ferrante FM, King LF, Roche EA, Kim PS, Aranda M, Delaney LR, Mardini IA, Mannes AJ. Radiofrequency sacroiliac joint denervation for sacroiliac syndrome. Reg Anesth Pain Med 2001; 26:137-142.

677. Cohen SP, Abdi S. Lateral branch blocks as a treatment for sacroiliac joint pain: A pilot study. Reg Anesth Pain Med 2003; 28: 113-119.

678. Pauza KJ, Howell S, Dreyfuss P. A randomized, placebo-controlled trial of intradiscal electrothermal therapy for the treatment of discogenic low back pain. Spine / 2004; 4:27-35.

679. Karasek M, Bogduk N. Twelve-month follow-up of a controlled trial of intradiscal thermal annuloplasty for back pain due to internal disc disruption. Spine 2000; 25 : 2601-2607.

680. Bogduk N, Karasek M. Two-year follow-up of a controlled trial of intradiscal electrothermal anuloplasty for chronic low back pain resulting from internal disc disruption. Spine J 2002; 2:343-350.

681. Saal JA, Saal JS. Intradiscal electrothermal treatment for chronic discogenic low back pain. Clin Sports Med 2002; 21:167-87.

682. Derby R, Eek B, Chen Y, O’Neill C, Ryan D. Intradiscal electrothermal annuloplasty (IDET): A novel approach for treating chronic discogenic back pain. Neuromodulation 2000; 3:82-88.

683. Singh V. Intradiscal electrothermal therapy: A preliminary report. Pain Physician 2000; 3:367-373.
684. Gerszten PC, Welch WC, McGrath PM, Willis SL. A prospective outcome study of patients undergoing intradiscal electrothermy (IDET) for chronic low back pain. Pain Physician 2002; 5:360-364.

685. Saal JA, Saal JS. Intradiscal electrothermal treatment for chronic discogenic low back pain: Prospective outcome study with a minimum 2-year follow-up. Spine 2002; 27:966-974.

686. Mekhail N, Kapural L. Intradiscal thermal annuloplasty for discogenic pain: An outcome study. Pain Practice 2004; 4:84-90.

687. Lee MS, Cooper G, Lutz GE, Doty S. Intradiscal electrothermal therapy (IDET) for treatment of chronic lumbar discogenic pain: A minimum 2-year clinical outcome study. Pain Physician 2003; 6:443-448.

688. Lutz C, Lutz GE, Cooke PM. Treatment of chronic lumbar diskogenic pain with intradiskal electrothermal therapy: a prospective outcome study. Arch Phys Med Rehabil 2003; 84:23-28.

689. Freedman BA, Cohen SP, Kuklo TR, Lehman RA, Larkin P, Giuliani JR. Intradiscal electrothermal therapy (IDET) for chronic low back pain in active-duty soldiers: 2year follow-up. Spine J 2003; 3:502-509.

690. Derby R, Lee S-H, Seo KS, Kazala K, Kim BJ, Kim MJ. Efficacy of IDET for relief of leg pain associated with discogenic low back pain. Pain Practice 2004; 4:281-285.

691. Saal JA, Saal JS. Intradiscal electrothermal treatment for chronic discogenic low back pain: a prospective outcome study with minimum 1-year follow-up. Spine 2000; 25:2622-2627.

692. Endres SM, Fiedler GA, Larson KL. Effectiveness of intradiscal electrothermal therapy in increasing function and reducing chronic low back pain in selected patients. WMJ 2002; 101:31-34.

693. Spruit M, Jacobs WC. Pain and function after intradiscal electrothermal treatment (IDET) for symptomatic lumbar disc degeneration. Eur Spine J 2002; 11:589-593597.

694. Davis TT, Delamarter RB, Sra P, Goldstein TB. The IDET procedure for chronic discogenic low back pain. Spine 2004; 29:752 756.

695. Webster BS, Verma S, Pransky GS. Outcomes of workers' compensation claimants with low back pain undergoing intradiscal electrothermal therapy. Spine 2004; 29:435-441.

696. Cohen SP, Larkin T, Abdi S, Chang A, Stojanovic $M$. Risk factors for failure and complications of intradiscal electrothermal therapy: A pilot study. Spine 2003; 28: 1142-1147.

697. Hsia AW, Isaac K, Katz JS. Cauda equina syndrome from intradiscal electrothermal therapy. Neurology 2000; 55:320.

698. Saal JA. Complications related to intradiscal electrothermal therapy: Technical considerations and prevention. Semin Spine Surg 2002; 14:163-165.
699. Lee J, Lutz GE, Campbell D, Rodeo SA, Wright T. Stability of the lumbar spine after intradiscal electrothermal therapy. Arch Phys Med Rehabil 2001; 82:120-122.

700. Chen YC, Lee SH, Chen D. Intradiscal pressure study of percutaneous disc decompression with nucleoplasty in human cadavers. Spine 2003; 28:661-665.

701. Chen YC, Lee SH, Saenz Y, Lehman NL. Histologic findings of disc, end plate and neural elements after coblation of nucleus pulposus: An experimental nucleoplasty study. Spine J 2003; 3:466-470.

702. Singh V, Piryani C, Liao K, Nieschulz S. Percutaneous disc decompression using Coblation (nucleoplasty) in the treatment of discogenic pain. Pain Physician 2002; 5 : 250-259.

703. Sharps LS, Isaac Z. Percutaneous disc decompression using Nucleoplasty. Pain Physician 2002; 5:121-126.

704. Singh V, Piryani C, Liao K. Role of percutaneous disc decompression using coblation in managing chronic discogenic low back pain: A prospective, observational study. Pain Physician 2004; 7:419-426.

705. Oakley J, Prager J. Spinal cord stimulation: Mechanism of action. Spine 2002; 22:2574-2583.

706. Turner JA, Loeser JD, Bell KG. Spinal cord stimulation for chronic low back pain. A systematic literature synthesis. Neurosurgery 1995; 37:1088-1096.

707. Burchiel KJ, Anderson VC, Brown FD, Fessler RG, Friedman WA, Pelofsky S, Weiner RL, Oakley J, Shatin D. Prospective: Multicenter study of spinal cord stimulation for relief of chronic back and extremity pain. Spine 1996; 21:2786-2794.

708. North RB, Kidd DH, Lee MS, Piantadosi S. Spinal cord stimulation versus reoperation for the failed back surgery syndrome: A prospective, randomized study design. Stereotact Funct Neurosurg 1994; 62:267272.

709. North RB, Wetzel FT. Spinal cord stimulation for chronic pain of spinal origin. Spine 2002; 27:2584-2591.

710. Raphael JH, Southall JL, Gnanadurai TV, Treharne GJ, Kitas GD. Multiple lead spinal cord stimulation for chronic mechanical low back pain: a comparative study with intrathecal opioid drug delivery. $\mathrm{Neu}$ romodulation 2004; 7:260-266.

711. Kemler MA, Barendse GA, van Kleef $M$, de Vet HC, Rijks CP, Furnee CA, van den Wildenberg FA. Spinal cord stimulation in patients with chronic reflex sympathetic dystrophy. N Engl J Med 2000; 343:618624.

712. Kemler M, Furnee C. Economic evaluation of spinal cord stimulation for chronic reflex sympathetic dystrophy. Neurology 2002; 59:1203-1209.

713. North RB, Kidd DH, Farrokhi F, Piantadosi SA. Spinal cord stimulation versus repeated lumbosacral spine surgery for chronic pain: A randomized, controlled trial. Neurosurgery 2005 ; 56:98-107. 
714. Barolat G, Oakley JC, Law JD, North RB, Ketcik B, Sharan A. Epidural spinal cord stimulation with a multiple electrode paddle lead is effective in treating low back pain. Neuromodulation 2001;4:59-66.

715. Calvillo O, Racz G, Didie J, Smith K. Neuroaugmentation in the treatment of complex regional pain syndrome of the upper extremity. Acta Orthop Belg 1998; 64:5763.

716. Kumar K, Malik S, Demeria D. Treatment of chronic pain with spinal cord stimulation versus alternative therapies: cost effectiveness analysis. Neurosurgery 2002; 51:106-116.

717. Dario A, Fortini G, Bertollo D, Bacuzzi A, Grizzetti C, Cuffari S. Treatment of failed back surgery syndrome. Neuromodulation 2001; 4:105-110.

718. Ohnmeiss DD, Rashbaum RF, Bogdanffy GM. Prospective outcome evaluation of spinal cord stimulation in patients with intractable leg pain. Spine 1996; 21:13441351.

719. Alo KM, Redko V, Charnov J. Four year follow-up of dual electrode spinal cord stimulation for chronic pain. Neuromodulation 2002; 5:79-88.

720. Villavicencio AT, Leveque JC, Rubin L, Bulsara K, Gorecki JP. Laminectomy versus percutaneous electrode placement for spinal cord stimulation. Neurosurgery 2000; 46:399-406.

721. Kemler MA, Barendse GA, Van Kleef M, Van Den Wildenberg FA, Weber WE. Electrical spinal cord stimulation in reflex sympathetic dystrophy: retrospective analysis of 23 patients. J Neurosurg 1999; 90:7983.

722. Taylor RS, Taylor RJ, Van Buyten JP, Buchser E, North R, Bayliss S. The cost effectiveness of spinal cord stimulation in the treatment of pain: a systematic review of the literature. J Pain Symp Manage 2004; 27:370-378.

723. Bennett G, Burchiel K, Buchser E, Classen A, Deer T, Du Pen S, Ferrante FM, Hassenbusch SJ, Lou L, Maeyaert J, Penn R, Portenoy RK, Rauck R, Serafini M, Willis $K D$, Yaksh T. Clinical guidelines for intraspinal infusion: Report of an expert panel. J Pain Symptom Manage 2000; 20:S37S43.

724. Walker SM, Goudas LC, Cousins MJ, Carr DB. Combination spinal analgesic chemotherapy: A systematic review. Anesth Analg 2002; 95:674-715.

725. Hassenbusch SJ, Portenoy RK, Cousins M, Buchser E, Deer TR, Du Pen SL, Eisenach J, Follett KA, Hildebrand KR, Krames ES, Levy RM, Palmer PP, Rathmell JP, Rauck RL, Staats PS, Stearns L, Willis KD. Polyanalgesic consensus conference 2003: an update on the management of pain by intraspinal drug delivery - report of an expert panel J Pain Symptom Manage 2004; 27:540 563.

726. Siddall PJ, Molloy AR, Walker S, Mather LE, Rutkowski SB, Cousins MJ The efficacy of intrathecal morphine and clonidine in the treatment of pain after spinal cord injury. Anesth Analg 2000; 91:1493-1498.

727. van Hilten BJ, van de Beek WJ, Hoff JI, Voormolen JH, Delhaas EM. Intrathecal baclofen for the treatment of dystonia in patients with reflex sympathetic dystrophy. N Engl J Med 2000; 343:654-656.

728. Smith TJ, Staats PS, Deer T, Stearns LJ, Rauck RL, Boortz-Marx RL, Buchser E, Catala E, Bryce DA, Coyne PJ, Pool GE; Implantable Drug Delivery Systems Study Group. Randomized clinical trial of an implantable drug delivery system compared with comprehensive medical management for refractory cancer pain: impact on pain, drug-related toxicity, and survival. I Clin Oncol 2002; 20:4040-4049.

729. Staats PS, Yearwood T, Charapata SG, Presley RW, Wallace MS, Byas-Smith M, Fisher R, Bryce DA, Mangieri EA, Luther RR, Mayo M, McGuire D, Ellis D. Intrathecal ziconotide in the treatment of refractory pain in patients with cancer or AIDS: A randomized controlled trial. JAMA 2004; 291:63-70.

730. Hassenbusch SJ, Stanton-Hicks M. Longterm intraspinal infusions in the treatment of neuropathic pain. J Pain Symptom Manage 1995; 10:527-543.

731. Angel IF, Gould HJ Jr., Carey ME. Intrathecal morphine pump as a treatment option in chronic pain of nonmalignant origin. Surg Neurol 1998; 49:92-99.

732. Anderson VC, Burchiel KJ. A prospective study of long-term intrathecal morphine in the management of chronic nonmalignant pain. Neurosurgery 1999; 44:289-301.

733. Corrado P, Gottlieb H, Varga CA. The effect of intrathecal morphine infusion on pain level and disability in pain patients with chronic intractable low back pain. AJPM 2000; 10:160-166.

734. Kumar K, Kelly M, Pirlot T. Continuous intrathecal morphine treatment for chronic pain of nonmalignant etiology: Long-term benefits and efficacy. Surg Neurol 2001; 55:79-88.

735. Deer T, Chapple I, Classen A, Javery K, Stoker V, Tonder L, Burchiel K. Intrathecal drug delivery for treatment of chronic low back pain: report from the National Outcomes Registry for Low Back Pain. Pain Med 2004; 5:6-13.

736. Onofrio BM, Yaksh TL. Long-term pain relief produced by intrathecal infusion in 53 patients. J Neurosurg 1990; 72:200-209.

737. Paice JA, Penn RD, Shott S. Intraspinal morphine for chronic pain: A retrospective, multicenter study. J Pain Symptom Manage 1996; 11:71-80.

738. Winkelmüller $\mathrm{M}$, Winkelmüller W. Longterm effects of continuous intrathecal opioid treatment in chronic pain of nonmalignant etiology. J Neurosurg 1996; 85:458467.

739. Roberts LJ, Finch PM, Goucke CR, Price LM. Outcome of intrathecal opioids in chronic non-cancer pain. Eur J Pain 2001; 5:353-
361.

740. Burton AW, Rajagopal A, Shah HN, Mendoza T, Cleeland C, Hassenbusch SJ 3rd, Arens JF. Epidural and intrathecal analgesia is effective in treating refractory cancer pain. Pain Med 2004; 5:239-247.

741. Mueller-Schwefe G, Hassenbusch SJ, Reig E. Cost-effectiveness of intrathecal therapy for pain. Neuromodulation 1999; 2:7784.

742. Manchikanti L. Documentation for evaluation and management services. Principles of Documentation, Billing, Coding \& Practice Management for the Interventional Pain Professional. ASIPP Publishing, Paducah KY 2004, pp 31-46.

743. Mikhail GR, Sweet LC, Mellinger RC. Parenteral long-acting corticosteroid effect on hypothalamic pituitary adrenal function. Ann Allergy 1973; 31:337-343.

744. Mikhail GR, Livingood CS, Mellinger RC, Paige TN, Salyer HL.. Effect of long-acting parenteral corticosteroids on adrenal function. Arch Dermatol 1969; 100:263268.

745. Melby JC. Drug spotlight program: Systemic corticosteroid therapy; pharmacologic and endocrinologic considerations. Ann Intern Med 1974; 81:505-512.

746. Schimmer BP, Parker KL. Adrenocorticotropic hormone; adrenocortical steroids and their synthetic analogs; inhibitors of the synthesis and actions of adrenocortical hormones. In Harman JG, Molinoff PB, Ruddon RW (eds). Goodman's \& Gilman's, The Pharmacological Basis of Therapeutics, Ninth Edition, McGraw-Hill, New York, 1996, pp 1459-1485.

747. McEvoy GK, Litvak K, Welsh OH. Adrenals. AHFS 99 drug information. American Society of Health-System Pharmacists, Bethesda, 1999, pp 2636-2662.

748. Boonen S, Van Distel G, Westhovens R, Dequeker J.. Steroid myopathy induced by epidural triamcinolone injection. Brit J Rheumatol 1995; 34:385-386.

749. Maillefert JF, Aho S, Huguenin MC, Chatard C, Peere T, Marquignon MF, Lucas B, Tavernier C. Systemic effects of epidural dexamethasone injections. Revue du Rhumatisme 1995; 62:429-432.

750. Ward A, Watson J, Wood P, Dunne C, Kerr D. Glucocorticoid epidural for sciatica: Metabolic and endocrine sequelae. Rheumatology 2002; 41:68-71.

751. Shishido H, Kikuchi S, Heckman H, Myers RR. Dexamethasone decreases blood flow in normal nerves and dorsal root ganglia. Spine 2002; 27:581-586.

752. Mace S, Vadas P, Pruzanski W. Anaphylactic shock induced by intraarticular injection of methylprednisolone acetate. J Rheumatol 1997; 24:1191-1194.

753. Weissman DE, Dufer D, Vogel V, Abeloff MD. Corticosteroid toxicity in neuro-oncology patients. J Neurooncol 1987; 5:125128.

754. Manchikanti L, Pampati V, Beyer CD, Damron KS, Cash KA, Moss TL The effect of 
neuraxial steroids on weight and bone mass density: A prospective evaluation. Pain Physician 2000; 3:357-366.

755. Delaney TJ, Rowlingson JC, Carron H, Butler A. Epidural steroid effects on nerves and meninges. Anesth Analg 1980; 58: 610-614.

756. Mackinnon SE, Hudson AR, Gentili F, Kline DG, Hunter D. Peripheral nerve injection injury with steroid agents. Plast Reconstr Surg 1982; 69:482-489.

757. Chino N, Awad EA, Kottke FJ. Pathology of propylene glycol administered by perineural and intramuscular injection in rats. Arch Phys Med Rehab 1974; 55:33-38.

758. Benzon HT, Gissen AJ, Strichartz GR,
Avram MJ, Covino BG. The effect of polyethylene glycol on mammalian nerve impulses. Anesth Analg 1987; 66:553-559.

759. Abram SE, Marsala M, Yaksh TL. Analgesic and neurotoxic effects of intrathecal corticosteroids in rats. Anesthesiology 1994; 81:1198-1205.

760. Latham JM, Fraser RD, Moore RJ, Blumbergs PC, Bogduk N. The pathologic effects of intrathecal betamethasone. Spine 1997; 22:1558-1562.

761. Robustelli della Cuna FS, Mella M, Magistrali G, Ricci M, Losurdo A, Goglio AM. Stability and compatibility of methylprednisolone acetate and ropivacaine hydrochloride in polypropylene syringes for epidur- al administration. Am J Health Syst Pharm 2001; 58:1753-1756.

762. Swai EA, Rosen M. An attempt to develop a model to study the effects of intrathecal steroids. Eur J Anaesthesiol 1986; 3:127136.

763. Dunbar SA, Manikantan P, Philip J. Epidural infusion pressure in degenerative spinal disease before and after epidural steroid therapy. Anesth Analg 2002; 94:417-420.

764. Slucky AV, Sacks MS, Pallares VS, Malinin TI, Eismont FJ. Effects of epidural steroids on lumbar dura material properties. J Spin Disord 1999; 12:331-340. 
